\title{
Low temperature oxidation of linseed oil: a review
}

\author{
Juita ${ }^{1}$, Bogdan Z Dlugogorski ${ }^{1 *}$, Eric M Kennedy ${ }^{1}$ and John C Mackie ${ }^{1,2}$
}

\begin{abstract}
This review analyses and summarises the previous investigations on the oxidation of linseed oil and the self-heating of cotton and other materials impregnated with the oil. It discusses the composition and chemical structure of linseed oil, including its drying properties. The review describes several experimental methods used to test the propensity of the oil to induce spontaneous heating and ignition of lignocellulosic materials soaked with the oil. It covers the thermal ignition of the lignocellulosic substrates impregnated with the oil and it critically evaluates the analytical methods applied to investigate the oxidation reactions of linseed oil.

Initiation of radical chains by singlet oxygen $\left({ }^{1} \Delta_{g}\right)$, and their propagation underpin the mechanism of oxidation of linseed oil, leading to the self-heating and formation of volatile organic species and higher molecular weight compounds. The review also discusses the role of metal complexes of cobalt, iron and manganese in catalysing the oxidative drying of linseed oil, summarising some kinetic parameters such as the rate constants of the peroxidation reactions.

With respect to fire safety, the classical theory of self-ignition does not account for radical and catalytic reactions and appears to offer limited insights into the autoignition of lignocellulosic materials soaked with linseed oil. New theoretical and numerical treatments of oxidation of such materials need to be developed. The self-ignition induced by linseed oil is predicated on the presence of both a metal catalyst and a lignocellulosic substrate, and the absence of any prior thermal treatment of the oil, which destroys both peroxy radicals and singlet $\mathrm{O}_{2}$ sensitisers. An overview of peroxyl chemistry included in the article will be useful to those working in areas of fire science, paint drying, indoor air quality, biofuels and lipid oxidation.
\end{abstract}

\section{Introduction}

Since the $15^{\text {th }}$ century, linseed oil has been extensively used in varnishes and oil-based house paints (Lazzari \& Chiantore 1999). It has also been applied for treating wood and in manufacturing of linoleum, a floor covering made from mixture of natural materials, such as wood, calcium, vegetable pigments and resin. Nowadays, it is also utilised in industrial lubricants, for the treatment of leather products, for bicycle maintenance, as well as rust inhibitor. Many studies have focussed on improving the drying performance of this oil and reducing the hazardous properties related to its application.

A herbaceous plant, Linum usitatissimum, linseed (also called flax) produces seeds which are oval and flattened in shape, $4-6 \mathrm{~cm}$ long, pale to dark brown and shiny. The oil prepared by crushing the seeds finds applications in formulating the so-called drying alkyd

\footnotetext{
* Correspondence: Bogdan.Dlugogorski@newcastle.edu.au

${ }^{1}$ Process Safety and Environmental Protection Group, School of Engineering, The University of Newcastle, Callaghan, NSW 2308, Australia Full list of author information is available at the end of the article
}

paints, which exhibit drying and hardening properties when exposed to air. This occurs as a consequence of high content of glycerol esters (also known as glycerides or triacylglycerols) of linolenic acid in linseed oil, an important component of the drying alkyd paints, with the unsaturated bonds in the acids undergoing the oxidation reactions. The non-drying alkyd resins are devoid of esters of unsaturated fatty acid and display no curing behaviour.

The properties of drying alkyd paints vary depending on the type and amount of unsaturated fatty acid employed in preparing the paint formulations (Oyman et al. 2005a). The primary remaining components of both the drying and non-drying alkyd resins include alcohols (polyols), such as pentaerythritol or glycerol, and dicarboxylic acid anhydrides, such as phthalic and maleic anhydrides. The term alkyd derives from the original acronym alcid, conveying the chemical meaning of polyesters (van Gorkum \& Bouwman 2005).

There are four varieties of linseed oil sold in the market, including raw, boiled, stand and refined linseed oils. Raw

\section{实}

(c) 2012 Juita et al.; licensee Springer. This is an Open Access article distributed under the terms of the Creative Commons Attribution License (http://creativecommons.org/licenses/by/2.0), which permits unrestricted use, distribution, and reproduction in any medium, provided the original work is properly cited. 
linseed oil refers to pure oil with no additional treatment and with no additives, while boiled linseed oil is produced by adding a mixture of hydrocarbon solvents and metallic dryers to speed its drying time. Boiled oil is a well known trade name, even though the process does not involve boiling of raw oil, whereas the stand linseed oil is processed by heating the oil to about $300^{\circ} \mathrm{C}$, over a few days in the absence of oxygen. During this process, polymerisation reaction occurs, increasing the oil's viscosity. It means that stand or polymerised oil has been boiled to make it unreactive and more viscous. The production of refined linseed oil involves the alkali treatment following the pressing process, improving the colour of this oil (paler and clearer). It is utilised as a medium to increase gloss and transparency of paint colours.

The drying rate of linseed oil is too slow for convenient applications, necessitating the addition of metallic salts (drying agents) to accelerate the drying process (Mallégol et al. 2000). Unfortunately, in the presence of lignocellulosic fuels, such as cotton fibres, these agents may induce the fuel's self-heating and autoignition. This dangerous side effect of the oil has been known to fire investigators for almost 200 years (Abraham 1996). Several cases of fire have been reported; in particular those induced by improperly disposed rags soaked with linseed oil. Typical ignition scenarios involve waste baskets filled with disposed cotton rags used to clean paint brushes.

Two recent cases of fire ignited by oily rags in California and Illinois, have been reported, one case occurred in the plant section where wooden cabinets have just been stained and finished, while the other was caused by a pile of oily rags in the storage area which had been used to treat the refinish deck. There were no injuries in either case, however they suffered estimated loss of $\$ 200,000$ and $\$ 2,000$, respectively. This substantial difference in losses resulted from the operation of sprinklers, in the case of the fire in Illinois (Evarts 2011).

The US Fire Administration's National Fire Incident Reporting System (NFIRS) and National Fire Protection Association (NFPA), which provide the average annual data of fires for 2005-2009, give account that the spontaneous heating of oily rags comprised $22 \%$ of fires ignited by spontaneous heating or chemical reaction. In 14,070 cases of fires caused by spontaneous heating or chemical reaction, there were 7 civilian deaths and 92 civilian injuries reported, with corresponding direct property damage of \$143 millions (Evarts 2011).

This review summarises the previous research studies dealing with oxidation of linseed oil itself and spontaneous ignition of lignocellulosic materials wetted with linseed oil. The review commences with the discussion of linseed oil composition, structure and oxidation characteristics. Several test methods for examining the oxidation and self-heating processes are then described, with application to the considered material. This is followed by illustrations of the effect of several transitional metals on the oxidation process. Subsequently, we discuss the chemistry involved in the oxidation reaction and the reaction pathways suggested in the literature, as well as the reported kinetic parameters. Finally, this review identifies the gaps in knowledge and proposes further investigation to gain improved fundamental understanding of the oxidation of linseed oil.

\section{Characteristics of linseed oil Composition and structure of linseed oil}

As linseed is grown in several geographical areas, including Europe, North and South America (especially Argentina) and Asia (especially India), the linseed oil pressed from the seeds displays natural variation in composition that reflects the growing, agronomic and environmental conditions (Gunstone 1996). In particular, climate affects the abundance of the unsaturated fatty acid in the oil; the colder the climate, the higher the iodine value of oil or the degree of its unsaturation (Fjällström et al. 2002). Iodine value is normally expressed in terms of grams of iodine added per 100 grams of oil. The oil consists almost exclusively of the esters of glycerol (C3 alcohol with three hydroxyl groups, one on each carbon atom) and five fatty acids, two of them saturated, C16 palmitic and C18 stearic, and three unsaturated, oleic, linoleic and linolenic, exhibiting one, two and three double bonds, respectively, as illustrated in Figure 1. The two and three double bonds are non-conjugated, being separated from each other by $\mathrm{CH}_{2}$ groups. The minor components that may also be present are monoacylglycerols (monoesters of glycerol), diacylglycerols (diesters of glycerol) and free fatty acids (Gunstone 1996).

Although linseed oil contains around $60 \%$ of linolenic acid, the most unsaturated fatty acid, this acid occurs only in small amounts, usually below $1 \%$ in other oil types. The notable exceptions are soybean and rape oil, with 8 and 7\% linolenic content, respectively (Gunstone 1996). This high level of linolenic acid in linseed oil affects the drying property of the oil, making it particularly suitable in formulations of drying alkyd paints. Table 1 summarises the composition of various natural oil; the symbols 16:0, $18: 0,18: 1,18: 2$ and 18:3 reflect the number of carbon atoms and (after the colon) the number of double bonds. They correspond to palmitic, stearic, oleic, linoleic and linolenic acids, respectively.

The natural unsaturated fatty acids exhibit one or more carbon double bonds with cis configuration starting at the location of the ninth carbon atom (Roberfroid \& Calderon 1995). Carbon-carbon double bonds in unsaturated fatty acids induce the chain to deviate by an angle of about $40^{\circ}$, requiring more space to accommodate the chain conformation (Jennings 1981). The chemical 


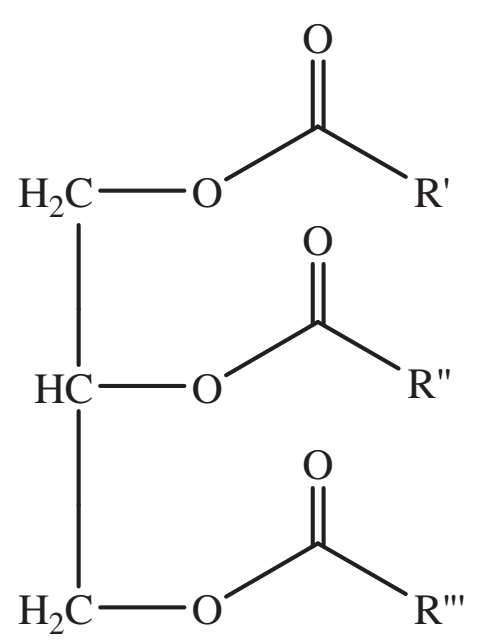

Figure 1 The structure of triacylglycerols $\left(R^{\prime}, R^{\prime \prime}\right.$ and $R^{\prime \prime \prime}$ represent species of five fatty acids).

structures of oleic, linoleic and linolenic acid are illustrated below Scheme 1:

Oleic acid incorporates 18 carbon atoms with one double bond at the position of the ninth carbon atom (counting from the carboxyl end) and displays a cis configuration. The index $\alpha$ refers to the numbering system, starting from the carboxyl end, while $\omega$ corresponds to that from the end of the carbon chain. Note that, each angle in the structures corresponds to the location of a carbon atom. Also, note that by organic chemistry convention, hydrogen atoms connected to carbon atoms are not shown. That is, although not shown, each carbon atom is bonded with hydrogen atoms, to make the total number of bonds for each carbon to be four.

Linoleic acid has the same length as oleic acid, but its structure includes two double bonds at positions 9 and 12 (counting from the location of the carboxyl group (Scheme 2)). Each double bond forms a cis configuration with the adjacent methylene $\left(\mathrm{CH}_{2}\right)$ groups.

Table 1 Fatty acid composition of the major vegetable oils (Lazzari \& Chiantore 1999; Gunstone 1996; Erasmus 2011)

\begin{tabular}{lllllll}
\hline Source & $16: 0$ & $18: 0$ & $18: 1$ & $18: 2$ & $18: 3$ & Other \\
\hline Corn & 13 & 3 & 31 & 52 & 1 & - \\
\hline Cottonseed & 27 & 2 & 18 & 51 & Trace & 2 \\
\hline Linseed & $6-7$ & $3-6$ & $14-24$ & $14-19$ & $48-60$ & - \\
\hline Olive & 10 & 2 & 78 & 7 & 1 & 2 \\
\hline Palm & 44 & 4 & 40 & 10 & Trace & 2 \\
\hline Safflower (high-linoleic) & 7 & 3 & 14 & 75 & - & 1 \\
\hline Soybean & 11 & 4 & 22 & 53 & 8 & 2 \\
\hline Sunflower (high-linoleic) & 6 & 5 & 20 & 69 & Trace & - \\
\hline Tall oil & 5 & 3 & 46 & 41 & 3 & 2 \\
\hline Rapeseed & - & 7 & 54 & 30 & 7 & 2 \\
\hline Tung (59\% of elaecostearic acid) & 3 & 2 & 11 & 15 & 3 & 59 \\
\hline
\end{tabular}

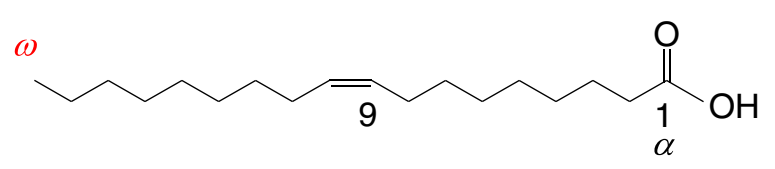

Oleic acid

Scheme 1 Oleic acid.

The chain of 18 carbon atoms with three double bonds at carbon atoms 9, 12 and 15 defines a molecule of linolenic acid (Scheme 3). Similarly to the other two naturally occurring C18 fatty acids, the double bonds in linolenic acid entail triple cis configuration. As the location of the first double bond is at the third carbon, counting from the end of the molecule, linolenic acid is an example of the so-called $\omega-3$ fatty acids, one of the essential unsaturated fatty acids with well known health benefits. For this reason, linseed oil serves as nutritional supplement. The same nomenclature denotes linoleic and oleic acids as $\omega-6$ and $\omega-9$ fatty acids, respectively, with linoleic acid providing similar essential health benefits, especially as a precursor to arachidonic acid $(20: 4, \omega-6)$, which controls several physiological functions in the human body. It is required for muscle growth and brain protection from oxidative stress.

Furfural (furan-2-carbaldehyde) serves as the preferred solvent for extraction of vegetable oils due to its miscibility and the ability of leaching out different types of oils as characterised by spread of iodine values. The tendency of furfural to form dark residues, accelerated by its exposure to heat, light and oxygen, constitutes its main disadvantage. In particular, these residues inhibit the oxidation of oil, retarding the formation of the paint film (Kenyon et al. 1948).

Linseed oil has been reported to contain $15.2 \mathrm{meq} / \mathrm{kg}$ of hydroperoxides, determined using iodometric method (Peinado et al. 1986); meq denotes mmol of monohydroperoxide equivalent to all hydroperoxide species. These peroxides probably build up during the extraction process. They may be generated from chemical oxidation involving heat or by the action of lipoxygenase enzyme, also called LOXes (linoleate:

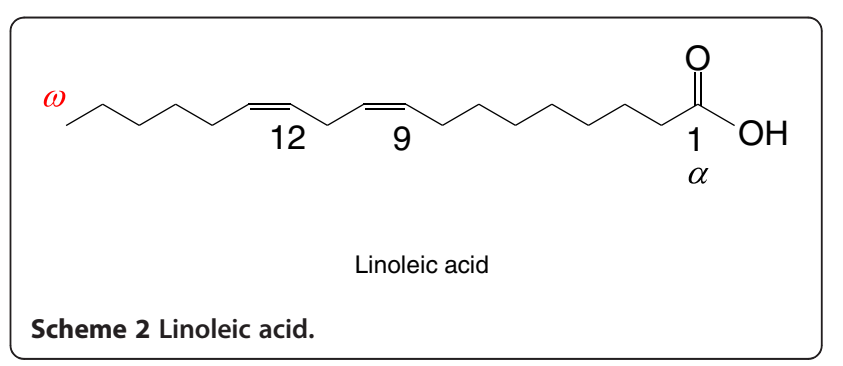




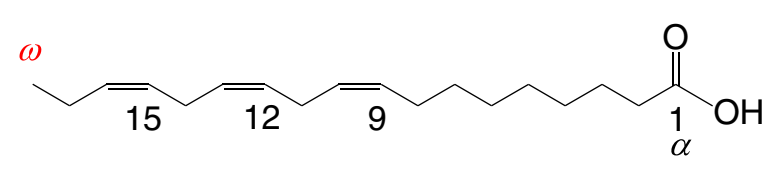

Linolenic acid

Scheme 3 Linolenic acid.

oxygen oxidoreductase). The enzyme belongs to a large family of non-iron containing fatty acid dioxygenases (Liavonchanka \& Feussner 2006). These enzymes occur widely in plants (cucumber, soybean, potato, sunflower) and animals (mammals) (Gunstone 1996; Liavonchanka \& Feussner 2006). The degradation process of lipid bodies in the plant seeds during early stages of germination results in the formation of several enzymes such as 13-lipoxygenase, phospholipase and triacylglycerol lipase (Feussner et al. 2001). This means that enzymes are present naturally in flax seeds. In particular, the lipoxygenase enzyme catalyses the oxidation reaction of polyunsaturated fatty acids with cis,cis-1,4-dienes structure to form hydroperoxides (Gunstone 1996).

\section{Oxidation process of linseed oil}

In biology, unsaturated fatty acids function as important biomolecules in cellular metabolism (Roberfroid \& Calderon 1995). The drying of alkyd paint follows a mechanism similar to the process in which lipids are oxidised in biological systems (Miccichè et al. 2006). Lipid peroxidation reactions occur in living systems, for instance in modification of DNA and proteins, radiation damage, aging and age pigment formation, modification of membrane structure, tumor initiation, and in the deposition of arterial plaque associated with low-density lipoprotein modification (Porter et al. 1995). While in food industry, the important parameter to measure the quality of oil and fat is the degree of oxidation (i.e., the extent of oil oxidation), since this process reduces the nutritional quality, produces rancid flavours and decreases safety in terms of its potential to develop disease (Muik et al. 2005).

Drying of alkyd paints consists of physical and chemical stages, the latter denoted as curing. In the first (physical) stage, the solvent evaporates prompting the formation of closed film, while the chemical drying involves lipid autoxidation, during which the cross-linking occurs (van Gorkum \& Bouwman 2005; Erich et al. 2006a; Ploeger et al. 2009a). This drying process is a consequence of the presence of linseed oil in the paints.

Linseed oil has the capacity to form a continuous film with good optical and mechanical properties after being spread out in a thin layer (Lazzari \& Chiantore 1999). It will cure in air without using a catalyst, although slowly (Marshall 1986). The double bonds of the unsaturated acids in the oil react with oxygen in air and with one another to form a polymeric network (Lazzari \& Chiantore 1999; Stava et al. 2007) that determines the drying power of such oils (Lazzari \& Chiantore 1999), resulting in the liquid layer evolving to a solid film (Roberfroid \& Calderon 1995; Marshall 1986). Thus, this hardening process arises as a result of the autoxidation followed by cross-linking polymerisation (Lazzari \& Chiantore 1999; Fjällström et al. 2002; Tanase et al. 2004). The formation of cross linked structures essentially consists of the intermolecular coupling of radicals originated by decomposition of the relatively unstable peroxide groups (Lazzari \& Chiantore 1999). The drying reaction of linseed oil continues for many years even when the oil film seems to completely dry in a few days (Lazzari \& Chiantore 1999). However, the presence of glycerides as plasticisers can moderate the hardening process (Lazzari \& Chiantore 1999). The oil can gain up to $40 \%$ of its original weight during oxidation in the drying process with some weight loss due to the decomposition and disappearance of volatile compounds during oxidation reaction (Fjällström et al. 2002).

Metals, light, heat and enzymes accelerate the oxidation of unsaturated acids in the oil, while antioxidants inhibit oxidation. Oxidation of fatty acids occurs through autoxidation or photo-oxidation. The rate of autoxidation depends on the presence of pro-oxidants (i.e., oxidising agents), antioxidants, temperature and the dissolved oxygen (Belhaj et al. 2010). Oleic acid, as a monounsaturated acid, can be oxidised only at elevated temperatures, while polyunsaturated acids such as linolenic and linoleic acids undergo rapid oxidation even at room temperature (Kumarathasan et al. 1992). Allyl hydroperoxides, chemical moieties containing both allyl $\left(-\mathrm{CH}=\mathrm{CH}-\mathrm{CH}_{2}-\right)$ and hydroperoxide $(-\mathrm{OOH})$ groups as in $-\mathrm{CH}=\mathrm{CH}-\mathrm{CH}(\mathrm{OOH})-$, constitute the primary oxidation products. The double bonds remain but may have changed position and/or configuration from their original form during the oxidation reaction, with the formation of hydroperoxides. The schematic diagram in Figure 2 illustrates further changes affecting the hydroperoxides (Gunstone 1996).

Autoxidation is a chain reaction process, with radical intermediates (odd electron species) of polyunsaturated fatty acids involved in initiation, propagation and termination steps (van Gorkum \& Bouwman 2005; Gunstone 1996; Kumarathasan et al. 1992). A slow induction period often precedes a more rapid reaction (Gunstone 1996). On the other hand, photo-oxygenation reactions (oxidation reactions that are induced by light) involve attacks of singlet (i.e., excited) oxygen molecules, formed from triplet (i.e., ground state) oxygen by light in the presence of a sensitiser. This type of reaction shows no induction period and no inhibition by antioxidants. Table 2 lists the rates of photo-oxygenation reactions that significantly 


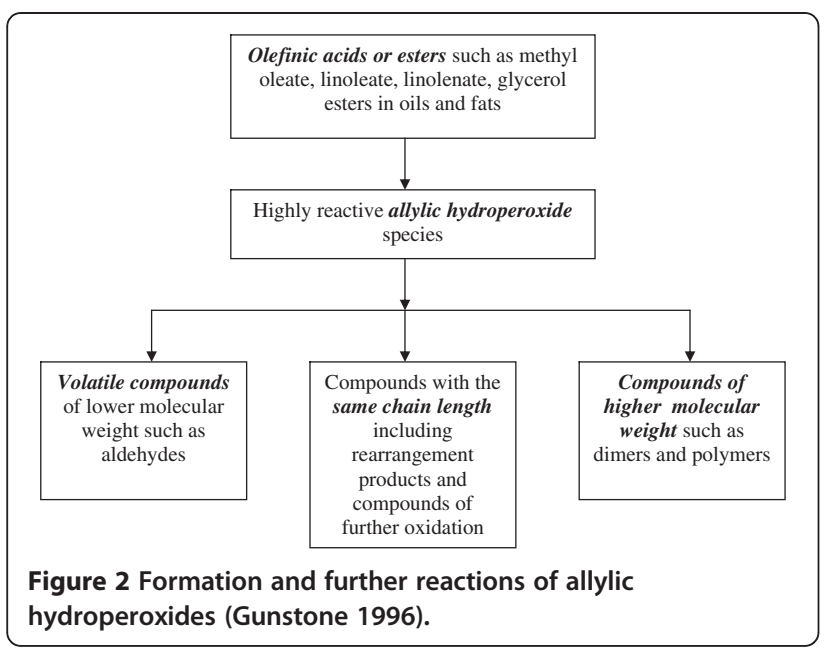

exceed those of the autoxidation reactions, particularly for monoene esters; note 30000 times enhancement (Gunstone 1996). Lazzari observed that thermal treatment at $80^{\circ} \mathrm{C}$ can give an acceleration of around 40 times and photo ageing of approximately 260 times compared with natural ageing (Lazzari \& Chiantore 1999).

A characteristic pungent smell arising from air drying of alkyd coating originates from the formation of volatile by-products, especially aldehydes (Oyman et al. 2007). In addition to the saturated aldehydes, small amounts of unsaturated aldehydes are also emitted (Fjällström et al. 2002), as are short-chain ketones, alcohols, acids, esters, ethers and hydrocarbons, all contributing to the odour (Gunstone 1996). Temperature and humidity affect the total emission of aldehydes, with the increasing temperature promoting the emissions and increasing humidity impeding them (Fjällström et al. 2002). Cyclic fatty acid monomers (CFAM) also emerge during heating of linseed oil, with CFAM-18:2 consisting of mostly C5-membered -rings and CFAM-18:3 containing a mixture of $\mathrm{C} 5$ and C6 membered-rings (Joffre et al. 2001). Figure 3 shows the example of CFAM.

\section{Experimental methods to test oxidation and self- heating reactions of linseed oil}

Thermal methods

Several test methods exist to assess the propensity of materials to self-heating. Those that have been applied to

Table 2 A comparison of relative rates of autoxidation and photo-oxygenation of oleate, linoleate and linolenate compounds (Gunstone 1996)

\begin{tabular}{llll}
\hline Compound & Autoxidation & $\begin{array}{l}\text { Photo- } \\
\text { oxygenation }\end{array}$ & $\begin{array}{l}\text { Ratio of relative rates } \\
\text { of photo-oxygenation } \\
\text { to autoxidation }\end{array}$ \\
\hline Oleate & 1 & $3 \times 10^{4}$ & 30000 \\
\hline Linoleate & 27 & $4 \times 10^{4}$ & 1500 \\
\hline Linolenate & 77 & $7 \times 10^{4}$ & 900 \\
\hline
\end{tabular}

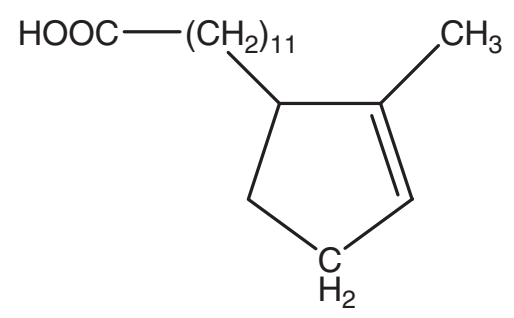

Figure 3 Example of cyclic fatty acid monomers (CFAM).

cotton, sawdust and similar materials impregnated with linseed include basket heating, crossing point temperature, adiabatic reactor, differential thermal analysis (DTA), thermogravimetric analysis (TGA), Ordway apparatus and Mackey apparatus, as described in the following discussion.

\section{Basket heating}

Basket heating apparatus consists of a container (basket) shaped as a cube, a cylinder or a sphere, made of wire mesh to hold the sample, an oven to maintain the temperature and a thermocouple to measure the temperature inside the sample. Measuring the runaway temperature involves the following steps: charging the basket with a sample, inserting the thermocouple in the middle of the basket, then placing this basket inside a preheated oven and finally recording the temperature with a data logger (Wang et al. 2006). The objective of this method is to determine the critical oven temperature that gives rise to self-heating. This approach assumes a single Arrhenius reaction rate, constant and isotropic material properties, and no water evaporation (Wang et al. 2006; Drysdale 1985). The measurements are normally analysed using the Frank-Kamenetskii theory as explained later in this review. Bowes et al. implemented this method to measure the self-heating and ignition temperature of sawdust for different concentrations of oxygen (Bowes \& Thomas 1966). This method is time and material consuming since a great number of tests must be performed to obtain the critical temperature. Moreover, locating the critical temperature is not straightforward. Worden attempted to implement this method to study the spontaneous ignition of cotton soaked with linseed oil, however, the critical temperature could not be determined due to difficulties in ascertaining the sub-critical conditions (Worden 2011). In other words, using boiled oil (oil with cobalt accelerant), Worden could not find conditions that did not ignite. This leads one to conclude that there is no safe quantity of rags soaked with boiled linseed oil, and that even a single oil soaked rag at room temperature can self-heat. In practical terms, these findings question the classical theory of self-heating that stipulates the existence of a sub-critical condition for which a material does not 
self-ignite. The classical theory of self-heating does not cover self-ignition reaction involving radical and catalytic reactions. New theoretical and numerical treatments remain to be developed for spontaneous ignition induced by radical and catalytic reactions.

\section{Crossing point methods of Chen and Jones}

The purpose of both crossing point methods and that of adiabatic reactor, to be discussed in the next section, is to derive the kinetic parameters, $E$ and $A$, which can then be applied to estimate the critical size of a material. The crossing point method of Chen, incorporates the following procedure: packing the solid particles into a steel mesh basket that has a steel mesh cover, followed by placing two thermocouples into the sample, one positioned at the centreline and the other at a small distance away, then situating the basket in the preheated oven and recording the temperature by a data logger. This test is completed when the temperature difference between the two thermocouples' reading disappears (Wang et al. 2006; Chen \& Chong 1998; Chen 1999). The reaction rate is expressed by first order kinetics and an Arrhenius expression for the rate constant. The analysis remains valid at temperature higher than $100^{\circ} \mathrm{C}$, since water evaporation is ignored in the energy balance (Wang et al. 2006).

The crossing point method of Jones requires the measurement of the temperature difference between the centre temperature and the oven temperature (Wang et al. 2006), as measured near the sample's surface. Worden implemented Jones' method to determine the global kinetic parameters of the cotton impregnated with boiled linseed oil (Worden 2011). At low oven temperatures, the crossing point temperature derived by Chen's method approximates that obtained by Jones' method (Chen 1999). However, the two temperatures diverge as the oven temperature increases. From a theoretical perspective, Chen's method yields fundamental kinetic parameters, provided that the first order kinetic rate model holds. On the other hand, Jones' method results in estimates of apparent kinetic parameters that nonetheless could be useful for ranking materials for their tendency to self ignite (Chen 1999). See Appendix for the derivation of both methods and more complete discussion of their limitations.

\section{Adiabatic reactor}

Gross and Robertson employed an adiabatic reactor to determine the kinetic constants, $E$ and $A$ (Gross \& Robertson 1958). It consists of a Dewar flask, enclosed within a close-fitting cylindrical shell to reduce heat losses and maintain the homogenous temperature inside the furnace. The shell comprises two concentric stainless steel cylinders, equipped with two electric heating elements and an insulating fill, as well as the bottom and centre guard heating elements. The top-guard heating element is located within the Dewar flask plug which is composed of several layers of asbestos board. A thyratron control system permits the adjustment of the guard heater cycle. The copper-constantan thermojunctions, arranged in series, serve to measure the mean temperature-difference between the specimen and the ambient medium (Gross \& Robertson 1958).

From a fundamental perspective, this method entails no heat transfer through the surfaces of the sample. This simplifies the heat transfer equation to two terms, heat generation and heat accumulation, leading to an integral heat balance expressed in terms of an ordinary differential equation with time as an independent variable. As the kinetic properties $(E, A)$ are obtained for an average temperature of the sample, they convey the meaning of apparent or effective values. Hence the technique yields measurements of similar quality as those of the crossing point method of Jones. Its advantage over the Jones' method lies in a requirement of a single experiment, at a cost of significantly more complicated experimental equipment to ensure the adiabatic operation of the reactor.

\section{Thermogravimetric analysis}

Thermogravimetry-differential thermal analysis (TGA-DTA), or thermogravimetry-differential scanning calorimetry (TGA-DSC), involves heating small samples of materials (in the order of 5 to $10 \mathrm{mg}$ ), usually by imposing a constant temperature rise (in the order of 5 to $10^{\circ} \mathrm{C} \mathrm{min}^{-1}$ ) and measuring mass loss of the sample and associated heat effects. A gentle temperature ramp allows heat to be transferred to the sample (or removed from the sample, in case of exothermic reactions) on a time scale that is shorter than the sample decomposition. Likewise, a small sample size permits the gaseous reaction products to be removed efficiently from above the sample, preventing or minimising the occurrence of reverse and secondary gas-phase reactions. The presence of reverse reactions makes the system operate close to equilibrium, introducing complications in the data analysis that normally assumes the existence of a forward reaction only (i.e., nonequilibrium conditions). On the other hand, secondary gas-phase reactions may affect TGA measurements by depositing secondary char onto the sample, and may impact the DTA readings due to heat effect of these reactions. It is not often appreciated that DTA or DSC instruments also detect energy released in the gas phase reactions, which occur near the sample surface. The method has been applied to examine the spontaneous ignition of cotton fabrics with and without linseed oil (Khattab et al. 1999).

In a typical study, the fabric materials impregnated with linseed oil, with sample sizes of around $10 \mathrm{mg}$ in mass, were placed in the DTA furnace and heated at rates of between 5 and $20^{\circ} \mathrm{C} / \mathrm{min}$, while the onset of spontaneous ignition was measured by oxygen consumption (Khattab 
et al. 1999). The authors did not report the effect of different gas flow rates and sample mass and therefore the possibility of backward and secondary reactions could not be concluded from these experiments. Particularly, it is uncertain whether the investigators executed their experiments under non-equilibrium conditions. A preliminary study to determine the optimal conditions (flow rate, sample mass) is essential to achieve accurate measurements.

Khattab found that as the linseed oil concentration in the cotton increases, the apparent activation energies of pyrolysis and oxidation decrease, due to hypothesised formation of free radicals from oxidation of linseed oil which then catalyse the pyrolysis reactions of cotton (Khattab et al. 1999). Linseed oil oxidation, which incorporates cross-linking reaction, involves oxygen consumption and induces increasing sample mass. Thus, the mass reading of a TGA instrument corresponds to a combined effect of mass-gaining (i.e., oxygen consumption) and mass-losing (i.e., emission of carbon oxides and water) reactions. For this reason, the gravimetric techniques alone are insufficient to probe the spontaneous ignition of linseed oil impregnated on the cellulose materials. These techniques should be accompanied by other methods such as infrared spectroscopy or mass spectrometry (i.e., TGA-DSC-FTIR or TGA-DSC-MS).

\section{Ordway apparatus}

Another somewhat dated method to test the spontaneous heating involves a comparison of the temperature histories (i.e., plots of temperature versus time) of two cotton balls (one oily and one as a blank), placed some distance apart from each other inside a light steel tube, known as the Ordway apparatus. The tube is then heated by an external air bath surrounding the tube. Fresh air is supplied to the sample and the two balls receive the same heat. Unfortunately, this method was found not to yield reproducible results (Thompson 1928).

\section{Mackey apparatus}

Mackey apparatus is a rather old test protocol that involves a jacketed cylinder $10 \mathrm{~cm}$ in diameter and $17.5 \mathrm{~cm}$ in height, covered on the top and equipped with a thermometer (Khattab et al. 1999). It was originally developed for testing the selfheating and ignition of oils utilised in the wood industry (Bowes 1984). Two tubes are connected to this apparatus, one extending down into the cylinder and the other upward from the cover. A cotton sample soaked with oil is placed in a wire gauze cylinder and held concentrically in the apparatus. The procedure involves boiling of the water in the bath, inserting the sample into the apparatus and recording the thermometer readings (Thompson 1928). The oil is categorised as safe if the temperature does not exceed $100^{\circ} \mathrm{C}$ in $1 \mathrm{~h}$ or $200^{\circ} \mathrm{C}$ in $2 \mathrm{~h}$.

Theory of thermal ignition and its application to linseed oil Three models, characterised by different temperature profiles, have been developed to describe a spontaneouslyheating system, as illustrated in Figure 4. Semenov, ignoring the temperature differences within the reacting gas mixtures, assumed a uniform temperature profile, neglected the reactant consumption and supposed that chemical reaction followed the Arrhenius temperature dependence. The Frank-Kamenetskii model incorporates the conduction from the material's surface as the only heat loss mechanism and assumes the equality of ambient and material temperatures at the surface. Within the material, the temperature profile arises as a consequence of chemical heat release, boundary conditions and heat conduction in the bulk. The Thomas model considers both conduction through the solid and convective heat loss from the surface (Drysdale 1985).

The results of the Semenov model are expressed as a difference between the critical ambient temperature, $T_{\mathrm{a}, \mathrm{cr}}$ and corresponding uniform gas temperature, $T$, as indicated in Eq. 1 (Drysdale 1985).

$$
\Delta T_{\text {crit }}=T-T_{\mathrm{a}, \mathrm{cr}} \approx \frac{R T^{2} \mathrm{a}, \mathrm{cr}}{E}
$$

Thomas' model applies the convective boundary condition, as expressed in Eq. 2 (Drysdale 1985) where surface and ambient temperatures, $T_{\mathrm{s}}$ and $T_{\mathrm{a}}$, respectively, are not the same.

$$
h\left(T_{\mathrm{s}}-T_{\mathrm{a}}\right)=k \frac{\mathrm{d} T}{\mathrm{~d} r}
$$

The basket heating method was developed based on the steady state theory of ignition by Frank-Kamenetskii. The critical condition for the onset of self ignition is represented by a critical dimensionless parameter, $\delta_{c}$, also named as the critical Damköhler number, as defined in Eq. 3 (Drysdale 1985; Chen \& Chong 1998; Hill \& Quintiere 2000):

$$
\delta_{c}=\frac{A \rho E \Delta H_{c} r_{o}^{2} \exp \left(-E / R T_{\mathrm{a}}\right)}{k R T_{a}^{2}}
$$

with the symbols explained in Table 3. Ignition occurs once the Damköhler number exceeds a critical value (Cox 1995). Values of $\delta_{\mathrm{c}}$ are known for several geometries.

Semenov, Frank-Kamenetskii and Thomas' models assume a single step global reaction (i.e., no competing or parallel reactions), no reactant consumption, no effect of oxygen availability, and constant thermal properties of 

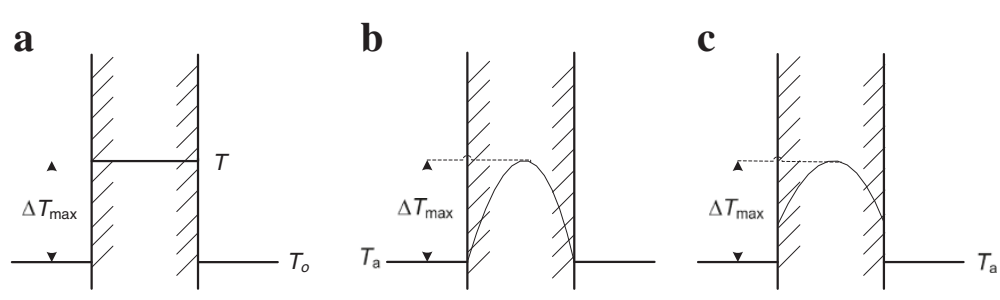

Figure 4 Temperature profiles inside spontaneously-heating materials based on the models of (a) Semenov; (b) Frank-Kamenetskii; (c) Thomas.

the system (Drysdale 1985; Worden 2011). Thus the models apply to systems characterised by simple lowtemperature oxidation chemistry, or to systems for which the global one-step kinetics provide a reasonable approximation to the actual chemical behaviour. This is not the case for self-heating of lignocellulosic materials soaked with linseed oil.

A typical approach is to obtain global kinetic parameters ( $E$ and $A$ ) from the crossing-point method of Chen (Chen \& Chong 1998) (Appendix) or from an adiabatic reactor, as the one used by Gross and Robertson (1958). These values are then substituted into the classical expression of Frank-Kamenetskii to yield a relationship between the characteristic length of a system and the critical ambient temperature

$$
\ln \left(\frac{\delta_{c} T_{a}^{2}}{r_{o}^{2}}\right)=\ln \left(\frac{E \Delta H_{c} A \rho}{k R}\right)-\frac{E}{R T_{a}}
$$

or into an analogous expression derived by Thomas (Drysdale 1985; Bowes 1984).

Worden, as well as Gross and Robertson, calculated the global kinetic parameters for the oxidation of cotton soaked with linseed oil. Worden studied the behaviour of boiled oil (i.e., oil that includes cobalt catalyst to accelerate drying), whereas Gross and Robertson investigated the performance of raw linseed oil. It is not surprising that the

Table 3 Definition of symbols for the Frank-Kamenetskii model (Equation 3) (Hill \& Quintiere 2000)

\begin{tabular}{lll}
\hline Symbol & Definition & Unit \\
\hline$\delta_{c}$ & critical Damköhler number & - \\
\hline$r_{\circ}$ & characteristic length & $\mathrm{m}$ \\
\hline$k$ & thermal conductivity & $\mathrm{W} \mathrm{m}{ }^{-1} \cdot \mathrm{K}^{-1}$ \\
\hline$h$ & convective heat transfer coefficient & $\mathrm{W} \mathrm{m} \cdot \mathrm{K}^{-1}$ \\
\hline$T_{\mathrm{a}}$ & critical ambient temperature & $\mathrm{K}$ \\
\hline$A$ & pre-exponential factor in the Arrhenius equation & $\mathrm{s}^{-1}$ \\
\hline$\Delta H_{\mathrm{c}}$ & heat of reaction & $\mathrm{J} \mathrm{kg}^{-1}$ \\
\hline$\rho$ & density & $\mathrm{kg} \mathrm{m}^{-3}$ \\
\hline$E$ & activation energy & $\mathrm{J} \mathrm{mol}^{-1}$ \\
\hline$R$ & universal gas constant (8.314) & $\mathrm{J} \mathrm{K}^{-1} \cdot \mathrm{mol}^{-1}$ \\
\hline
\end{tabular}

results are quite different. But, as one would expect, Worden obtained significantly lower estimates of the global activation energy and substantially higher evaluation of the global pre-exponential factor (Table 4). Two considerations should be pointed out. Firstly, the researchers applied different methodologies, Gross and Robertson used the adiabatic reactor, whereas Worden relied on the Jones' crossing-point method (see Appendix). This method is inferior to that of Chen. Secondly, Worden's results have convincingly demonstrated the failure of the classical selfignition theory for cotton soaked with linseed oil. In particular, Worden found both global kinetic parameters ( $E$ and $A$ ) to vary, whereas they are constant in the classical treatment. This indicates that the simple first order kinetic model employed in the classical theory is inconsistent with the actual behaviour of the material. This conclusion also follows from large differences between measured and predicted self-ignition temperature for cotton linters provided in Table 2 of the paper of Gross and Robertson (Gross \& Robertson 1958).

There is a kinetic compensation effect in the results of Worden (Worden 2011); i.e., a linear relationship between $E$ and $\log \left(A \Delta H_{\mathrm{c}}\right)$ of the form of $\ln \left(A \Delta H_{\mathrm{c}}\right)=$ constant $+E /(R T)$, with the isokinetic temperature of $361 \mathrm{~K}$ (Figure 5). This temperature signifies approximately the same reaction rate for the three sets of Worden's measurements of $A \Delta H_{\mathrm{c}}$ and $E$, and the compensation itself means that the effect of the change in the activation energy is compensated by the change in $A \Delta H_{\mathrm{c}}$. There is no generally accepted mechanistic explanation of the compensation effect, although it stands to reason to suggest that the effect arises due to availability of more than one radical species to bind with oxygen. A further investigation of this effect is required to elucidate its explanation for the present system and to confirm its existence by statistical tests.

The NFPA Handbook (Drysdale 1985) includes linseed oil absorbed on to the fibrous combustible materials such as cotton rags in the list of materials with the tendency of spontaneous heating. Cotton fabric materials soaked in linseed oil, which contains dryers, can auto-ignite about six to eight hours after the rags start to dry, in a process preceded by smoke and rancid odour (Howitt et al. 1995). 
Table 4 Self-heating properties of cotton soaked with linseed oil (Worden 2011; Gross \& Robertson 1958; Babrauskas 2003)

\begin{tabular}{|c|c|c|c|c|c|c|}
\hline $\begin{array}{l}\text { Linseed oil mass } \\
\text { percentage (\%) }\end{array}$ & $\begin{array}{l}E \\
\mathrm{~kJ} \mathrm{~mol}^{-1}\end{array}$ & $\begin{array}{l}A \Delta H_{\mathrm{c}} \\
\mathrm{W} \mathrm{kg}^{-1}\end{array}$ & $\begin{array}{l}\rho \\
\mathrm{kg} \mathrm{m}^{-3}\end{array}$ & $\begin{array}{l}k \\
\mathrm{~W}(\mathrm{~m} \cdot \mathrm{K})^{-1}\end{array}$ & $\begin{array}{l}c \\
\mathrm{~J}(\mathrm{~kg} \cdot \mathrm{K})^{-1}\end{array}$ & Ref \\
\hline 16.7 & 88 & $4.7 \times 10^{13}$ & 309 & 0.046 & 1400 & (Gross \& Robertson 1958; Babrauskas 2003) \\
\hline 33.3 & 42.37 & $2.60 \times 10^{10}$ & 96 & 0.089 & 1465 & (Worden 2011) \\
\hline 50 & 27.4 & $2.27 \times 10^{8}$ & 128 & 0.104 & 1548 & (Worden 2011) \\
\hline 75 & 16.97 & $5.30 \times 10^{6}$ & 329 & 0.125 & 1672 & (Worden 2011) \\
\hline
\end{tabular}

$\Delta H_{\mathrm{c}}$ is the heat of reaction; $\rho$ is density; $k$ is thermal conductivity; and $c$ is heat capacity.

The material's low surface to volume ratio encourages self-ignition, as this limits heat losses, facilitating the material's temperature rise. This ratio is inversely proportional to a characteristic dimension (radius) of the material; the larger this characteristic dimension, the lower the surface to volume ratio and higher the propensity to self-heat. The ignition occurs once the size of a material exceeds its critical radius, with smaller values of critical radius indicating increasing risk of self-ignition. For example, at $100^{\circ} \mathrm{C}$, wood fibreboard, cork and cotton soaked with raw linseed oil possess critical radii of $0.5,0.55$ and $0.017 \mathrm{~m}$ (Gross \& Robertson 1958), while coal exhibits self-heating only under bulk storage conditions. This supports the previous statement that linseed oil applied onto the cotton induces a greater tendency of the resulting material to self-heat.

Table 5 compares the physicochemical properties, which govern the self-heating, of several materials to cotton with linseed oil content of $16.7 \%$. Clearly, the activation energies of other materials remain much higher than that of cotton impregnated with linseed oil, with the exception of cork which displays a similar value. This further reinforces the particularly hazardous nature of cotton soaked with linseed oil, in comparison with other materials. Consistent with the findings for cotton, Napier and Vlatis (Napier \& Vlatis 1981) reported a decrease in the minimum ignition

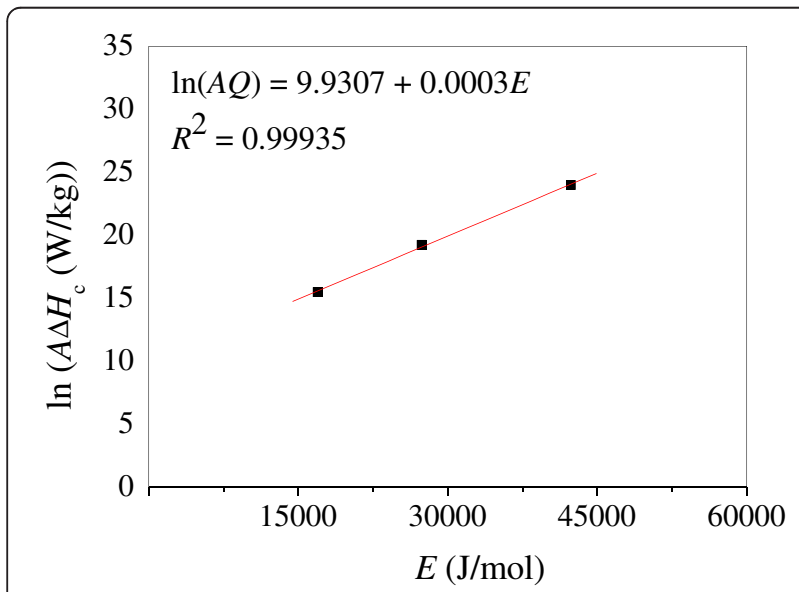

Figure $\mathbf{5}$ The kinetic compensation effect in the measurements of Worden (Worden 2011). or self-heating temperature of the mixture of beech saw dust and raw linseed oil with larger sample sizes, an increase in oil content in the range of $0-50 \%$ and a decrease in particle size. However, the presence of moisture in the material increases the self-heating temperature. These effects are not included in the classical theory of selfignition, suggesting caution in applying this theory to lignocellulosic materials impregnated with linseed oil.

\section{Measurement of oxidation of linseed oil}

Different methods have been applied to investigate the oxidation reactions of linseed oil. One of these methods comprises spreading the oil to achieve a given film thickness on selected supports, and then imposing different oxidation conditions on the samples. These conditions may involve thermal treatment in a forced-air circulation oven at $80^{\circ} \mathrm{C}$, natural ageing in the laboratory at room temperature and photo-ageing in a high speed exposure unit with a xenon lamp. The final step comprises the analyses of chemical changes during the treatments, as described later in the review (Lazzari \& Chiantore 1999). The difficulty of this method is to maintain the same accurate film thickness to collect reproducible quantitative results.

Fjällström et al. employed test chambers made of glass jars, equipped with metal lid and teflon disc, immersed into a water bath to control the temperature, and preconditioned air flowing through the chambers. The authors controlled the air humidity, the light intensity and the bath temperature, and measured the variation of temperature in the chambers. The authors placed linseed oil paint applied on the glass plates in the chamber and the gaseous products were passed through the silica gel impregnated with 2,4-dinitrophenylhydrazine and then analysed with high performance liquid chromatography (HPLC) (Fjällström et al. 2002). Increasing temperature and humidity enhanced total emission of aldehydes, while artificial light and air exchange rate produced no significant effects. This method required complex and time consuming procedures for sample preparation prior to analysis, involving solvent washing, evaporation, decantation and desorption of adsorbent with solvent.

Thompson reported that absorption of oxygen is an indicator of the spontaneous heating of oil. A brass 
Table 5 Self-heating properties of several materials compared to cotton impregnated with linseed oil (Gross \& Robertson 1958)

\begin{tabular}{|c|c|c|c|c|c|}
\hline Material & $\begin{array}{l}E \\
\mathrm{~kJ} \mathrm{~mol}^{-1}\end{array}$ & $\begin{array}{l}A \Delta H_{\mathrm{c}} \\
\mathrm{W} \mathrm{kg}^{-1}\end{array}$ & $\begin{array}{l}\rho \\
\mathrm{kg} \mathrm{m}\end{array}$ & $\begin{array}{l}k \\
W(m \cdot K)^{-1}\end{array}$ & $\begin{array}{l}\mathrm{c} \\
\mathrm{J}(\mathrm{kg} \cdot \mathrm{K})^{-1}\end{array}$ \\
\hline Wood fibre board & 108 & $3.3 \times 10^{13}$ & 250 & 0.050 & 1382 \\
\hline Cotton linters & 144 & $6.9 \times 10^{15}$ & 320 & 0.042 & 1340 \\
\hline Cork & 80.0 & $8.1 \times 10^{9}$ & 130 & 0.042 & 2010 \\
\hline Natural foam rubber & 116 & $2.9 \times 10^{15}$ & 108 & 0.040 & 2093 \\
\hline $16.7 \%$ of linseed oil on the cotton & 88.0 & $4.7 \times 10^{13}$ & 309 & 0.046 & 1400 \\
\hline
\end{tabular}

bottle with a rubber stopper was immersed in a bath of boiling water, equipped with a thermometer. The net amount of oxygen absorbed was measured by a pressure decrease (Thompson 1928). However, Thompson's methodology needs to be treated with caution since the pressure reading corresponds to the combined effect of the oxygen absorption and release of gaseous products of the oxidation reactions.

Thermal degradation of oil samples has been studied by differential scanning calorimetry (DSC) and thermogravimetric analysis (TGA). DSC has been applied to examine the kinetic parameters such as activation energy, preexponential factor and rate constant (Litwinienko \& Kasprzycka-Guttman 1999) of oxidation of linseed oil. The thermal decomposition of raw linseed oil analysed by DSC consisted of three steps, an exothermic process related to oxidation between 150 and $250^{\circ} \mathrm{C}$, the first stage of oxidative decomposition between 250 and $400^{\circ} \mathrm{C}$ and the main processes of decomposition above $400^{\circ} \mathrm{C}$ (Lazzari \& Chiantore 1999). An exothermic peak at $155^{\circ} \mathrm{C}$ and degradation, which started at $300^{\circ} \mathrm{C}$, were also observed by Suryanarayana et al. during curing of linseed oil (Suryanarayana et al. 2008). The peroxide formation may occur in the first step, followed by the decomposition of peroxides into radicals. The reaction of these radicals with unsaturated compounds is an exothermic process, accompanied by partial mass loss due to the fragmentation reactions (Lazzari \& Chiantore 1999).

Tuman et al. used differential scanning calorimetry (DSC) to study the autoxidation of linseed oil catalysed by manganese and zirconium dryer, as well as titanium alkoxide. The authors reported the manganese dryer catalysed the autoxidation step at the top surface of the coating only, while the zirconium dryer appeared active throughout the film (Tuman et al. 1996). This observation contradicts that of Mallégol et al. (Mallégol et al. 2000) and Meneghetti et al. (Meneghetti et al. 1998) who reported that a zirconium dryer exhibits no influence on the curing of linseed oil without a primary dryer.

The oxidation reaction of linseed oil can also be performed with the method described by Niczke et al. (Niczke et al. 2007). These authors carried out the oxidation of rapeseed oil methyl ester in a flask at $200^{\circ} \mathrm{C}$ with the air flowing for $25 \mathrm{~h}$. The liquid products were collected for analysis every $5 \mathrm{~h}$ and the volatile products were trapped in a scrubber with trichloroethylene for analysis employing FTIR, H-NMR and GC-MS as described later in this paper (Niczke et al. 2007).

Additionally, a flow reactor served to study oxidation of linseed oil, as illustrated in Figure 6 (Juita et al. 2011a; Juita et al. 2010a; Juita et al. 2010b; Juita et al. 2011b). The study incorporated glass or lignocellulosic substrates impregnated with linseed oil, corresponding to the cases of spontaneous combustion of rags soaked with linseed oil. The reactor, made of copper, $11.8 \mathrm{~cm}$ in length and $0.94 \mathrm{~cm}$ in diameter and located inside a Thermoline oven, operated at temperature of either 80 or $100^{\circ} \mathrm{C}$. Mass flow controllers measured the flowrate of oxygen and nitrogen gases prior to entering the reactor. A particulate filter enhanced the mixing of those gases (in equimolar proportions). The feed gases were subsequently preheated in copper coil tubing in the reactor oven, allowing the temperature of the feed gases to equilibrate with the oven temperature. A micro gas chromatograph enabled the quantitation of the gaseous products from the output of the reactor. Gas sampling bags collected and stored the reaction product gases for identification on a Fourier transform infrared spectrometer and a gas chromatographmass spectrometer.

Another experimental technique able to provide high quality kinetic measurements is a jet stirred reactor (JSR). A typical JSR consists of four capillary jets that eject incoming gases at high velocity (on the order of 50 to $100 \mathrm{~m} / \mathrm{s}$ ) into a spherical reactor vessel inducing thorough stirring of the reactor's content, allowing one to assume perfect mixing. The mathematical description of the reactor involves a system of algebraic equations, which are more readily solved than a system of ordinary differential equations or partial differential equations required for turbulent (plug) and laminar flow reactors, respectively. JSR allows obtaining high quality measurements of formation of chemical species needed for developing kinetic models of oxidation. A study on the oxidation of linseed oil in the gas phase in a JSR in the temperature window from 550 to $750 \mathrm{~K}$ may yield significant insights into the mechanism of 


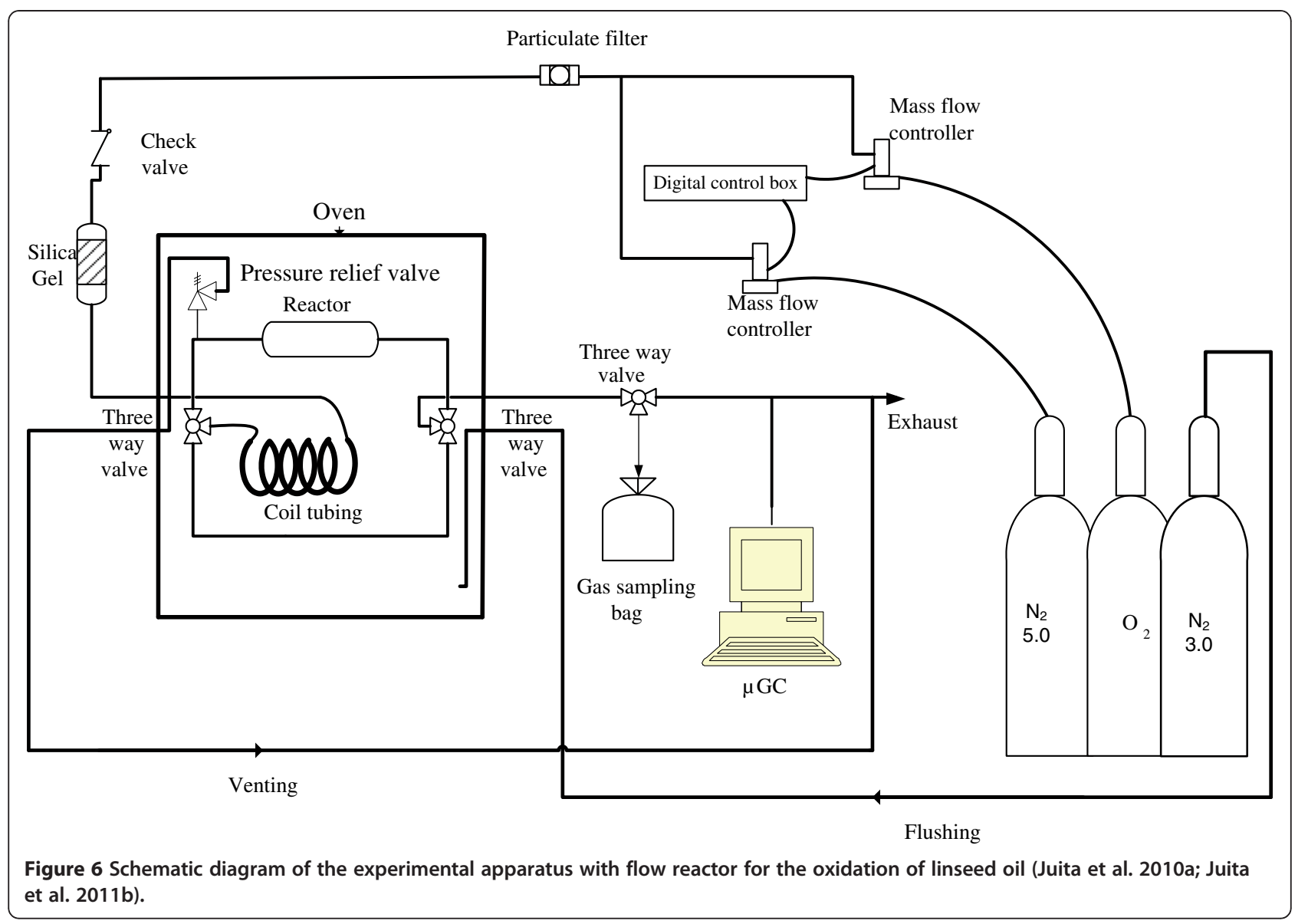

hydroperoxide formation, suggesting a new avenue of inquiry for future research. This temperature window covers the peroxy reactions that govern the formation of cool flames. Similar reactions operate in spontaneous ignition of linseed oil, though at lower temperatures. In previous studies, the measurements obtained from the experiments involving JSR were applied to validate kinetic models of oxidation of n-butanol (Sarathy et al. 2009), methyl octanoate-1-butanol (Togbe et al. 2010a), n-decane (Dagaut \& Cathonnet 2006), mixture of $n$-decane and $n$-propyl benzene as surrogate fuels of kerosene (Dagaut \& Cathonnet 2006), and methyl octanoate-ethanol as surrogate fuel of biodiesel-bioethanol (Togbe et al. 2010b). From this perspective, an initial investigation, to gain insights into the oxidation of linseed oil, may involve a study on ethyl linoleate or linoleic acid.

Figure 7 illustrates a jet-stirred reactor (JSR), made from a fused-silica sphere, $4 \mathrm{~cm}$ in diameter. Four nozzles, $1 \mathrm{~mm}$ in diameter, inject the gases into the reactor inducing their mixing. Fuel enters the reactor together with nitrogen via an atomiser-vaporiser that is maintained at $200^{\circ} \mathrm{C}$. A thermocouple (0.1 $\mathrm{mm} \mathrm{Pt}-\mathrm{Pt} / \mathrm{Rh} 10 \%)$ monitors the temperature along the vertical axis of the reactor (Dayma et al. 2011; Dagaut et al. 1986).
A laminar flow reactor presents an alternative approach to JSR to elucidate the oxidation reaction of linseed oil at low temperatures, with literature examples including investigations of the pyrolysis and oxidation of catechol, captan, folpet and alpha-cypermethrin (Chen et al. 2011a; Chen et al. 2011b; Summoogum et al. 2011; Thomas et al. 2007; Wornat et al. 2001). A typical experimental apparatus comprises a vaporiser, isothermal flow reactor and a product collection system as shown in Figure 8. The sample was loaded into a vertical tube and placed in an isothermal oven that functioned as a vaporiser. Carrier gas entrained the vapour and flowed to the high temperature laminar flow reactor where the pyrolysis or oxidation reactions took place. The reactor constituted a central constanttemperature zone ( $T_{2}$ in Figure 8$)$ of an alumina tube affording residence time of 0.3 to $1 \mathrm{~s}$ at a temperature in excess of $300^{\circ} \mathrm{C}$. The gaseous products were trapped in a sampling bag, while the condensed-phase products were collected in separate experiments by activated charcoal adsorbent and XAD-2 resin cartridges (Chen et al. 2011a; Thomas et al. 2007). Charcoal is no longer recommended for this application, as its strong adsorption properties result in low recoveries of some VOCs. 


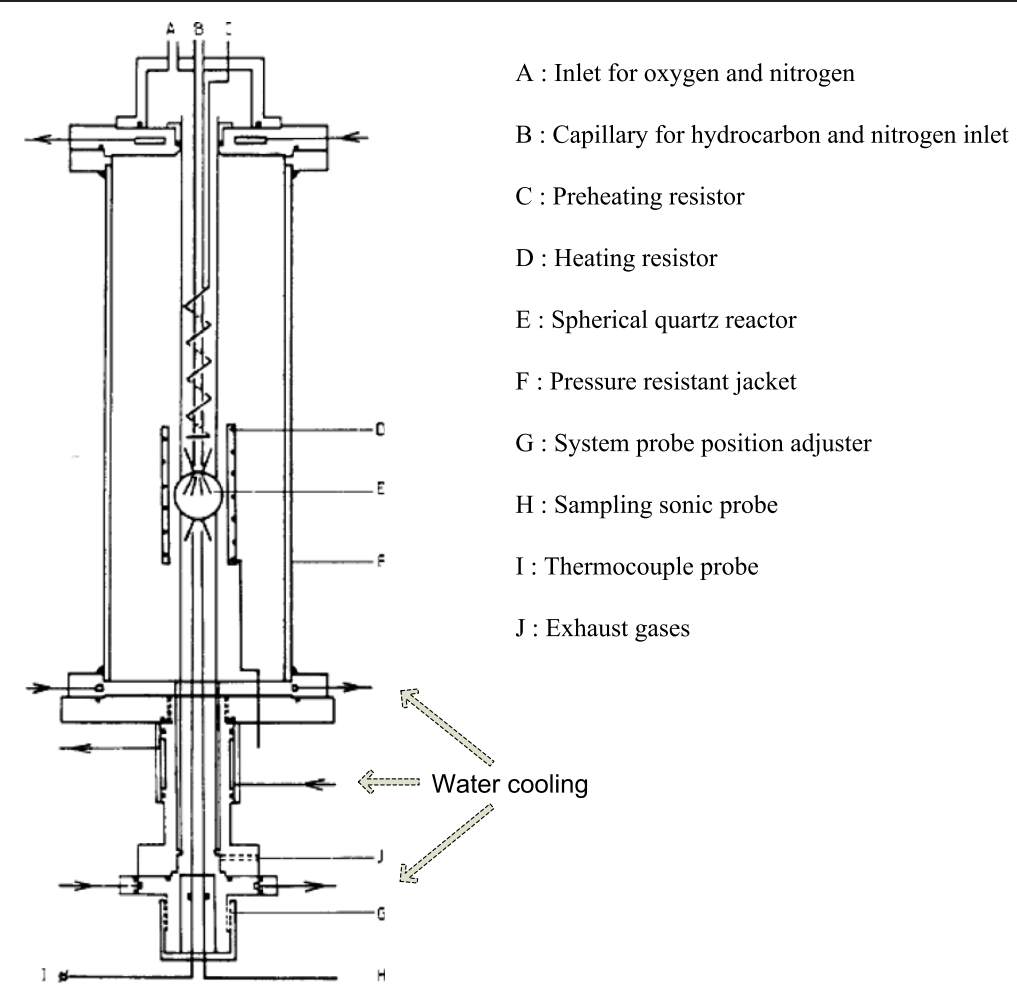

Figure 7 Jet-stirred reactor for kinetic studies of oxidation reaction (Dagaut et al. 1986).

\section{Analytical methods to study the oxidation chemistry of linseed oil Spectroscopic techniques}

Fourier transform infrared spectroscopy (FTIR), nuclear magnetic resonance (NMR), Raman spectroscopy, UVvis spectrometry and chemiluminescence have been implemented to investigate the structural changes of the active compounds in the linseed oil (i.e., oleic, linoleic and linolenic acids) during their oxidation. Lazzari et al.

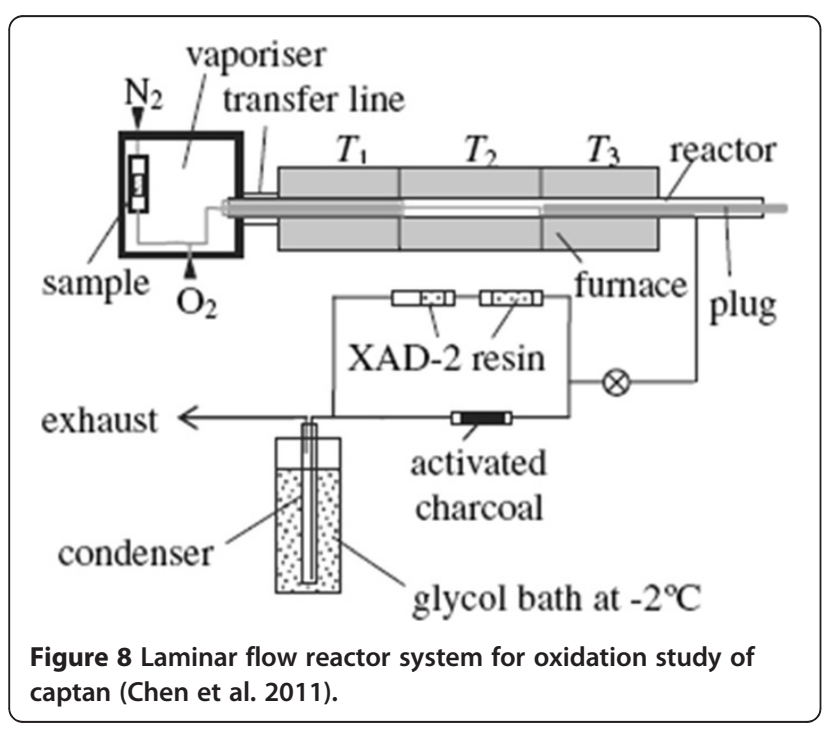

investigated the degradation of linseed oil, by natural and accelerated weathering, by means of FTIR (Lazzari \& Chiantore 1999). The results of their FTIR analysis on linseed oil film, which had been treated isothermally at $80^{\circ} \mathrm{C}$, indicated that, after an induction period of around $4 \mathrm{~h}$, the hydroxyl groups increased in abundance up to a constant value, and the double bonds commenced to disappear, indicating that significant chemical changes occur between 4 and $8 \mathrm{~h}$ into the drying process (Lazzari \& Chiantore 1999). Intensity of specific infrared bands, as measured by FTIR, provides a convenient method for monitoring the sample consumption. For example a cis $\mathrm{C}=\mathrm{CH}$ vibration at $3010 \mathrm{~cm}^{-1}$ (Stava et al. 2007; Oyman et al. 2004; Warzeska et al. 2002), or emergence of a particular functional group, such as hydroperoxide, may be determined by monitoring the absorption of the infrared signal at $3472 \mathrm{~cm}^{-1}$ (Meneghetti et al. 1998). These results indicate that FTIR provides an excellent means to identify the functional groups present in the oil. However, the method cannot determine the structure of the reacting species, and appears to have no capacity to quantitate the oil's triacylglycerol content.

Mallégol et al. observed that the variation in the magnitude of the easily-detected vibrational bands of conjugated compounds gauges the rate of oxidation reaction, which exceeds that of the saturation reaction, in the presence of dryer (Mallégol et al. 2000). The epoxidation reaction of 
linseed oil manifests itself by the disappearance of the $3010 \mathrm{~cm}^{-1}$ band and the emergence of oxirane rings indicated by the appearance of two bands at 825 and $845 \mathrm{~cm}^{-1}$ (Martini et al. 2009).

FTIR analysis of gaseous products of linseed oil oxidation has identified the presence of carbon dioxide in the spectral region of 2240 to $2411 \mathrm{~cm}^{-1}$, carbon monoxide in the region of 2060 to $2220 \mathrm{~cm}^{-1}$, formic acid in 1060 to $1144 \mathrm{~cm}^{-1}$, propionaldehyde in the band of 828 to $867 \mathrm{~cm}^{-1}$, acrolein in 900 to $1000 \mathrm{~cm}^{-1}$, whereas between 1700 and $1800 \mathrm{~cm}^{-1}$ the spectrum displays strongly overlapping bands of formic acid, acetaldehyde, propionaldehyde, acrolein and crotonaldehyde. Similarly, propionaldehyde, crotonaldehyde and ethane overlap between 2500 and $3100 \mathrm{~cm}^{-1}$ (Juita et al. 2010a).

Time-resolved FTIR (TR-FTIR) and attenuated total reflectance (ATR) techniques can assess the chemical changes during the oxidation of linseed oil, as demonstrated by their application to oxidation of ethyl linoleate, a model compound for linseed oil. For example, applications of TR-FTIR yielded understanding of the behaviour of different pyrazoles as anti-skinning additives (to prevent the formation of solid skin during drying) in the oxidation of ethyl linoleate by bis (acetylacetonato)cobalt(II) $\left[\mathrm{Co}(\mathrm{acac})_{2}\right]$ (Tanase et al. 2004) and have unravelled the effect of cobalt dryer and ferrocene derivatives on the induction time (Stava et al. 2007); that is, the time before significant changes are observed in the concentration of ethyl linoleate.

The results of the H-NMR spectroscopic analysis of Niczke et al. (Niczke et al. 2007) have demonstrated that the relative number of methyl protons $(\delta=0.86 \mathrm{ppm})$ remains unaffected by the oxidation of rapeseed oil methyl ester. However, the relative concentration of protons $(\delta=5.3 \mathrm{ppm})$ attached to alkenyl $(-\mathrm{HC}=\mathrm{CH}-)$ carbons reduces dramatically from 2.6 in rapeseed oil methyl ester to 1.1 in liquid products of oxidation of rapeseed oil methyl ester and 0.6 in volatile products of oxidation of the ester. Niczke et al. report a less significant decrease in methylene protons $(\delta=1.96 \mathrm{ppm})$ attached to $\alpha$ carbons (i.e., $-\mathrm{CH}_{2}-\mathrm{HC}=\mathrm{CH}-$ ), with changes in relative concentration from 4.0 (unoxidised ester) to 2.4 (liquid products) and 1.5 (volatile products) (Niczke et al. 2007). In comparison, protons $(\delta=1.57 \mathrm{ppm})$ attached to $\beta$ carbons display relative decrease from 20.6 to 18.4 and 12.6. These results demonstrate a preferential cleavage of the bonds between $-\mathrm{CH}_{2}-$ and $-\mathrm{CH}_{2}-\mathrm{HC}=\mathrm{CH}-$ groups during the formation of gaseous products in the oxidation process, and removal of protons attached to alkenyl carbons both during the oligomerisaton and formation of gaseous products. The H-NMR spectra of linseed oil are illustrated in Figure 9. The chemical changes diagnosed by H-NMR during oxidation of ethyl linoleate (EL), catalysed by combination of ascorbic acid 6-palmitate (AsA6p) and

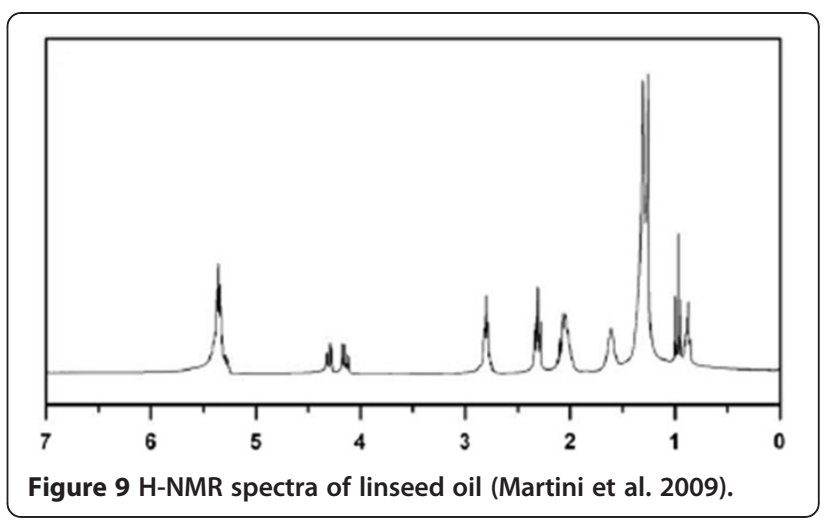

iron(II)-2-ethylhexanoate (Fe-eh), include a decrease in intensity of the cis-double bonds (a), bisallylic methylene (b) and monoallylic methylene (c), the formation of conjugated double bonds at 5.5-6.6 ppm, allylic methine protons $\left(\mathrm{a}_{1}\right)$ at $4.3 \mathrm{ppm}$, as well as growth of conjugated EL hydroperoxides at 7.9 and 8 ppm (Miccichè et al. 2006), as shown in Figure 10.

H-NMR was also applied to probe the epoxidation reaction of linseed oil, indicated by the disappearance of vinylic hydrogens at $5.3 \mathrm{ppm}$ and the appearance of epoxy groups at 2.9-3.1 ppm (Martini et al. 2009). NMR spectroscopy is a useful method for identification of very fine structural components, however, it requires costly instrumentation and significant expertise to interpret the spectra.

Raman spectroscopy complements FTIR spectroscopy by identifying the symmetric vibrational modes, while FTIR measures the absorption of infrared energy by the asymmetric vibrational modes and polar groups (Muik et al. 2005). Thus, Raman spectroscopy detects the symmetric diatomic molecules such as nitrogen and oxygen which cannot be measured by infrared spectroscopy, but fails to detect asymmetric vibrational modes. Raman spectroscopy provides chemical spectra that can probe the chemical changes during oxidation of linseed oil, which are reflected in changes of the magnitude of the cis $\mathrm{C}=\mathrm{C}-\mathrm{H}$ asymmetric stretch $\left(3012 \mathrm{~cm}^{-1}\right)$ (Oyman et al. 2004).

Oyman et al. used Raman spectroscopy to compare changes in the abundance of double bonds during oxidation of linseed and tung oils. For linseed oil, the abundance of the non-conjugated double bond decreased as the oxidation proceeded and non-conjugated double bonds converted to conjugated double bonds (Oyman et al. 2005a). In contrast, the abundance of the conjugated double bonds in tung oil decreased during oxidation, and, after $90 \mathrm{~h}$ of an experimental run, only a small peak signified the residual amount of conjugated trans double bond left (Oyman et al. 2005a). By means of a Raman spectrometer, Muik et al. analysed aldehydes and epoxy compounds, such as trans-9,10- and cis-9,10- 


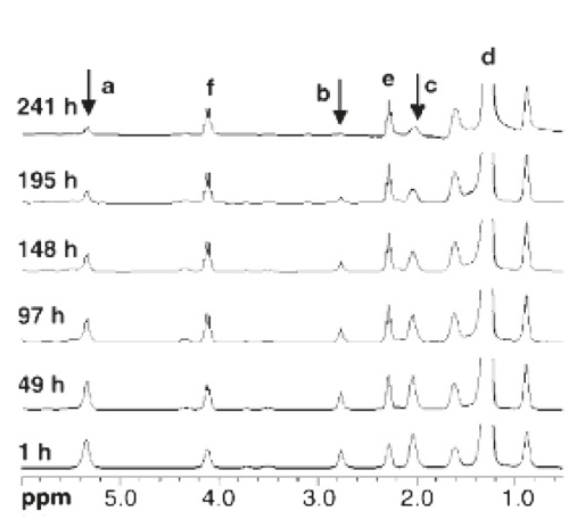

(a)

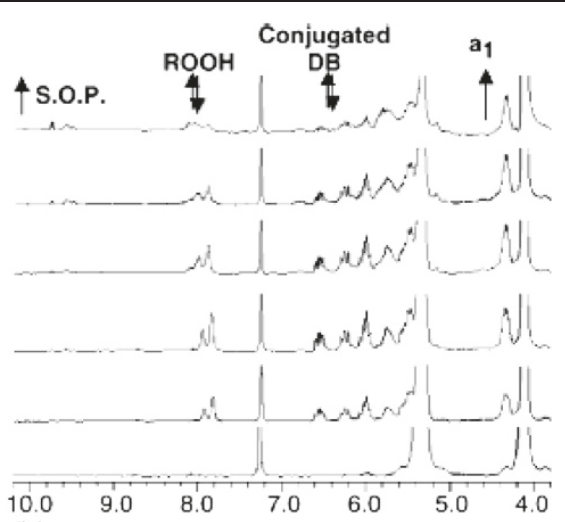

(b)
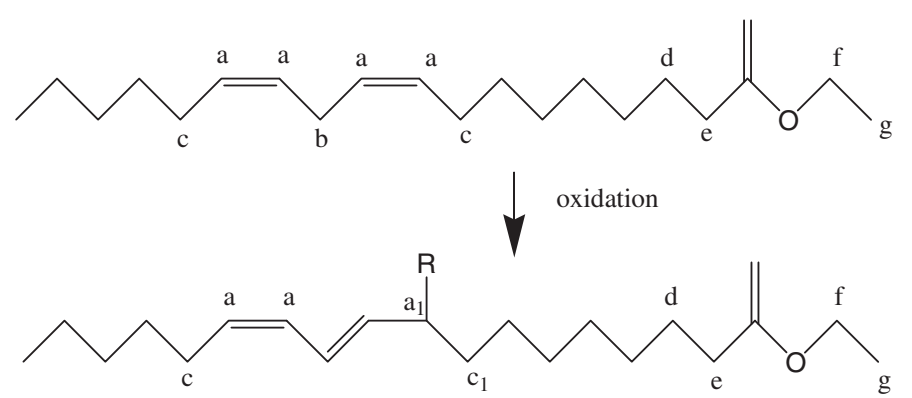

Figure 10 Structural changes of ethyl linoleate observed by H-NMR during oxidation catalysed by AsA6p/Fe-eh, molar ratio 2. $\mathrm{SOP}$ and DB refer to secondary oxidation products and double bonds. $\mathrm{R}=-\mathrm{OOH},-\mathrm{OL},-\mathrm{OOL}, \mathrm{L}$ represents another ethyl linoleate molecule (Miccichè et al. 2006).

epoxystearic acids as the oxidation products of oleic acid (Muik et al. 2005). They reported a weak band at $1724 \mathrm{~cm}^{-1}$ to relate to the $\mathrm{C}=\mathrm{O}$ stretching of hexanal and a very strong band at $1641 \mathrm{~cm}^{-1}$ to correspond to the conjugated $\mathrm{C}=\mathrm{C}$ stretching of the trans-trans-2,4decadienal, the major decomposition product of linoleate (Muik et al. 2005).

UV-vis spectroscopy detects the formation of ligand complexes of cobalt, an active catalyst for the decomposition of hydroperoxides in ethyl linoleate (Tanase et al. 2004). UV-vis has been also implemented to observe the conjugated diene structure at the absorption maximum of 232-232.5 nm (Belhaj et al. 2010; Hendriks et al. 1979). The concentration of conjugated dienes in the oil samples increases during the storage (Belhaj et al. 2010), indicating that oxidation proceeds during this period. In its application to oxidation of linseed oil, UV-vis yields rapid qualitative information. However, it requires the determination of absorption coefficients to produce quantitative measurements. This however may not always be possible for complex mixtures of chromophores.

Chemiluminescence provides another approach to analyse the lipid peroxidation. Rolewski et al. reported that hydroperoxides produced during oxidation of linseed oil at $60^{\circ} \mathrm{C}$ increased almost linearly during $2 \mathrm{~h}$, then reached a constant value whence finally their concentration slowly decreased. This method affords fast measurements with higher sensitivity compared to the determination of peroxide value using iodometric titration. However, carotenes, flavones and riboflavin, if present in oil, confound the measurements (Rolewski et al. 2009).

\section{Chromatographic and mass spectrometric techniques}

Chromatographic techniques serve to identify and quantitate the oxidation products of linseed oil. These techniques comprise micro gas chromatography $(\mu \mathrm{GC})$, high performance liquid chromatography (HPLC), gas chromatography-mass spectrometry (GC-MS), solid phase micro extraction (SPME) combined with GC-MS and size exclusion chromatography (SEC). The application of each method is described below.

Micro gas chromatography $(\mu \mathrm{GC})$ quantitated the emission of gaseous products during oxidation of linseed oil, with carbon dioxide as the major product. The concentration profile of each species comprises three stages: the first period whereupon the concentration rises significantly to reach a maximum value, followed by a sharp decay in the second stage and finally the concentration declines slowly (Juita et al. 2011a).

High performance liquid chromatography (HPLC) has been deployed to investigate the aldehyde products of 
paint oxidation. A silica gel cartridge impregnated with 2,4-dinitrophenylhydrazine (DNPH) sampled the products, with authentic reference substances employed to identify them (Fjällström et al. 2002). Liquid chromatography-mass spectrometry/mass spectrometry analysis (LC-MS/MS) confirmed the structure of the compounds. Methanal, ethanal, propanal, pentanal and hexanal constituted the most abundant aldehydes emitted from the paint oxidation at ambient temperature (Fjällström et al. 2002), and their emission occurred mostly during the first day of the oxidation process.

In general, HPLC affords analysis of a larger range of compounds than is possible with GC. However, HPLC is a more costly technique than GC owing to the solvent usage and at present cannot match GC when considering resolution and sensitivity. These considerations make $\mathrm{GC}$ the preferred technique for analysis of volatile analytes.

The methanolic extracts of paint samples of different historical ages (5, 26 and 373 year old), analysed by GCMS, revealed that younger paint film contained more monounsaturated fatty acid and less diacids compared to older paints. This means that the oxidation process continues in paints over hundreds of years. The unsaturated fatty acids are oxidised leading to the higher amount of diacids in older paints. Analysis of 5-year old stand oil film identified short chain fatty acids $\left(\mathrm{C}_{7}-\mathrm{C}_{10}\right)$, diacids $\left(C_{7}-C_{11}\right)$, saturated long chain fatty acids $\left(C_{16}-C_{18}, C_{20^{-}}\right.$ $\mathrm{C}_{22}$ ), a cyclic $\mathrm{C}_{18}$ fatty acid and some unsaturated and/or oxidised $\mathrm{C}_{18}$ fatty acids, in the extracts. In addition, the analysis detected monounsaturated $C_{18}$ fatty acids, but no doubly and triply unsaturated fatty acids, although all acids had been initially present in high concentrations in the oil (van den Berg et al. 2002).

Solid phase microextraction (SPME) method has been employed for the analysis of volatile components in food, oils, water, soil (Havenga \& Rohwer 1999) and in environmental samples. The advantages of this method include solvent-free operation, small quantity of sample needed, low cost (Ribeiro et al. 2008) and fast sample preparation compared to conventional liquid-liquid extraction or soxhlet extraction (Eriksson et al. 2001). This is a simple method which incorporates sampling, extraction, concentration, and sample introduction (Contini \& Esti 2006), replacing the tedious sample pretreatment and extraction process required for classical techniques.

Different types of fibre have been found suitable for analyte absorption, including $100 \mu \mathrm{m}$ polydimethylsiloxane (PDMS) for samples of virgin olive oil (Jiménez et al. 2004; Baccouri et al. 2007), 30 and $50 \mu \mathrm{m}$ divinylbenzene/ carboxen/polydimethylsiloxane (DVB/CAR/PDMS) for linseed oil (Wiesenborn et al. 2005; Krist et al. 2006), oil in water emulsion and marine salt (Beltran et al. 2005; Silva et al. 2010), rapeseed oil (Jeleń et al. 2000) and sunflower oil (Guillen \& Goicoechea 2008), $75 \mu \mathrm{m}$ CAR/PDMS for tonalin oil and safflower oil (García-Martínez et al. 2009), $100 \mu \mathrm{m}$ PDMS and $85 \mu \mathrm{m}$ polyacrylate (PA) for olive oil (Ribeiro et al. 2008). Among the four types of fibres, PA, PDMS, carbowax/divinylbenzene (CW/DVB) and DVB/CAR/PDMS, the last one was reported to provide the best detection of analysed compounds, followed by CW/DVB which afforded the detection of all compounds even with smaller peak areas. PDMS had lower extraction capacities and PA showed the lowest extraction ability (Jeleń et al. 2000).

The critical aspect in solid phase microextraction is the establishment of an equilibrium condition between gaseous and adsorbed species. The conditions that influence the establishment of the equilibrium include the temperature and duration of the adsorption experiments, fibre type, as well as the size of the compounds and their concentration. From this perspective, researchers explored different conditions to attain the equilibrium, for instance, varying sampling temperature from ambient to $60^{\circ} \mathrm{C}$ and absorption time of between $15 \mathrm{~min}$ and 10 h (Havenga \& Rohwer 1999; Ribeiro et al. 2008; Jiménez et al. 2004; Baccouri et al. 2007; Wiesenborn et al. 2005; Krist et al. 2006; Beltran et al. 2005; Silva et al. 2010; Jeleń et al. 2000; Guillen \& Goicoechea 2008; GarcíaMartínez et al. 2009). The sampling typically proceeds at $60^{\circ} \mathrm{C}$ for 15 to $20 \mathrm{~min}$.

The SPME-GC-MS method has been exploited for the quantitation and identification of VOC in the headspace of raw and boiled (with metal dryer content) linseed oil. Several types of VOC were identified, including saturated and unsaturated aldehydes, ketones, alcohols, carboxylic acids and furans. The concentration of propanal, hexanal, 2-pentenal, 1-penten-3-ol, 2,4-heptadienal, 2,4decadienal, 3,5-octadien-2-one, acetic acid and hexanoic acid increased during $6 \mathrm{~h}$ oxidation at $80^{\circ} \mathrm{C}$. The emission of VOC from raw linseed oil is significantly lower than from boiled linseed oil (Juita et al. 2011c), owing to metal catalysed reactions in the latter.

Krist et al. utilised SPME technique to analyse volatile compounds in the headspace of three types of linseed oil, two of them produced by pressing flax seeds at room temperature (Lower Austria, and Saxony, Germany), while the third (Styria, Austria) was obtained by pressing the seeds, previously heated at $60^{\circ} \mathrm{C}$ for $30 \mathrm{~min}$, at room temperature. VOC detected from all types of oil comprised acetic acid, trans-2-butenal, trans-2-pentenal, hexanol, trans,trans-2,4-hexadienal, 2-pentylfuran, trans, trans-3,5-octadiene-2-one and nonanal. Some species, including 2-butanol, ethylbenzene, heptanal, benzaldehyde, octanal, decanal, were only identified in linseed oil from Germany. The differences in the composition of VOC appear to originate in plant varieties, cultivation and extraction conditions (Krist et al. 2006). 
Volatile organic compounds produced from linseed oil have also been studied by thermal desorption gas chromatography - mass spectrometry combined with olfactometry odour recognition (TD-GC-O/MS); the latter performed by combination of expert and non expert panellists who had been requested to report the first perception of an odour (Clausen et al. 2008). A detection frequency method was implemented to measure the odour intensity (Clausen et al. 2008), by counting the number of panellists who detect an odour active VOC. This method routinely serves to detect and identify odour active VOC, in the perfume and food industries, and to evaluate odour from paint emission in indoor environment (Clausen et al. 2008).

Literature reports the application of combined matrixassisted laser desorption/ionisation -reflectron-time-offlight (MALDI-RTOFMS) and electrospray ionisation (ESI-MS/MS) to analyse the triacylglycerol composition of linseed oil. Figure 11 demonstrates the spectra of triacylglycerols in linseed oil generated by MALDI-MS. The experiment determined that more than $50 \%$ of triacylglycerols comprise one to three linolenic acid groups (Krist et al. 2006) in linseed oil.

Two dimensional gas chromatography time-of-flight mass spectrometry (GC $\times$ GC-TOFMS) has been developed to analyse the volatile and semi volatile compounds from complicated mixtures, employing separation based on the volatility in the first dimension and polarity in the second dimension (Silva et al. 2010), including the identification of volatile compounds in virgin olive oil (Kanavouras et al. 2005). In this technique, the sample is initially separated in the first column, and the eluent collected over short time periods and then injected into the second column. This method can resolve the problem of co-elution encountered in one-dimensional chromatography which limits the automatic species identification by library searches (Silva et al. 2010). Figure 12 illustrates that the coeluting compounds of similar volatilities on a non-polar column can be well separated on a polar column due to their different polarities (Silva et al. 2010). Clearly, two dimensional GC significantly improves the analysis. Kanavouras et al. reported that a combination of SPME (using PDMS-DVB fibres) and GC-TOFMS seems to be faster and simpler compared to dynamic headspace thermal desorption (DHS-TD)/GC-MS using Tenax TA trap; however, the latter displays higher efficiency in terms of the number of compounds separated (Kanavouras et al. 2005).

Size exclusion chromatography (SEC) is particularly suitable to analyse the product of the polymerisation reaction of linseed oil involving its active constituents. It was employed to observe the polymerisation of ethyl linoleate in the presence of $\mathrm{Co}(\mathrm{acac})_{2}$ /additive mixture (Tanase et al. 2004) and the oligomerisation of ethyl linoleate catalysed by 1,4,7-trimethyl-1,4,7-triazacyclononane (MnMeTACN/HMTETA) (Oyman et al. 2004). During the first day of drying, oligomer formation was observed relatively quickly for the oxidation reaction of ethyl linoleate in the presence of cobalt/calcium/zirconium dryers. No significant change in the oligomeric distribution occurred on further drying (Muizebelt et al. 1994). This method quantitates the abundances of hydroperoxides, dimers, trimers and higher oligomers, providing information about rates of cross linking reactions (Wu et al. 2004). By applying SEC, Lazzari et al. identified the peak eluting at $32.5 \mathrm{~min}$ as corresponding to the formation of dimers. These researchers reported that the weight of the sample increased up to a maximum of $7 \%$ after $20 \mathrm{~h}$ of oxidation at a constant temperature of $80^{\circ} \mathrm{C}$ (Lazzari \& Chiantore 1999). This increase could be related to the incorporation of oxygen that manifests itself by fast accumulation of insoluble fractions as a result of cross-linking reactions. The formation of small amounts of volatiles caused the weight to decrease after 20 h treatment (Lazzari \& Chiantore 1999).

Different paints emit distinct species of aldehydes. For instance, paints rich in linoleic and linolenic acids produce mostly hexanal (Hancock \& Leeves 1989) and propanal (Serfert et al. 2009), respectively, as analysed by GC-MS techniques (Fjällström et al. 2002). Nonanal arises as the major volatile species produced during oxidation of lipids present in oleic acid (Beltran et al. 2005; García-Martínez et al. 2009). Oils rich in conjugated linoleic acid, such as tonalin oil, produce a combination of hexanal and heptanal as the two main oxidation products, with hydroperoxides as minor products (García-Martínez et al. 2009).

The presence of 2-pentenal, hexanal, 2-heptenal, 2octenal, octanal and nonanal defines the rancidity of fats, while hexanal, octanal and 2,4-decadienal characterise the rancidity of food (Jiménez et al. 2004). Hexanal

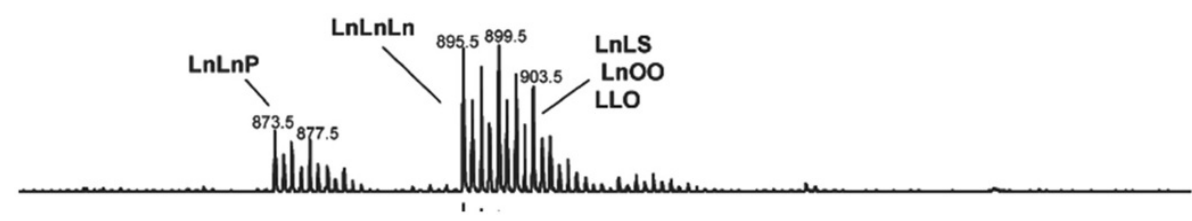

Figure 11 Identification of tryacylglycerol composition of linseed oil from Lower Austria, pressed at room temperature. Fatty acid chains in triacylglycerols are denoted as follow: Ln: linolenic acid, L: linoleic acid, O: oleic acid, S: stearic acid, P: palmitic acid (Krist et al. 2006). 


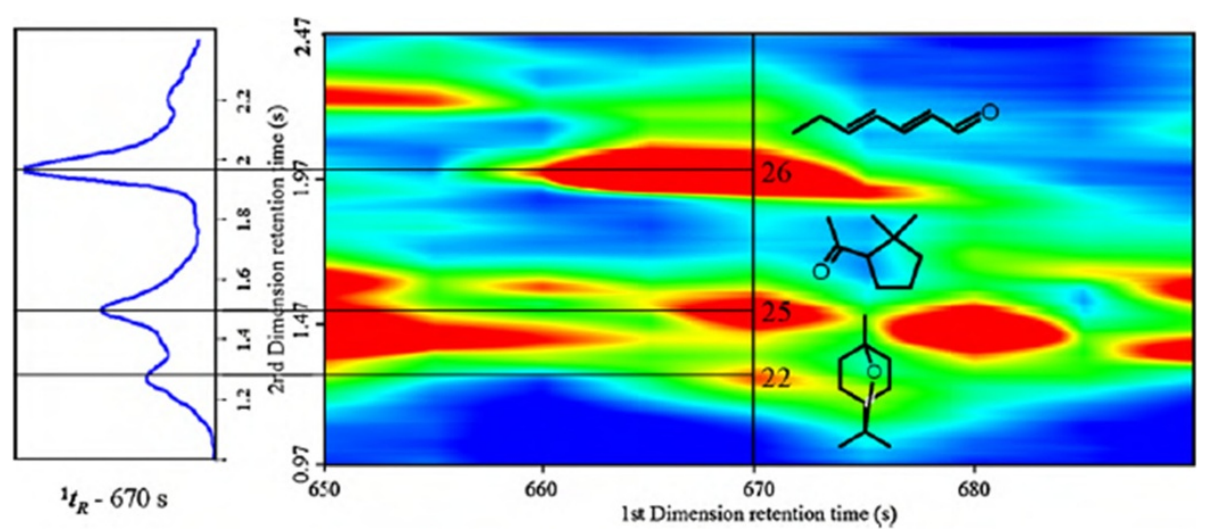

Figure 12 Two-dimensional GC contour plot shows the separation of compound 22, 25 and 26 which corresponds to 1,8-cineole, 1-(2,2-dimethylcyclopentyl)-ethanone and 2,4-heptadienal, respectively (Silva et al. 2010).

comprises the most abundant compound found in fresh rapeseed oil obtained by cold pressing and after 5 days of storage at $60^{\circ} \mathrm{C}$, while, after 10 days, 2-heptenal commenced to dominate the aldehyde distribution (Jeleń et al. 2000). For this reason, the ratio of hexanal to nonanal has been suggested as an index describing the quality of olive oil (Mildner-Szkudlarz et al. 2003).

The secondary degradative oxidation compounds could be classified as acids, alcohols, esters, hydrocarbons, furan and carbonylic derivatives (Guillen \& Goicoechea 2008). The main acids detected in the headspace of the oil samples include formic, acetic and hexanoic acid, while hydrocarbon compounds emitted comprise saturated, monounsaturated, diunsaturated and cyclic hydrocarbons (Guillen \& Goicoechea 2008).

Table 6 assembles analytical techniques employed to study the oxidation of linseed oil, including types of chemical reactions investigated, and compounds detected.

\section{Parameters and indices assessing progress of oxidation of linseed oil}

Iodine, peroxide, saponification and hydroxyl values constitute common parameters describing the reactivity and chemistry of the components of fats and oils (Knothe 2002). The iodine value measures the amount of unsaturation of fats and oils. The saponification value relates to the average molecular weight or chain length of the compound. Finally, the hydroxyl value yields the abundance of species containing hydroxyl group, providing an estimate of the degree of oil oxidation.

A small increase in iodine number of oils may indicate a significant self-heating potential of the oil, as the relationship between the iodine number and the content of double bonds appears non-linear (Howitt et al. 1995). Linseed oil has a saponification value of 189-195 and an iodine value of more than 177 , respectively. This iodine value significantly exceeds that of palm oil, 50-55, peanut oil, 80-106, rapeseed oil, 94-120, cottonseed oil, 99-199, fish oil, 109 (Knothe 2002; Pocklington 1990) and therefore indicates the highest tendency of linseed oil to self-heat over other types of oil. Iodine values decline during oxidation of linseed oil (measured in bulk), indicating the consumption of double bonds during the reaction, with the rate constant for overall disappearance of double bonds of $0.030 \pm 0.007 \mathrm{~h}^{-1}$ at $80^{\circ} \mathrm{C}$ (Juita et al. 2011d).

Peroxide value directly measures the total amount of peroxide compounds present in the oil, yielding its propensity for further oxidation reactions. This value reflects the net rate of formation and decomposition of the peroxides. In one study, the peroxide value increased up to a maximum of about $500 \mathrm{mmol}(\mathrm{kg} \text { oil })^{-1}$ within $5 \mathrm{~h}$ of oxidation at $100^{\circ} \mathrm{C}$. The rate of the peroxide decomposition increases as the temperature rises, resulting in the lower peroxide value at higher oxidation temperatures (Juita et al. 2011d).

Lazzari et al. compared the hydroxyl index of linseed oil as a function of treatment conditions. The hydroxyl index achieved a constant maximum value after an induction time of around $200 \mathrm{~h}$ for linseed oil exposed to indoor laboratory conditions, $4 \mathrm{~h}$ for treatment at $80^{\circ} \mathrm{C}$ and no induction for photo-aged linseed oil. This suggests that the photo-ageing treatment induces the highest degree of oxidation (Lazzari \& Chiantore 1999).

Allylic position equivalent (APE) and bis-allylic position equivalent (BAPE) have been developed as an alternative to the iodine value since this value does not distinguish the differences in the rate of oxidation; all double bonds are considered as having equal reactivity toward oxidation. APE and BAPE account for the number of reactive positions in oxidation (Knothe 2002).

$$
A P E=a p_{a} \times A_{c a}+a p_{b} \times A_{c b}+a p_{c} \times A_{c_{c}}+
$$




\begin{tabular}{|c|c|c|c|c|}
\hline Method & $\begin{array}{l}\text { Variables measured or } \\
\text { reactions observed }\end{array}$ & Chemical species detected & Location of peaks & References \\
\hline \multirow[t]{4}{*}{$\overline{\text { FTIR }}$} & Hydroxyl group formation & Hydroxyl group & $3430 \mathrm{~cm}^{-1}$ & (Lazzari \& Chiantore 1999) \\
\hline & $\begin{array}{l}\text { Double bond decreasing } \\
\text { in abundance }\end{array}$ & Cis double bond & $3011,1654,722 \mathrm{~cm}^{-1}$ & (Lazzari \& Chiantore 1999) \\
\hline & $\begin{array}{l}\text { The cis- trans isomerisation } \\
\text { reaction and changes } \\
\text { of conjugation }\end{array}$ & Trans conjugated double bond & $987,971 \mathrm{~cm}^{-1}$ & $\begin{array}{l}\text { (Oyman et al. 2005a; } \\
\text { Mallégol et al. 2000) }\end{array}$ \\
\hline & $\begin{array}{l}\text { The broadening of carbonyl } \\
\text { peak }\end{array}$ & Carbonyl compounds & $1747 \mathrm{~cm}^{-1}$ & (Lazzari \& Chiantore 1999) \\
\hline \multirow[t]{7}{*}{ H-NMR } & $\begin{array}{l}\text { Decreasing the abundance } \\
\text { of cis double bonds }\end{array}$ & Non-conjugated cis double bonds & $5.4 \mathrm{ppm}$ & $\begin{array}{l}\text { (Oyman et al. 2005a; } \\
\text { Miccichè et al. 2006) }\end{array}$ \\
\hline & $\begin{array}{l}\text { Decreasing the abundance } \\
\text { of double allylic hydrogen }\end{array}$ & Double allylic hydrogen & $2.7 \mathrm{ppm}$ & (Oyman et al. 2007) \\
\hline & The changes in conjugation & Conjugated double bond & 5.5-6.6 ppm & $\begin{array}{l}\text { (Oyman et al. 2005a; } \\
\text { Miccichè et al. 2006) }\end{array}$ \\
\hline & $\begin{array}{l}\text { Formation of conjugated } \\
\text { hydroperoxides }\end{array}$ & $\begin{array}{l}\text { Conjugated ethyl linoleate } \\
\text { hydroperoxide }\end{array}$ & 7.9 and 8 ppm & (Miccichè et al. 2006) \\
\hline & $\begin{array}{l}\text { Isomerisation of cis double } \\
\text { bonds }\end{array}$ & Allylic methane & $4.3 \mathrm{ppm}$ & (Miccichè et al. 2006) \\
\hline & $\begin{array}{l}\text { Disappearance of vinylic } \\
\text { hydrogen }\end{array}$ & Vinylic hydrogens & $5.3 \mathrm{ppm}$ & (Martini et al. 2009) \\
\hline & Epoxidation reaction & Epoxy groups & 2.9-3.1 ppm & (Martini et al. 2009) \\
\hline \multirow[t]{5}{*}{ Raman } & $\begin{array}{l}\text { Changes of double bond } \\
\text { abundance }\end{array}$ & Non-conjugated cis double bond & $1265,1655 \mathrm{~cm}^{-1}$ & (Oyman et al. 2005a) \\
\hline & $\begin{array}{l}\text { Changes of conjugation } \\
\text { structure }\end{array}$ & Conjugated double bond & $1599,1634 \mathrm{~cm}^{-1}$ & (Oyman et al. 2005a) \\
\hline & Oxirane group formation & $\begin{array}{l}\text { Trans-9,10- and cis-9,10- } \\
\text { epoxystearic acids }\end{array}$ & $1064,1295,1443 \mathrm{~cm}^{-1}$ & (Muik et al. 2005) \\
\hline & \multirow[t]{2}{*}{ Carbonyl formation } & Saturated aldehydes & $1725 \mathrm{~cm}^{-1}$ & \multirow[t]{2}{*}{ (Muik et al. 2005) } \\
\hline & & $\begin{array}{l}\text { Conjugated unsaturated } \\
\text { aldehydes }\end{array}$ & $1690 \mathrm{~cm}^{-1}$ & \\
\hline \multirow[t]{2}{*}{ UV-vis } & $\begin{array}{l}\text { Formation of ligand } \\
\text { complex of cobalt catalyst }\end{array}$ & Co(II) octoate solution in toluene & $590 \mathrm{~nm}$ & (Tanase et al. 2004) \\
\hline & Hydroperoxide formation & Conjugated diene & $232-232.5 \mathrm{~nm}$ & $\begin{array}{l}\text { (Belhaj et al. 2010; } \\
\text { Hendriks et al. 1979) }\end{array}$ \\
\hline Chemiluminescence & Hydroperoxides formation & Hydroperoxides & & (Rolewski et al. 2009) \\
\hline Oxygen uptake & Oxygen consumption & & & (Oyman et al. 2005a) \\
\hline \multirow[t]{2}{*}{ DSC-TGA } & $\begin{array}{l}\text { Thermal decomposition } \\
\text { reactions }\end{array}$ & & & (Lazzari \& Chiantore 1999) \\
\hline & Reaction exotherm profiles & & & (Tuman et al. 1996) \\
\hline HPLC & $\begin{array}{l}\text { Identification and } \\
\text { quantitation of } \\
\text { aldehyde emissions }\end{array}$ & $\begin{array}{l}\text { Aldehydes compounds such as } \\
\text { ethanal, propanal, pentanal, hexanal. }\end{array}$ & & (Fjällström et al. 2002) \\
\hline GC-MS & Fatty acid composition & Fatty acid methyl esters & $\begin{array}{l}\text { Retention times depend on } \\
\text { the columns and methods }\end{array}$ & (García-Martínez et al. 2009) \\
\hline $\begin{array}{l}\text { MALDI-RTOF-MS } \\
\text { and ESI-MS }\end{array}$ & Triacylglycerol composition & Triacylglycerols & $\begin{array}{l}\text { Based on mass-to-charge } \\
\text { ratio }(\mathrm{m} / \mathrm{z})\end{array}$ & (Krist et al. 2006) \\
\hline \multirow[t]{3}{*}{ SPME-GC-MS } & \multirow[t]{3}{*}{$\begin{array}{l}\text { Identification and } \\
\text { quantitation of VOC }\end{array}$} & $\begin{array}{l}\text { Saturated and unsaturated } \\
\text { hydrocarbons }\end{array}$ & \multirow[t]{3}{*}{$\begin{array}{l}\text { Retention times depend on } \\
\text { the columns and methods }\end{array}$} & \multirow{3}{*}{$\begin{array}{l}\text { (Krist et al. 2006; Jeleń et al. } 2000 \\
\text { García-Martínez et al. 2009; } \\
\text { Lee et al. 105; Lee \& Min 2010) }\end{array}$} \\
\hline & & $\begin{array}{l}\text { Aldehydes, ketones, carboxylic } \\
\text { acids, alcohols, furans }\end{array}$ & & \\
\hline & & Aromatic compounds & & \\
\hline
\end{tabular}


Table 6 Comparison of several analytical methods, reaction types observed and species detected during oxidation of linseed oil (Continued)

\begin{tabular}{|c|c|c|c|c|}
\hline \multirow[t]{3}{*}{ SEC } & \multirow{3}{*}{$\begin{array}{l}\text { Polymerisation } \\
\text { (cross-linking) reaction }\end{array}$} & Hydroperoxides & \multirow[t]{3}{*}{ Retention time varies } & \multirow{3}{*}{$\begin{array}{l}\text { (Lazzari \& Chiantore } 1999 \\
\text { Miccichè et al. 2006) }\end{array}$} \\
\hline & & Dimeric fraction & & \\
\hline & & Higher oligomer & & \\
\hline \multirow[t]{2}{*}{$\begin{array}{l}\text { EPR/ESR (discussed } \\
\text { later in this paper) }\end{array}$} & Radical formation & $\begin{array}{l}\text { Allylic, pentadienyl, peroxyl, } \\
\text { hydroxyl, alkoxyl radicals }\end{array}$ & & $\begin{array}{l}\text { (Zhu \& Sevilla 1989; } \\
\text { Dikalov \& Mason 2001) }\end{array}$ \\
\hline & & Metal-dioxygen complexes & & (Yamada et al. 1984) \\
\hline
\end{tabular}

$$
\mathrm{BAPE}=A_{\mathrm{C} 18: 2}+2 \times A_{\mathrm{C} 18: 3}
$$

where $a p_{\mathrm{x}}$ is the number of allylic positions in a specific fatty acid and $A_{\mathrm{Cx}}$ is the percentage of each fatty acid in a mixture (Knothe 2002).

Anisidine value (AV) gauges the amount of high molecular weight saturated and unsaturated carbonyl compounds in the secondary oxidation products from oxidation of linseed oil (Guillén \& Cabo 2002). The method employs spectrophotometric measurement at $350 \mathrm{~nm}$ probing both saturated and unsaturated carbonyl compounds (Muik et al. 2005). Furthermore, the conjugated dienes and trienes are observed at 232234 nm and 268-270 nm (Muik et al. 2005; Guillén \& Cabo 2002), respectively. The abundance of conjugated dienes has been suggested as a parameter for assessing the primary oxidation of lipids (Lee et al. 2007). Figure 13 illustrates typical histories of the anisidine value during the oxidation process; a slow initial increase, followed by a significant increase, especially for the rapeseed oil (Guillén \& Cabo 2002). Anisidine value remains to be

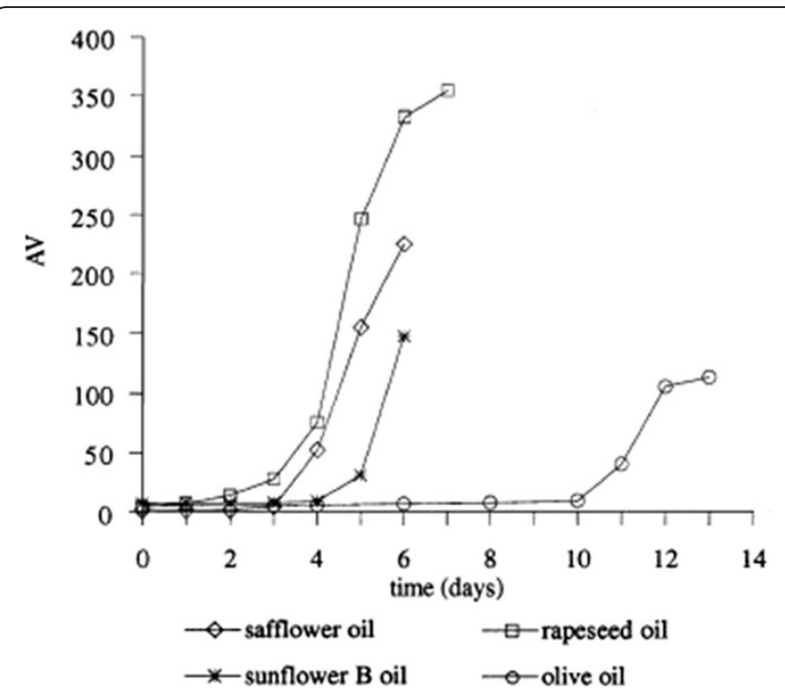

Figure 13 Comparison of anisidine value profiles of several vegetable oils during oxidation at $70^{\circ} \mathrm{C}$ in a convection oven with the exposure to the circulating air (Guillén \& Cabo 2002). collected and interpreted for linseed oil. In our view, measurements of the anisidine value could provide valuable assessment of the formation of carbonyl compounds during oxidation, possibly allowing differentiating the propensity to self-heat of various linseed oils.

Oxygen uptake represents another suitable parameter to monitor the oxidation reaction of linseed oil, usually performed with a luminescence oxygen analyser equipped with fibre optics (Oyman et al. 2005a; Oyman et al. 2004). This type of oxygen analyser measures the quenching of luminescence caused by collisions between oxygen and luminescent dye molecules in the excited state. The oxygen uptake increased sharply up to $20 \mathrm{~h}$ during oxidation of linseed oil in bulk at room temperature in the presence of $\mathrm{Co}(\mathrm{II})$-2-ethylhexanoate (Co-EH) then declined to a steady state level (Oyman et al. 2005a). Fibre optics-based measurements require a dark environment to prevent the ambient light being collected by the sensor (Wofbeis 1987). This effect can be corrected by applying optical isolation, although this slows down the response time by $4 \mathrm{~s}$ to about less than $10 \mathrm{~s}$. A luminescence analyser is particularly suitable for quantitating oxygen dissolved in liquids. On the other hand, a paramagnetic oxygen analyser provides very precise measurements of the changes in oxygen concentration in the gas phase. This analyser has been applied with success to monitor oxygen uptake for self-heating materials, to derive kinetic rate parameters, especially for coal (Wang et al. 1999; Wang et al. 2002).

Film hardness provides an index to appraise the drying of linseed oil, normally measured with a pendulumdamping test (Miccichè et al. 2005a). The test measures a number of pendulum swings required for dampening the amplitude of the pendulum oscillations, to a defined level. Harder films afford more swings. This method yields rapid evaluation of the effect of additives on the hardness of a film coating. The addition of ferrocene derivatives to the cobalt dryer, as ingredients of alkyd paints, can reduce the period needed for the paints to reach a certain hardness value (Stava et al. 2007). Therefore the usage of ferrocene derivatives can reduce the content of the cobalt dryer in coatings.

The Braive and BK drying recorder is an instrument frequently employed in the coatings industry to measure 
the drying performance of a paint film operated with different lengths of a test strip; hence the two names used to denote it. This recorder consists of hemispherically ended needles, moving along the length of the test strip, which is made from plain glass and coated with a thin film. The drying characteristics of paint film are classified into four stages: the paint flows together (wet-edge time), the paint begins to polymerise (dust-free time), surface dries and finally lines become no longer visible on the film (total drying or through drying time) (Miccichè et al. 2005a). However, Klaasen et al. classified the drying performance into three phases: open time (a scratch line traced by a pin closes up), dust free time (pin leaves a visible scratchy line, partially closed) and tack free time (a scratch line does not close) (Klaasen \& van der Leeuw 2006). Clearly, assessing the drying of film suffers from subjective evaluation.

\section{Measurement of radicals involved in oxidation of linseed oil}

EPR (electron paramagnetic resonance), also known as ESR (electron spin resonance), spectroscopy has been used by many researchers to study the radicals involved in the oxidation reaction of linseed oil. Several variables such as hyperfine structure, splitting factor ( $g$ value) and line shape in the EPR spectrum afford identification of a radical (Halliwell \& Gutteridge 2008). For instance, this technique has been implemented to study the reaction of alkyl radicals with oxygen to form peroxyl radical (Swern 1972), occurring in the oxidation reaction of linseed oil. In general, peroxyl radicals exhibit very long half-life of up to $7 \mathrm{~s}$ in comparison with hydroxyl $\left(10^{-9} \mathrm{~s}\right)$ and alkoxyl $\left(10^{-6} \mathrm{~s}\right)$ radicals.

The stability and reactivity of radicals involving catalysts have been investigated through the formation and disappearance of the radicals obtained by the reaction of $\mathrm{Co}(\mathrm{acac})_{2}$ with $t$ - $\mathrm{BuOOH}$ in the presence of pyrazole ligands as anti skinning additives (Tanase et al. 2004). The stable coordinated radical, $\left[\mathrm{Co}^{\mathrm{III}}(\mathrm{acac})_{2}(\mathrm{ROO} \bullet) \mathrm{L}\right]^{+}$, produced during this reaction inhibits the radical chain reaction in the drying of paint; where $L$ denotes a neutral donor ligand such as pyrazole and 3,5-dimethylpyrazole. EPR analysis indicates that the stability of these complex radicals depends on the molar ratio between cobalt and an organic additive L (Tanase et al. 2004).

The EPR method has also been employed to study the kinetics of free radical reactions in the low temperature autoxidation of triacylglycerols. Fremy's salt was used to determine the EPR parameters such as $g$ values and hyperfine splittings and the spin intensity was measured by using cupric sulfate as a standard (Zhu \& Sevilla 1989). The major species present in the EPR spectra included allylic and pentadienyl radicals in trilinolein and trilinolenin samples, respectively. Peroxyl radicals were formed after warming the lipid sample to $105 \mathrm{~K}$ and stopped at 135 , 132 and $127 \mathrm{~K}$ for triolein, trilinolein and trilinolenin, respectively, suggesting that the most stable peroxyl radicals tend to exist in saturated lipids due to the capability of these radicals to abstract the allylic hydrogen in unsaturated lipids.

Peroxyl and alkoxyl radicals have been identified during oxidation of methyl linoleate employing methyl-N -duryl nitrone (MDN) as the spin trap and observed by EPR (Yamada et al. 1984). This technique was also applied for determining the type of structure of metaldioxygen complexes (Boca 1983). This dioxygen coordination can be classified by the formal oxidation state such as superoxo-like $\left(\mathrm{O}_{2}^{-}\right)$or peroxo-like $\left(\mathrm{O}_{2}^{2-}\right)$ complexes (Boca 1983).

Dikalov et al. investigated the spin trapping of the linoleic and linolenic acid-derived radicals in a mixture of soybean lipoxygenase and 5,5-dimethyl-1-pyrroline $N$-oxide (DMPO) as the spin trap. Four different radical adducts have been detected in the EPR spectra of radicals derived from linoleic acid as shown in Figure 14 (Dikalov \& Mason 2001), while EPR spectra of alkoxyl radicals derived from linolenic acid are illustrated in Figure 15.

Despite its ability to analyse radicals arising in the oxidation of linseed oil, the technique exhibits limitations. The detection of free radicals requires low temperature, limiting the use of the instrument to specialised laboratories. The instability of radicals also causes difficulties in achieving an accurate and repeatable analysis, in spite of development of several types of spin traps.

\section{Effect of catalysts on oil oxidation}

The types of inorganic pigments added to the paint determine the rate of autoxidation, since the pigments contain transition metals such as cobalt, iron and manganese (Ploeger et al. 2009b). Several metal complexes have been reported to catalyse the oxidative drying of alkyd paints, especially metal soaps which significantly accelerate the paint drying (van Gorkum \& Bouwman 2005). Typical metal soaps, whose role is to accelerate oxidation of paint films and subsequent polymerisation (i.e., drying), correspond to transition metal salts (typically $\mathrm{Co}, \mathrm{Fe}, \mathrm{Mn}$ ) of long chain fatty acids (Miccichè et al. 2006) with the overall formula of $\left(\mathrm{Me}^{\mathrm{n}+}\right)\left(\mathrm{X}^{-}\right)_{\mathrm{n}}$; where $\mathrm{Me}^{\mathrm{n}+}$ is a transition metal ion, $\mathrm{X}^{-}$is a $\mathrm{C}_{6}-\mathrm{C}_{18}$ aliphatic carboxylate (Miccichè et al. 2005a). Metal catalysts have been classified as primary, secondary and auxiliary dryers. Example of primary dryers include $\mathrm{Co}^{2+}$, $\mathrm{Mn}^{2+}, \mathrm{Ce}^{3+}, \mathrm{V}^{3+}, \mathrm{Fe}^{2+}$, secondary $\mathrm{Pb}^{2+}, \mathrm{Zr}^{4+}, \mathrm{Al}^{3+}$ and auxiliary $\mathrm{Ca}^{2+}, \mathrm{Li}^{+}, \mathrm{K}^{+}$and $\mathrm{Zn}^{2+}$ (Meneghetti et al. 1998). The primary and secondary dryers become active in the oxidation and polymerisation stages, respectively, while auxiliary dryers modify the activity of primary dryers. 


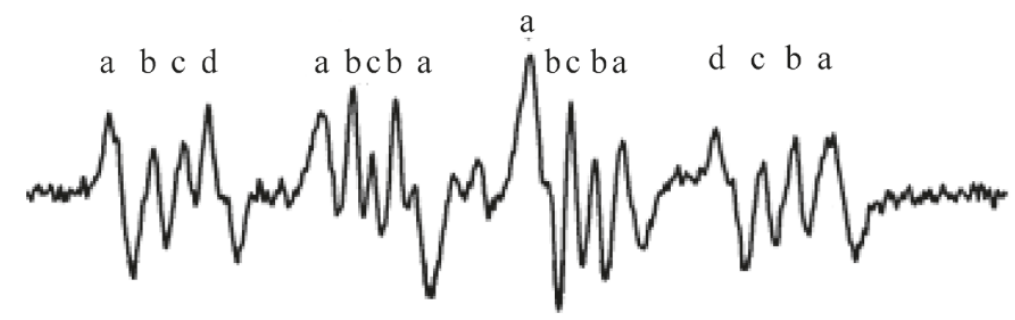

a DMPO/carbon-centered radical adduct

b DMPO/carbonyl radical adduct

C DMPO/hydroxyl radical adduct

d DMPO/oxygen-centered PUFA radical adduct

Figure 14 EPR spectra of polyunsaturated fatty acid-derived radicals generated by soybean lipoxygenase and linoleic acid using DMPO as the spin trap (Dikalov \& Mason 2001).

\section{Role of cobalt on oxidation reactions}

Cobalt 2-ethylhexanoate dryer has been proven as a particularly effective catalyst to promote the oxidative drying of alkyd paints (Oyman et al. 2005b). Cobalt(II) displays better catalytic properties compared to manganese (II) and iron(II), as indicated by higher concentration of products released during oxidation of linseed oil catalysed by cobalt(II) (Juita et al. 2011a). Mallégol et al. have shown that the activity of cobalt as primary dryer is modified by the addition of a secondary dryer such as zirconium or a combination of calcium and zirconium (Mallégol et al. 2000). The cobalt primary dryer accelerates the hydroperoxide decomposition (Mallégol et al. 2000; Tanase et al. 2004; Tuman et al. 1996), while the zirconium catalyses the further polymerisation (Meneghetti et al. 1998; Sharma \& Kundu 2006); typically Co:Zr ratio has an optimum value of 1:3. It was found that the addition of lead to the cobalt catalyst has no enhancement on the oxidative polymerisation (Meneghetti et al. 1998).

According to Sailer et al,, cobalt also catalyses the generation of singlet oxygen which is significantly more reactive than ground state oxygen in initiating the formation of the peroxides (Sailer \& Soucek 2000). Excess of cobalt can lead to the inhibition of the oxidative polymerisation process due to the consumption of peroxyl

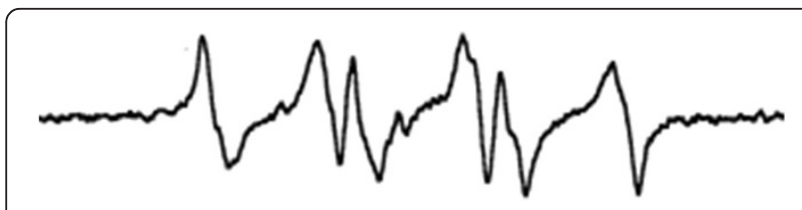

Figure 15 EPR spectra of alkoxyl radical generated by soybean lipoxygenase and linolenic acid using DMPO as the spin trap (Dikalov \& Mason 2001). radicals formed in the reaction (Meneghetti et al. 1998). Cobalt enhances the rate of cis-trans isomerisation (De Oliveira Vigier et al. 2009). For catalytic mixtures of cobalt and tin, the cis-trans isomerisation decreases, as the tin content increases. This indicates that active sites for this reaction correspond to cobalt species (De Oliveira Vigier et al. 2009). The cobalt catalyst accelerates the peroxide formation at the early stage of the oxidation process, as demonstrated by the addition of dicumyl peroxide into the raw rapeseed oil methyl ester (Niczke et al. 2007).

Transition metal carboxylates such as cobalt octoate present better catalytic performance compared to manganese or iron (Stava et al. 2007). The reactivity of these metals could be improved with some organic ligands such as ferrocene and its derivatives. The catalytic reactivity is improved by altering the electron density at the metal centre of a complex ion, therefore enhancing the redox potential of the metal (Stava et al. 2007).

\section{Role of other metals on oxidation reactions}

Cobalt has been reported as carcinogenic (Erich et al. 2006a; Erich et al. 2006b; Liu et al. 2007) and genotoxic (Stava et al. 2007), prompting a trend to replace cobalt by manganese or iron. Wu et al. reported that the addition of chelating ligands such as 2-aminomethylpyridine and 2-hydroxymethylpyridine can improve the inferior catalytic activity of manganese 2-ethylhexanoate (Wu et al. 2004). A Schiff base ligand, which forms in the reaction between 2-pyridinealdehyde and 2-aminopyridine in combination with the manganese salt, was found to be an efficient catalyst for autoxidation of ethyl linoleate, a model compound for linseed oil.

Bipyridine displays excellent catalytic activity in autoxidation if added to manganese 2-ethylhexanoate, 
but it has a retarding effect on the catalytic activity of cobalt dryers (Warzeska et al. 2002). Polyamines, such as 1,1,4,7,10,10-hexamethyl triethylenetetramine (HMTETA) in a complex with manganese, accelerate the oxidation of ethyl linoleate (Oyman et al. 2004). Likewise, another polyamine 1,4,7-trimethyl-1,4,7-triazacyclononane (MeTACN) forms a complex with manganese(IV) (MnMeTACN) that catalyses the oxidation of ethyl linoleate (Oyman et al. 2004). Working with ethyl linoleate as a surrogate for linseed oil, van Gorkum has reported $\left[\mathrm{Mn}(\mathrm{III})(\right.$ tbpppy)$(\mathrm{dpm})]$ (where $\mathrm{H}_{2}$ tbpppy is 2-[bis(2-hydroxy-3,5-di-tert-butylbenzyl)aminomethyl] pyridine and Hdpm is dipivaloylmethane) to be the best potential alkyd paint dryer, acting through a reduction of $\mathrm{Mn}(\mathrm{III})$ to $\mathrm{Mn}$ (II) (van Gorkum et al. 2007). Cobalt and copper salts have been reported to enhance the catalytic activity of the manganese salt in the decomposition of hydroperoxides (Minisci et al. 2003).

Iron has not been widely used in the coatings or paints due to observation that iron becomes catalytically active at temperatures above $130^{\circ} \mathrm{C}$ and its application darkens the paint colour (Miccichè et al. 2005a). However, the combination of iron salts with reducing agent, such as ascorbic acid (Miccichè et al. 2005b), and nitrogen donor ligands, such as 2-ethyl-4-methylimidazole, has been identified to form an excellent dryer (Miccichè et al. 2005a). Combination of ascorbic acid 6-palmitate (AsA6p) and iron reaches the maximum activity at a ratio of three moles of AsA6p to one mole of iron. Fatty acid chain length of 8 to 12 in the ascorbic derivatives is required to provide better catalytic properties (Miccichè et al. 2005a) However, Micciche et al. (Miccichè et al. 2006) reported that the combination of AsA6p and Fe-2-ethylhexanoate (Fe-eh) achieves the optimum activity towards the oxidation of ethyl linoleate at the molar ratio of two. The addition of monodentate two-nitrogen donor ligands to the AsA6p/Fe improves the drying time and film hardness (Miccichè et al. 2005a). Ferrocene derivatives such as 1,1'-dicarbomethoxyferrocene show a synergic effect with cobalt dryer during the oxidation of ethyl linoleate (Stava et al. 2007). Soluble iron has been reported to be a much better catalyst compared to iron wire or powder (Colclough 1987).

Ioakimoglou et al. have studied the effect of several copper compounds on the oxidation of films of linseed oil. Copper acetate and copper abietate have been found to catalyse the oxidative degradation of linseed oil more efficiently than copper carbonate. However, copper salts with high oxidising capacity possibly inhibit the cross linking reaction (Ioakimoglou et al. 1999). Finally, the presence of metal in pigments in the paints may enhance the thermal discolouration and degradation processes of paintings (Ioakimoglou et al. 1999).
Copper salts are known as excellent catalysts for the decomposition of peroxides (Kochi \& Mains 1964), including the decomposition of lipid peroxides (Halliwell \& Gutteridge 2008). The rate of the decomposition reaction by copper(I) exceeds that by copper(II) (Halliwell \& Gutteridge 2008). On the other hand, copper(II) represents a better initiation catalyst for radical chains compared to copper(I) (Allen \& Patrick 1974). Acetyl-acetonate complexes of copper(II) react with hydroperoxides to produce alkyl peroxyl radicals which are effective initiators for polymerisation reactions (Allen \& Patrick 1974). Copper salt has been reported to accelerate the decomposition of cumene hydroperoxide (Ioakimoglou et al. 1999). Transition metals can activate the carbon-hydrogen bond, hence in some cases can cause scission reactions (Vastine \& Hall 2009).

\section{Inhibitors for oxidation of oils}

Certain types of sulfur compounds and aromatics can inhibit the oxidation of mineral oils by radicals, especially peroxyl radicals. For example, this effect is displayed by zinc dialkyldithiocarbamate (ZDC) (Colclough 1987). Flavonoids and tocopherol demonstrate antioxidant effects on the lipid oxidation, since the phenolic hydrogens in those substances can react with lipid free radicals (Belhaj et al. 2010). Vitamin $\mathrm{E}$ is another example, as it is composed of tocopherol. Tocopherol induces several chain breaking reactions, including the reduction of peroxyl and alkoxyl radicals, reactions with carbon centred radicals and the addition of a tocopheroxyl itself to a peroxyl radical (Antunes et al. 1996).

\section{Kinetics and reaction mechanisms of oil oxidation Reaction pathways involved in oxidation Mechanism of radical chain reactions}

The essential processes in the oxidation, involving radical chain reactions, consist of primary initiation, where radicals are formed from the parent molecules, propagation, which conserves the number of radicals, termination that removes the radicals, branching, which multiplies the number of radicals and secondary initiation that forms new radicals from a stable intermediate product (Pilling 1997). The rate of oxidation is mostly influenced by the rates of branching and termination.

Antunes et al. (Antunes et al. 1996) reported that the primary initiation agents in the basic scheme of lipid peroxidation consist of hydroxyl, perhydroxyl and $\alpha$-tocopheroxyl radicals. Reactions (7) to (9) describe the abstraction reactions by those radicals. Hydroxyl radical reacts nonselectively with organic compounds (Antunes et al. 1996), while the less reactive peroxyl radical abstracts hydrogen selectively at the bis-allylic methylene bridge (Bors et al. 1987). Pentadienyl radical, produced by this hydrogen 
abstraction, has an unpaired electron distributed over five carbon atoms (Bors et al. 1987; Gardner 1989).

$$
\begin{aligned}
& \mathrm{RH}+\mathrm{OH}^{\bullet} \rightarrow \mathrm{R}^{\bullet}+\mathrm{H}_{2} \mathrm{O} \\
& \mathrm{HO}_{2}{ }^{\bullet}+\mathrm{ROOH} \rightarrow \mathrm{ROO}^{\bullet}+\mathrm{H}_{2} \mathrm{O}_{2} \\
& \mathrm{TocO}^{\bullet}+\mathrm{RH} \rightarrow \mathrm{R}^{\bullet}+\text { TocOH }
\end{aligned}
$$

Since the addition of ground state $\mathrm{O}_{2}$ (i.e., triplet oxygen) to biomolecules is spin forbidden, the direct reaction proceeds very slowly with the rate constant of less than $10^{-5} \mathrm{M}^{-1} \mathrm{~s}^{-1}$ (Miller et al. 1990). Thus the critical step in the oxidation of biomolecules, in the presence of atmospheric oxygen, corresponds to the formation of the initial radicals.

The initiation reaction of the oil oxidation can proceed through the formation of singlet oxygen by photosensitised oxidation (Choe \& Min 2006). Singlet oxygen could be generated from triplet oxygen in chlorophyll photosensitisation, inducing the formation of 2-pentyl furan, trans-2-heptenal and 1-octen-3-ol in linoleic acid samples (Lee \& Min 2010). Chlorophyll, commonly found in vegetable oils, serves as a photosensitiser. Photosensitisers absorb light energy very rapidly and convert the singlet state to excited triplet state sensitisers. The reaction of these excited sensitisers with triplet oxygen produces singlet oxygen (Choe \& Min 2006; Min \& Boff 2002; Rawls \& Santen 1970). The reactions involving singlet oxygen are probably responsible for initiating the self-heating of linseed oil. While autoxidation incorporates the formation of alkyl radicals, photosensitised oxidation involves the reaction between singlet oxygen and double bonds without the formation of these alkyl radicals to generate hydroperoxides at the double bonds (Choe \& Min 2006).

Reactions with singlet oxygen exhibit low activation energies, 0 to $25 \mathrm{~kJ} \mathrm{~mol}^{-1}$, allowing facile oxidation of biomolecules (Lee \& Min 2010). Different hydroperoxides arise from reactions involving singlet and triplet oxidation. The former generates C9, C10, C,12 and C13 hydroperoxides and the later, known as autoxidation, forms C9 and C13 hydroperoxides (Lee \& Min 2010).

Propagation reactions proceed through four dominant pathways: atom transfer, electron transfer, addition and scission reactions. Abstraction of hydrogen represents the common reaction of atom transfer in the propagation step (Roberfroid \& Calderon 1995), for example the abstraction of hydrogen from fatty acid chain by peroxyl radical (Halliwell \& Gutteridge 2008). The combination of molecular oxygen with an electron to form superoxide characterises the second type of propagation via electron transfer (Roberfroid \& Calderon 1995). In this reaction, an electron transfers from a transition metal ion to a peroxide compound. The third pathway operates in the lipid peroxidation and involves the addition of oxygen to the alkyl radical (Roberfroid \& Calderon 1995). This reversible reaction of oxygen with an initial carbon centred radical to form a peroxyl radical constitutes the most important pathway (Antunes et al. 1996). It is controlled by oxygen migration with the apparent activation energy of $24 \mathrm{~kJ} \mathrm{~mol}^{-1}$ in unsaturated lipids (Zhu \& Sevilla 1989). Kinetically, it is a very fast pathway, hence the concentration of peroxyl radicals is much higher than alkyl radicals (Hanson et al. 2004; Kubow 1992). The last of the four dominant propagation pathways involves the transformation of peroxyl radicals into allylic and pentadienyl radicals (Zhu \& Sevilla 1989).

Peroxyl radicals can abstract hydrogen to form hydroperoxides. Hydrogen abstraction by radicals is least favourable from alkanes, more favourable from a monoallylic position in alkenes and most favourable from a double allylic position, as a consequence of decreasing $\mathrm{C}-\mathrm{H}$ bond dissociation energies (Oyman et al. 2005a). In addition to the hydrogen abstraction from substrate, peroxyl radicals also play an important role in the abstraction of the weakly bonded $\alpha$ hydrogen atom of the hydroperoxide product (Figure 16) as described in reactions (11) and (12). The decomposition of $\mathrm{R}_{-\alpha \mathrm{H}}^{\cdot} \mathrm{OOH}$ ( $\alpha \mathrm{H}$ refers to the weakly bonded $\alpha$ hydrogen) to $\mathrm{Q}=\mathrm{O}$ ( $\mathrm{Q}$ denotes $\mathrm{R}_{-\mathrm{\alpha H}}$ ) and ${ }^{\circ} \mathrm{OH}$ releases around $126 \mathrm{~kJ} \mathrm{~mol}^{-1}$. The hydroxyl radical rapidly abstracts a hydrogen atom from substrate and this reaction is also exothermic (Hermans et al. 2007).

$$
\begin{aligned}
& \mathrm{ROO}^{\bullet}+\mathrm{RH} \rightarrow \mathrm{ROOH}+\mathrm{R}^{\bullet} \\
& \mathrm{ROO}^{\bullet}+\mathrm{ROOH} \rightarrow \mathrm{ROOH}+\mathrm{R}_{-\alpha \mathrm{H}} \mathrm{OOH} \\
& \rightarrow \mathrm{ROOH}+\mathrm{Q}=\mathrm{O}+{ }^{\cdot} \mathrm{OH}
\end{aligned}
$$

Moreover, peroxyl radical could undergo cyclisation reactions by the intramolecular arrangement through four and five membered rings. Quantum chemical calculations identified low energy pathways for the decomposition of cyclic peroxides into aldehydes and ketonic species (Juita et al. 2011e).

An alkoxyl radical forms as the result of the decomposition of lipid hydroperoxide by transition metals such as $\mathrm{Fe}^{2+}$. These radicals can abstract hydrogen from unsaturated fatty acid or add to double bonds to form carbon centred radicals (Antunes et al. 1996). Heteroatom-centred radicals display higher ratios of hydrogen abstraction to addition than carbon-centred radicals. For instance, an alkoxyl radical prefers to abstract hydrogen over addition due to the difference in exothermicity between the two reactions of $30 \mathrm{~kJ} \mathrm{~mol}^{-1}$ (Moad \& Solomon 1995).

The termination reactions proceed through the radical-radical recombination or cross linking reaction. 


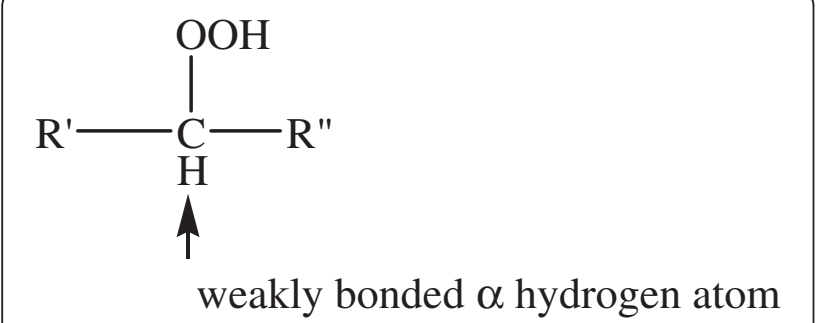

Figure 16 Position of weakly bonded a-hydrogen atom in hydroperoxide compound.

The reaction between two peroxyl radicals predominates over reaction between carbon-centred radicals and between a carbon-centred radical and a peroxyl radical (Antunes et al. 1996). Recombination of the carbon-centred radicals has an apparent activation energy of $40 \mathrm{~kJ} \mathrm{~mol}^{-1}$ (Zhu \& Sevilla 1989). The rate constant for the termination reaction depends on the chain lengths of the two radicals and it is affected by the diffusion mechanisms (Moad \& Solomon 1995). The primary radicals involved in the polymerisation reaction are hydroxyl and alkoxyl radicals (Allen \& Patrick 1974). Cobalt(II) complexes, as the chain transfer agents, can catalyse the polymerisation reaction through the combination of metal with carboncentred radicals (Moad \& Solomon 1995).

The addition of oxygen to a free radical and the termination step by crosslinking involve exothermic processes, while decomposition of hydroperoxides constitutes an endothermic process. The addition of dryers and metal alkoxides can decrease the onset temperature of the reaction exotherm. This affects the extent of curing, as measured by the indentation hardness of the drying films (Tuman et al. 1996).

In the autoxidation reaction of cyclohexane $(\mathrm{CyH})$, which has similarity with that of linseed oil, the major chain initiation reaction is the homolytic dissociation of $\mathrm{CyOOH}$ into $\mathrm{CyO}^{*}$ and ${ }^{\circ} \mathrm{OH}$ radicals, while the major termination step is the reaction of two peroxyl radicals into $\mathrm{CyOH}, \mathrm{Q}=\mathrm{O}$ and $\mathrm{O}_{2}$. The hydrogen abstraction reaction by peroxyl radical represents the rate determining step in the chain propagation reaction. The addition of oxygen to the cyclohexane radical is diffusion controlled under sufficient oxygen pressure (Hermans et al. 2006).

$$
\begin{aligned}
& \mathrm{CyOOH} \rightarrow \mathrm{CyO}^{\bullet}+{ }^{\bullet} \mathrm{OH} \\
& \mathrm{CyOO}^{\bullet}+\mathrm{CyOO}^{\bullet} \rightarrow \mathrm{CyOH}+\mathrm{Q}=\mathrm{O}+\mathrm{O}_{2} \\
& \mathrm{CyOO}{ }^{\bullet}+\mathrm{CyH} \rightarrow \mathrm{CyOOH}+\mathrm{Cy}^{*} \\
& \mathrm{Cy}^{\bullet}+\mathrm{O}_{2} \rightarrow \mathrm{CyOO}^{\bullet}
\end{aligned}
$$

Isomerisation reactions and hydroperoxides as important intermediates

Thermal decomposition of peroxides proceeds mostly through the homolytic fission of the O-O bond (Swern 1972), as a consequence of the low dissociation energy of this bond. Cobaltous ion assists the decomposition of hydroperoxide into alkoxyl radical (Yamada et al. 1984). The rate of hydroperoxide decomposition increases at elevated pH (Rolewski et al. 2009). Hydroperoxides formed during oxidation of lipid represent stable intermediates, therefore, their detection indicates the initial lipid oxidation (Rolewski et al. 2009). The amount of monohydroperoxides decreases with increasing temperature due to the faster degradation of monohydroperoxides (Haslbeck et al. 1983). Linseed oil produces hydroperoxide at abundances one order of magnitude higher than linoleic acid due to a large modal content of linolenic acid in linseed oil (Rolewski et al. 2009).

Table 7 illustrates different hydroperoxide species that form from oxidation of methyl esters of oleic, linoleic and linolenic acids. For each methyl ester, the product species differ by the position of double bonds and the location of $\mathrm{OOH}$ attachment. Oxidation of linoleic esters produces almost exclusively 9- and 13-hydroperoxides, which are categorised as outer hydroperoxides. Inner hydroperoxides such as 10- and 12-hydroperoxides arise in minor amounts, possibly as a consequence of other reaction pathways, leading to formation of cyclic peroxides (i.e., endoperoxides) and resulting in smaller amounts of inner hydroperoxides, as illustrated in the following scheme (Gunstone 1996; Roberfroid \& Calderon 1995; Halliwell \& Gutteridge 2008) Scheme 4.

This cyclic peroxide forms when a peroxyl radical attacks another double bond in the same compound (Halliwell \& Gutteridge 2008).

Table 7 Major hydroperoxides emitted during autoxidation of methyl oleate, linoleate and linolenate (Gunstone 1996)

\begin{tabular}{lllll}
\hline $\begin{array}{l}\text { Methyl } \\
\text { ester }\end{array}$ & $\begin{array}{l}\text { Position } \\
\text { of } \mathbf{O O H}\end{array}$ & $\begin{array}{l}\text { Position of } \\
\text { double bond }\end{array}$ & Configuration & $\begin{array}{l}\text { Yield }^{\mathbf{a}} \\
\mathbf{( \% )}\end{array}$ \\
\hline Oleate & 8 & 9 & cis or trans & 27 \\
\hline 9 & 10 & mainly trans & 24 \\
\hline 10 & 8 & mainly trans & 23 \\
\hline 11 & 9 & cis or trans & 26 \\
\hline Linoleate & 9 & 10,12 & trans, cis, conjugated diene & 52 \\
\hline 13 & 9,11 & cis, trans, conjugated diene & 48 \\
\hline & 9 & $10,12,15$ & conjugated diene & 32 \\
\hline 12 & $9,13,15$ & $\begin{array}{l}\text { conjugated diene, can } \\
\text { form cyclic peroxide }\end{array}$ & 11 \\
\hline & 16 & $9,12,14$ & $\begin{array}{l}\text { conjugated diene, can } \\
\text { form cyclic peroxide }\end{array}$ & 11 \\
\hline
\end{tabular}

${ }^{\mathrm{a} Y i e l d s}$ are calculated from total mono-hydroperoxides only. 
Oxygen concentration influences the mechanism of peroxidation. For instance, self reaction of carbon centred radicals is more likely to occur at a very low concentration of oxygen (Halliwell \& Gutteridge 2008). As a consequence of this sensitivity, many complex mixtures of compounds can be produced from the decomposition of lipid peroxides, involving epoxides, saturated and unsaturated aldehydes, ketones and hydrocarbons (Halliwell \& Gutteridge 2008).

There are literature reports on the mechanistic differences between the oxidation of conjugated and non-conjugated fatty acids. The $\mathrm{H}$ abstraction rate of non-conjugated fatty acid is faster than that of the conjugated acids. This is because of resonance stabilisation of conjugated double bonds and also the presence of trans double bonds (Muizebelt et al. 2000). For example, conjugated ethyl linoleate is estimated to be $12-17 \mathrm{~kJ} \mathrm{~mol}^{-1}$ more stable than non-conjugated ethyl linoleate (Muizebelt et al. 2000). For comparison, radicals arising from $\mathrm{H}$ abstraction from non-conjugated fatty acids are stabilised by resonance. This results in lower abundance of peroxide species present in oils containing conjugated fatty acids (Oyman et al. 2005a). Polymerisation reactions can occur by direct addition of free radicals to the conjugated double bonds and by radical recombination (Oyman et al. 2005a). Conjugated fatty acids tend to favour radical addition to double bonds, whereas non-conjugated species prefer to enter into radical recombination reactions (Muizebelt et al. 2000).

A cis, non-conjugated diene structure changes to a cis, trans conjugated hydroperoxide during autoxidation of methyl linoleate or methyl linolenate (Hendriks et al. 1979). A similar transformation also takes place during hydrogenation of unsaturated lipids. As for the autoxidation reactions, the ratio of cis to trans as the result of the partial hydrogenation of oil depends on the initial oil composition, catalyst and temperature (De Oliveira Vigier et al. 2009).

The isomerisation reaction of hydroperoxides during oxidation of linseed oil is similar to the mechanism that occurs in isoprene oxidation. Peeters et al. studied the addition of hydroxyl radical to isoprene and found the major adducts to be $1-\mathrm{OH}$ (about 60\%) and 4-OH (around 30\%). Trans isoprene is the more stable and dominant structure which releases $159 \mathrm{~kJ} \mathrm{~mol}^{-1}$ of energy upon $\mathrm{OH}$ addition to form around 50\% trans- and 50\% cis-1-OH. The reaction entails the formation of an allyl resonance configuration permitting addition at two positions. These activated adducts can undergo cis-trans isomerisation with the barriers of only $59-63 \mathrm{~kJ} \mathrm{~mol}^{-1}$. The addition of oxygen to the $\mathrm{OH}$-isoprene occurs rapidly at two addition sites, as illustrated in the third row of Figure 17. The substitution at a $\beta$ site enables the internal rotation of the $-\mathrm{CH}=\mathrm{CH}_{2}$ group, forming both cis and trans $\mathrm{OH}$-isoprene radicals. Addition to the $\alpha$ sites induces the formation of $E$ - and $Z$-substituted alkenes. $\beta$-OH-peroxyl radicals undergo the $1,5-\mathrm{H}$ shift of the $\mathrm{OH}$-hydrogen to form a $\beta$-HOO-alkoxyl radical, which displays a very low barrier to further decomposition. Additionally, the Z-1-OH-4-OO can isomerise via 1,6-Hshift of the weakly bonded $\alpha-\mathrm{OH}$ hydrogen to the peroxyl radical site by overcoming a barrier of $75 \mathrm{~kJ} \mathrm{~mol}^{-1}$ (Peeters et al. 2009; Stavrakou et al. 2010).

\section{Mechanism of epoxidation reactions}

The epoxidation of alkene has been proposed to occur by a butterfly mechanism that involves the peroxyl oxygen atom of the peracid attaching to a double bond and the hydrogen atom of the peracid connecting with the carbonyl oxygen (Okovytyy et al. 2002). Hilker et al. described the chemo-enzymatic epoxidation of unsaturated plant oils in which the peracid transfers an oxygen atom to the double bond to form epoxide. This is called the Prilezhaev reaction, as described in Figure 18 (Hilker et al. 2001). This reaction has been reported to be second order, first order in perstearic acid and in double bonds, with an activation energy of $51.2 \mathrm{~kJ} \mathrm{~mol}^{-1}$ (Hilker et al. 2001).

Oxygen in an epoxide ring can be attacked by acid causing the opening of the ring and the formation of a hydroxyl species and a carbocation (Chiniwalla et al. 2003). Crosslinking can occur when the oxygen of an epoxide group is attacked by a carbocation (Chiniwalla et al. 2003). A naturally epoxidised vegetable oil, vernonia oil, employed in formulations of alkyd and epoxy coating, consists of a triacylglycerol of vernolic (cis-12,13-epoxy-cis-9-octadecenoic) acid. It contains one epoxy ring and one double bond separated by a single methylene group in each acid chain (Muturi et al. 1994). The epoxidation process increases the viscosity of the oil. The fully epoxidised oil possesses no double bonds therefore it cannot dry further (Muturi et al. 1994). Oligomeric cobalt complexes have been utilised as catalysts for hydrolysis of epoxides compounds, causing the opening of the epoxide ring to form hydroxyl compounds (Ready \& Jacobsen 2002).

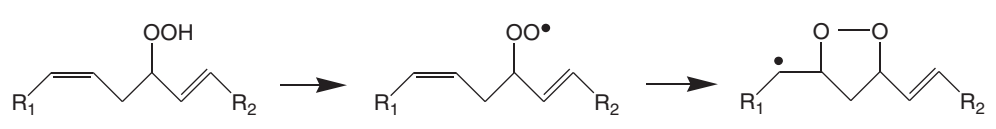

Scheme 4 Formation of cyclic peroxides from inner hydroperoxides. 


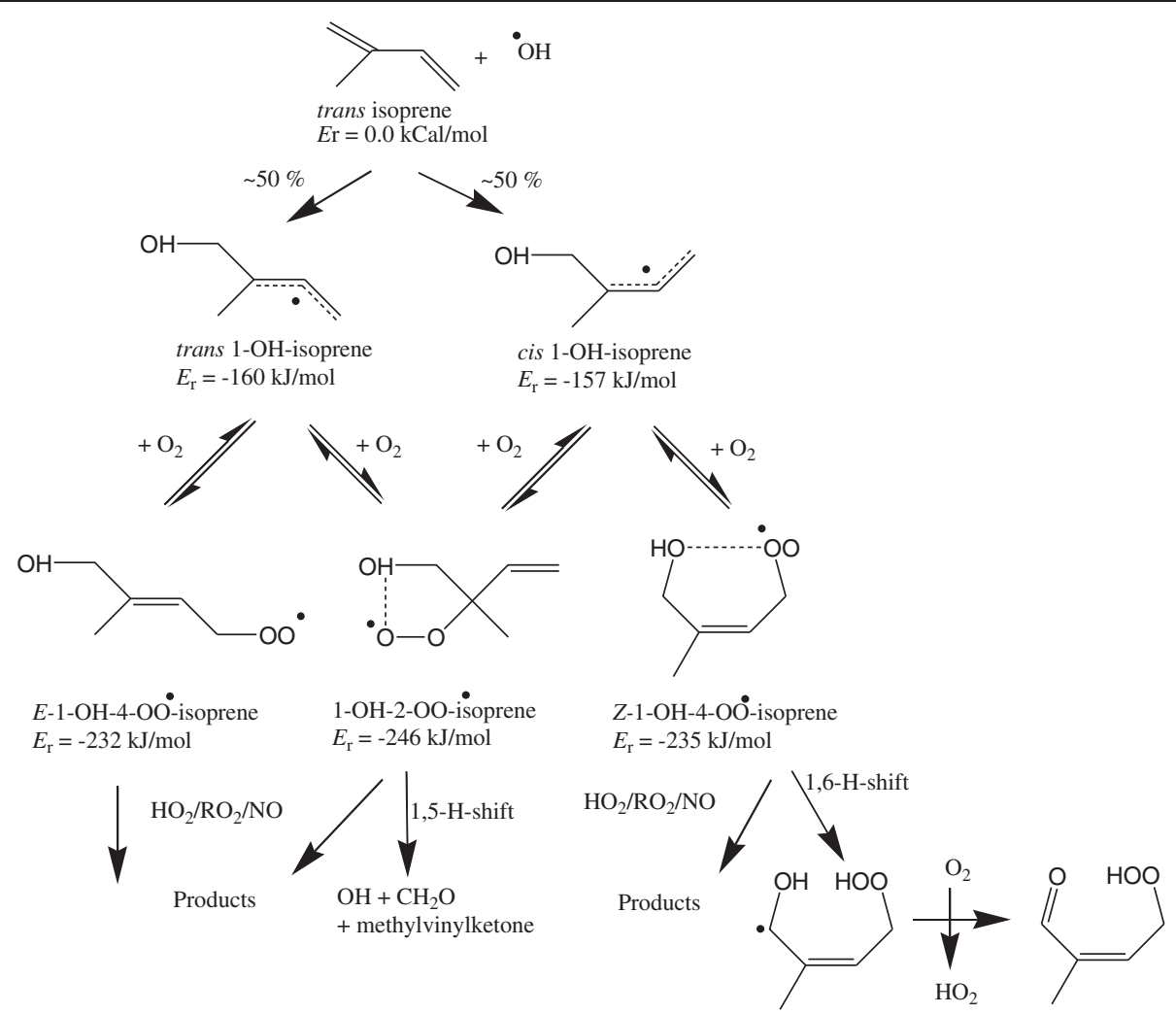

Figure 17 Reaction scheme of 1-OH addition to isoprene that operates at around $303 \mathrm{~K}$ in pristine forest (untouched forest which exists in its original condition without interference from human activities), characterised by high abundance of $\mathrm{OH}$ radicals (Peeters et al. 2009). $E_{\mathrm{r}}$ denotes the reaction energy.

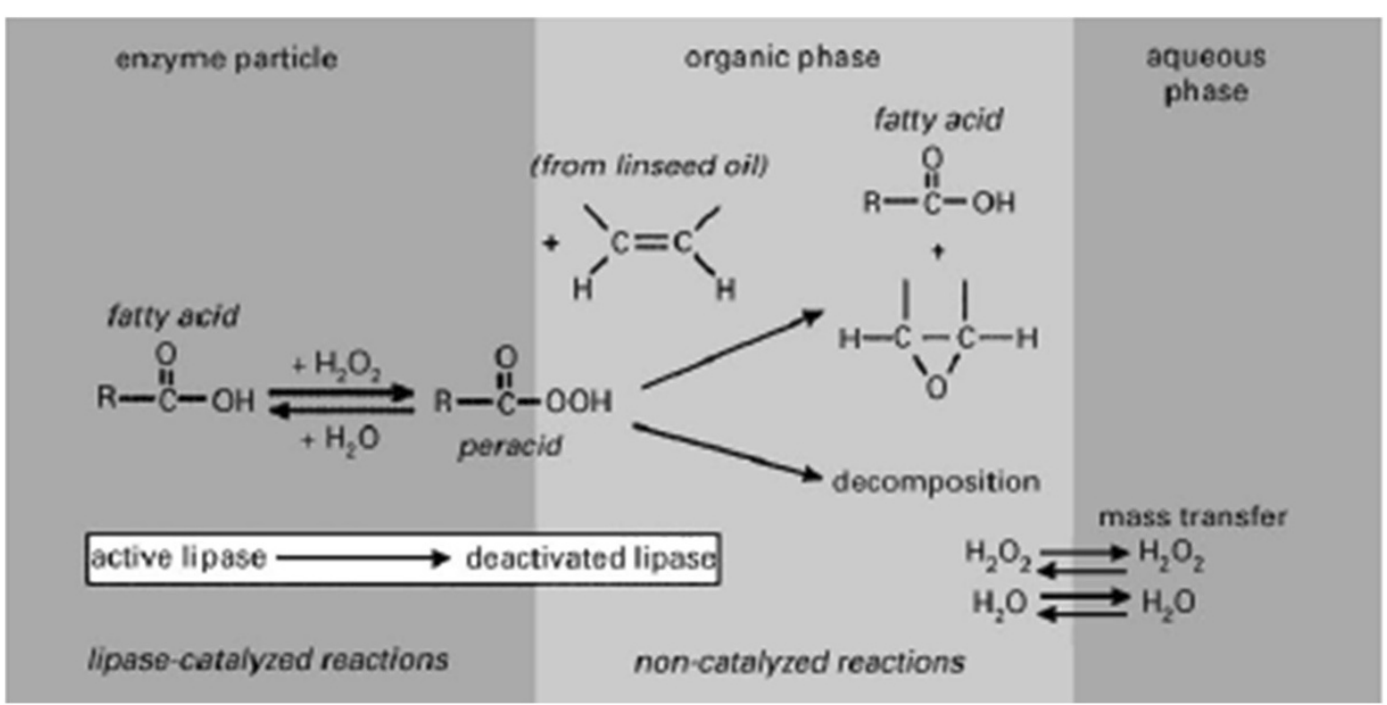

Figure 18 Reaction mechanism of the chemo-enzymatic epoxidation (Hilker et al. 2001). 


\section{Catalytic pathways involving transition metals}

Four modes of catalytic reactivity have been reported to operate in the presence of transition metal complexes, including: (1) free radical autoxidation; (2) coordination of an organic substrate to a metal centre which is followed by reaction of an oxygen-containing nucleophile; (3) oxygen atom transfer from a high valent oxo-metal compound; and, (4) decomposition of hydroperoxide catalysed by metal (Bailey \& Drago 1987). Organometallic cobalt derivatives enhance the polymerisation reactions of olefins through the coordinative and radical pathways, illustrated in Figure 19 (Milani et al. 2003). The coordinative pathway occurs through the dissociation of the Co-N (cobalt-nitrogen) bonds resulting in the formation of a unsaturated coordination complex, while radical polymerisation reaction is initiated by the homolytic cleavage of the cobalt-carbon bond (Milani et al. 2003).

\section{Catalytic mechanism of decomposition of hydroperoxides}

Transition metal complexes have been reported to catalyse the decomposition of hydroperoxides into peroxyl radical or alkoxyl radical (Roberfroid \& Calderon 1995; Aust et al. 1985). The reaction of metal in a lower oxidation state with peroxides is generally faster than that involving metal in a higher oxidation state (Kochi 1973). Iron(II) chelates can split the O-O bond in the peroxide to produce an alkoxyl radical. On the other hand, a peroxyl radical is formed in the presence of iron(III) (Halliwell \& Gutteridge 2008). Iron(II) induces a higher rate of hydroperoxide decomposition than iron(III). However, too high an amount of iron(II) can scavenge radicals hence the ratio of iron(II) to peroxides affects the kinetic pathways of peroxidation reactions (Halliwell \& Gutteridge 2008).

During oxidation of benzoin (2-hydroxy-1,2-di(phenyl) ethanone or $\mathrm{PhCH}(\mathrm{OH}) \mathrm{C}(\mathrm{O}) \mathrm{Ph})$ catalysed by $\mathrm{Co}(\mathrm{II})$ $(\text { acac })_{2}$, oxygen reacts with $\mathrm{Co}(\mathrm{II})$-benzoin complex to

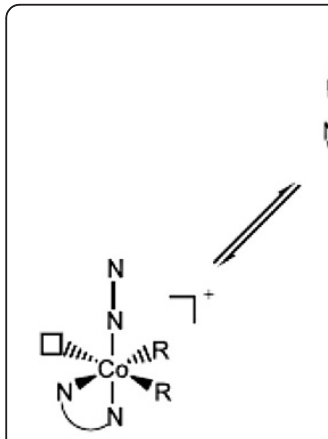

(a)
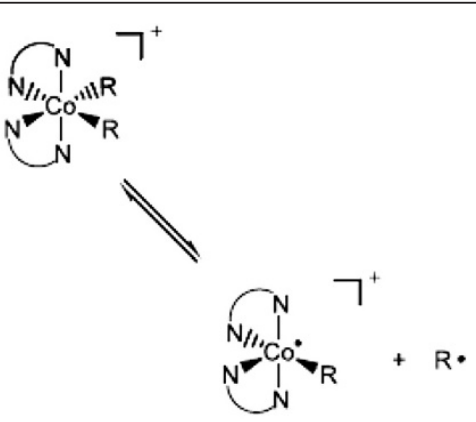

(b)
Figure 19 Activation of cobalt complexes through (a) coordinative and (b) radical pathways (Milani et al. 2003). form $\mathrm{Co}(\mathrm{III})_{2}\left(\mathrm{O}_{2}^{2-}\right)\left(\mathrm{PhCHO}^{-} \mathrm{COPh}\right)$, therefore cobalt(II) converts to cobalt(III). Cobalt(II) nitrate has been reported as the most active catalyst, among other cobalt(II) salts, for the oxidation of benzoin in acetonitrile solvent due to stronger interaction between cobalt(II) nitrate and acetonitrile molecule compared to the interaction involving cobalt(II) halide (Tsuruya et al. 1981).

As already well recognised in this review, oxidation of linseed oil involves peroxyl chemistry, displaying importance to other industrial applications, such as that described by Turra et al. (Turra et al. 2010). These authors reported the mechanism of the decomposition of tertbutylhydroperoxides catalysed by cobalt(II) acetylacetonate (in cyclohexane). The first step involves the reaction of cobalt(II) and hydroperoxide to form alkoxyl radical and $\mathrm{Co}^{\mathrm{III}}-\mathrm{OH}$ compound with the activation energy of $54 \mathrm{~kJ} \mathrm{~mol}^{-1}$. This species then reacts with another hydroperoxide to regenerate cobalt(II) and produce peroxyl radical in the second step which is part of the Fenton-like cycle. Alcohols display a tendency to inhibit catalytic deperoxidation reactions by cobalt which probably occurs due to the coordination of alcohol to cobalt species. Quantum calculation predicted that reaction (17) remains slightly slower than reaction (18). The rate of this deperoxidation decreases at higher cobalt concentration, for instance at $333 \mathrm{~K}$, the rate decreases once the concentration of $\mathrm{Co}(\mathrm{acac})_{2}$ exceeds $100 \mu \mathrm{M}$ (Turra et al. 2011). The proposed explanation invokes the termination reaction of the $\mathrm{Co}{ }^{\mathrm{III}}-\mathrm{OH}$ to form a stable bis ( $\mu$-hydroxo) dimer, Co- $(\mathrm{OH})_{2}-\mathrm{Co}$,(Turra et al. 2010) as illustrated in the following Scheme 5:

Reaction (22) controls the propagation rate of the overall mechanism of the decomposition of hydroperoxide.

Alkoxyl radicals arise as the main products of the self reaction of tertiary peroxyl radical reactions (reaction 22 ), while the minority pathway comprises the termination reaction (23), with about $10 \%$ of the ROO radicals consumed through reaction (24) (Turra et al. 2010). Alkoxyl radical produced by reaction (17) can interact with the cyclohexane $(\mathrm{CyH})$ solvent (20) or with the hydroperoxide (21), however, reaction (21) consumes the majority of the alkoxyl radicals (Turra et al. 2010).

$$
\begin{aligned}
& \mathrm{Co}^{\mathrm{II}}+\mathrm{ROOH} \rightarrow \mathrm{Co}^{\mathrm{III}}-\mathrm{OH}+\mathrm{RO}^{\bullet} \\
& \mathrm{Co}^{\mathrm{III}}-\mathrm{OH}+\mathrm{ROOH} \rightarrow \mathrm{Co}^{\mathrm{II}}+\mathrm{H}_{2} \mathrm{O}+\mathrm{ROO}^{\bullet} \\
& 2 \mathrm{ROOH}^{\circ} \mathrm{RO}^{\bullet}+\mathrm{ROO}^{\bullet}+\mathrm{H}_{2} \mathrm{O} \\
& \mathrm{RO}^{\bullet}+\mathrm{CyH} \rightarrow \mathrm{ROH}+\mathrm{Cy}^{\bullet}
\end{aligned}
$$




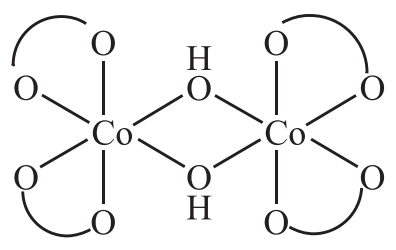

Scheme 5 Stable bis( $\mu$-hydroxo) dimer.

$$
\begin{aligned}
& \mathrm{RO}^{\bullet}+\mathrm{ROOH} \rightarrow \mathrm{ROH}+\mathrm{ROO}^{\bullet} \\
& \mathrm{ROO}^{\bullet}+\mathrm{ROO}^{\bullet} \rightarrow \mathrm{RO}^{\bullet}+\mathrm{RO}^{\bullet}+\mathrm{O}_{2} \\
& \mathrm{ROO}^{\bullet}+\mathrm{ROO}^{\bullet} \rightarrow \mathrm{ROOR}+\mathrm{O}_{2} \\
& \mathrm{ROO}^{\bullet}+\mathrm{CyH} \rightarrow \mathrm{ROOH}+\mathrm{Cy}^{\bullet}
\end{aligned}
$$

The presence of a metal catalyst decreases the activation energy required to decompose two moles of hydroperoxide from 90-170 to $40-50 \mathrm{~kJ} \mathrm{~mol}^{-1}$ via reactions (25) and (26) (Mallégol et al. 2000). The activation energy required for the reaction between oxygen and unsaturated fatty acid esters in the presence of cobalt dryers is only one tenth of that in the absence of cobalt dryer (Skalský 1976). The activation energies for the decomposition of hydroperoxyl linoleic and linolenic acid methyl ester at $25^{\circ} \mathrm{C}$ are $36 \mathrm{~kJ} \mathrm{~mol}^{-1}$ and $38.5 \mathrm{~kJ} \mathrm{~mol}^{-1}$, respectively (Hendriks et al. 1979). In contrast, cobalt complexes may stabilise the resulting peroxidic product through the coordination (Nishinaga et al. 1988). In practice, peroxide value serves to estimate the extent of oxidation and curing.

$$
\begin{aligned}
& \mathrm{M}^{\mathrm{n}+}+\mathrm{ROOH} \rightarrow \mathrm{M}^{(\mathrm{n}+1)+}+\mathrm{RO}^{\bullet}+\mathrm{OH}^{-} \\
& \mathrm{M}^{(\mathrm{n}+1)+}+\mathrm{ROOH} \rightarrow \mathrm{M}^{\mathrm{n}+}+\mathrm{ROO}^{\bullet}+\mathrm{H}^{+}
\end{aligned}
$$

\section{Catalytic mechanism of complex formation}

Cobalt(II)-Schiff base complexes can react with oxygen to form dioxygen complexes (Nishinaga et al. 1988); Nishinaga et al. reported that cobalt(II) complex displays a four-coordinate structure (Nishinaga et al. 1988). This reaction appears non-radical in nature, and entails the formation of a charge transfer complex, $\left[\mathrm{Co}^{\mathrm{III}}\left(\mathrm{O}_{2}^{-}\right)\right]$, in an energetically favourable transformation (Boca 1981). In this process, an electron transfers from $\mathrm{Co}(\mathrm{II})$ to the coordinated dioxygen to form superoxide, $\mathrm{Co}(\mathrm{III})\left(\mathrm{O}_{2}^{-}\right)$ (Boca 1981). In comparison, a general reaction of the first row transition metals represents the radical chain autoxidation (Bailey \& Drago 1987; Nishinaga et al. 1988). The activation of dioxygen through coordination to cobalt
(II) complexes produces a strong oxidant (Boca 1983). The initiation step in the oxidation of substrate proceeds as follows (Boca 1981):

$$
\begin{aligned}
& {\left[\mathrm{Co}^{\mathrm{III}}\left(\mathrm{O}_{2}^{-}\right)\right]} \\
& \quad+\mathrm{RH} \rightarrow\left[\mathrm{Co}^{\mathrm{III}}\left(\mathrm{O}_{2}{ }^{-}\right) \mathrm{HR}\right] \rightarrow\left[\mathrm{Co}^{\mathrm{III}}\left(\mathrm{OOH}^{-}\right)\right] \\
& \quad+\mathrm{R}^{*}
\end{aligned}
$$

Dioxygen complexes are well known for their role in biological processes and in catalysis (Boca 1983). The dioxygen activation is indicated by the $\mathrm{O}-\mathrm{O}$ bond lengthening and Co-O distance shortening (Boca 1983). Transition metal complexes fulfil important roles in activating the molecular oxygen through the coordination and partial reduction of oxygen (Bakac 2010). Smeets et al. investigated the coordination and activation of oxygen employing transition metal ions in zeolites (Smeets et al. 2010). The metal and oxygen oxidation states undergo changes during the activation process. Ligands coordinating to the metals (Fukuzumi et al. 2002) control the redox reactivities of transition metal ions. Most organic radicals can reduce oxygen to form superoxide due to their redox potentials (Roberfroid \& Calderon 1995).

\section{Kinetic parameters for radical chain reactions}

The relative stabilities of peroxyl radicals in triacylglycerols follow the order from the most stable tristearin, to triolein, trilinolein and trilinolenin. There is no formation of peroxyl radicals below $100 \mathrm{~K}$, the peroxidation starts at $105 \mathrm{~K}$. The activation energies for the decomposition of peroxyl radicals into allylic and pentadienyl radicals in triolein, trilinolein and trilinolenin amount to $88 \pm 11,34 \pm 8$ and $9 \pm 2 \mathrm{~kJ} \mathrm{~mol}^{-1}$, respectively (Zhu \& Sevilla 1989).

The autoxidation reaction of methyl linoleate and methyl linolenate have been reported to be first order in the ester concentration at temperatures between 25 and $75^{\circ} \mathrm{C}$ (Hendriks et al. 1979). The ratio of rate constants for oxidation of mono, di and triunsaturated esters have been obtained at $90^{\circ} \mathrm{C}$ as 1:3:12 (Litwinienko \& KasprzyckaGuttman 1999). The activation energies of oxidation of methyl oleate, linoleate and linolenate derived from DSC measurements correspond to $95.0 \pm 4.7,76.4 \pm 5.0$ and $74.5 \pm 8.2 \mathrm{~kJ} \mathrm{~mol}^{-1}$, respectively (Litwinienko \& Kasprzycka-Guttman 1999). The addition of dryers reduces the activation energy for the onset of autoxidation of linolenic acid from $71 \mathrm{~kJ} \mathrm{~mol}^{-1}$ by about two thirds (Howitt et al. 1995). The initial oxidation temperature of unsaturated fatty acids is lower by $20^{\circ} \mathrm{C}$ compared to that of esters of the same fatty acids (Litwinienko \& Kasprzycka-Guttman 1999).

Lipid peroxidation in biological systems has been modelled for reactions involving polyunsaturated fatty acids (PUFA), tissue activator enzymes, antioxidants and glutathione, with lipid peroxidation representing the 
main pathways (Tappel et al. 1989). Rate constants for several important reactions in the lipid peroxidation are listed below (Antunes et al. 1996):

1. $\mathrm{LH}+\mathrm{LOO}^{\cdot} \rightarrow \mathrm{L}^{\cdot}+\mathrm{LOOH} \quad k=1.4 \times 10^{1} \mathrm{M}^{-1} \mathrm{~s}^{-1}$

2. $\mathrm{LH}+\mathrm{LO}^{*} \rightarrow \mathrm{L}^{\cdot}+\mathrm{LOH} \quad k=6.6 \times 10^{6} \mathrm{M}^{-1} \mathrm{~s}^{-1}$

3. $\mathrm{LOO}^{*}+\mathrm{LOO}^{*} \rightarrow$ products $k=6.6 \times 10^{4} \mathrm{M}^{-1} \mathrm{~s}^{-1}$

4. LOO $^{*}-$ LOO $^{*} \rightarrow$ products $k=4.4 \times 10^{4} \mathrm{~s}^{-1}$

5. $\mathrm{P}-\mathrm{LOOH}+\mathrm{Fe}^{2+} \rightarrow \mathrm{P}-\mathrm{LO}^{\bullet}+\mathrm{HO}^{-}$ $+\mathrm{Fe}^{3+} \mathrm{k}=3.2 \times 10^{2} \mathrm{M}^{-1} \mathrm{~s}^{-1}$

6. $\mathrm{P}-\mathrm{LOO}^{*}+\mathrm{TocOH} \rightarrow \mathrm{P}-\mathrm{LOOH}$

$$
+ \text { TocO }^{*} \mathrm{k}=5.8 \times 10^{3} \mathrm{M}^{-1} \mathrm{~s}^{-1}
$$

$$
\begin{aligned}
\text { 7. } \mathrm{P}-\mathrm{LO}^{\bullet}+\mathrm{TocOH} \rightarrow \mathrm{P}-\mathrm{LOH} \\
+\mathrm{TocO}^{*} \mathrm{k}=1.0 \times 10^{8} \mathrm{M}^{-1} \mathrm{~s}^{-1}
\end{aligned}
$$

L stands for lipid, P refers to phospholipid and Toc denotes tocopherol.

Halliwell and Gutteridge (Halliwell \& Gutteridge 2008) reported the rate constant of the reaction of carboncentred radicals with oxygen to form peroxyl radicals to be greater than $10^{9} \mathrm{M}^{-1} \mathrm{~s}^{-1}$. Peroxyl and alkoxyl radicals, known as good oxidising agents, play important roles in lipid peroxidation, especially as agents for hydrogen abstraction from the lipid molecules (Halliwell \& Gutteridge 2008). Table 8 lists the reaction rate constant of hydrogen abstraction from unsaturated fatty acid by several kinds of radicals and that of oxygen reaction with alkyl radical.

The oxidative cross linking process of linseed oil in the presence of metal catalysts is not autocatalytic at temperatures between 120 to $155^{\circ} \mathrm{C}$ (Tuman et al. 1996). Non-conjugated trienoic acid (fatty acid) esters undergo thermal polymerisation reaction at $275^{\circ} \mathrm{C}$ with much lower rate compared to the various conjugated trienoic esters (Ault et al. 1942). Furthermore, the rate of oxidative polymerisation is lower than the autoxidation process (Litwinienko \& Kasprzycka-Guttman 1999).

Güler et al. (Güler et al. 2004) studied the kinetics of oxypolymerisation reaction of linseed oil by estimating the rates of reactions from changes in viscosity and found that the reaction order varied with temperature. At 200,120 and $80^{\circ} \mathrm{C}$ and for the flow rate of air of
$2 \mathrm{dm}^{3} \min ^{-1}$, the reactions were first, second and third order, respectively, indicating a complex elementary reaction mechanism underlying the observed overall kinetics. The drying performance of oil with a high percentage of linolenic acid is faster and the induction time is shorter compared to an oil rich in linoleic acid. This is because oil rich in linolenic acid tends to form a skin layer, causing a diffusion barrier to oxygen resulting in a high level of residual unsaturation in the film (Stenberg et al. 2005).

Another practical study examining the overall kinetics was performed by Khattab et al. (Khattab et al. 1999) who investigated the effect of contamination of cotton fabric with linseed oil on the activation energies of pyrolysis and oxidation of the fabric. These authors described the apparent activation energy of the gaseous oxidation product $\left(E_{\mathrm{ox}}\right)$ by the following expression:

$$
\begin{aligned}
\ln \left(\frac{H_{r}}{T_{i}^{2}}\right)= & -\frac{E_{p}}{R}\left(\frac{1}{T_{i}}\right)+\ln A_{p} \\
& -\ln \left(\frac{E_{p}-E_{o x}}{R}\right)
\end{aligned}
$$

where $E_{\mathrm{p}}$ is the apparent activation energy of pyrolysis, $T_{\mathrm{i}}$ denotes the onset of spontaneous ignition, $H_{\mathrm{r}}$ corresponds to heating rate, and $A_{\mathrm{p}}$ stands for the apparent Arrhenius factor describing the pyrolysis. The presence of oil in fabrics reduces the activation energy of pyrolysis and oxidation, and increases oxygen demand, demonstrating the sensitivity of the process to oxygen concentration (Khattab et al. 1999).

\section{Digression on cool flames}

Peroxide chemistry is also important in low temperature combustion, in the temperature window associated with cool flames, followed by a region denoted as the negative temperature coefficient (where the oxidation rate decreases with increasing temperature), and then by the fuel auto-ignition. A significant body of literature exists on these subjects, as recently reviewed by Battin-Leclerc (Battin-Leclerc 2008) and prior to that by Pilling (Pilling 1997). In particular, these reviews

Table 8 Aggregated rate constants applied in the lipid peroxidation model (Antunes et al. 1996)

\begin{tabular}{llll}
\hline Reactions & \multicolumn{3}{l}{ Unsaturated Fatty Acid (UFA) } \\
\cline { 2 - 4 } & $\mathbf{1 8 : 1}$ & $\mathbf{1 8 : 2}$ & $\mathbf{1 8 : 3}$ \\
\hline $\begin{array}{l}\text { Hydrogen abstraction from UFA by } \\
\text { perhydroxyl radicals }\left(\mathrm{M}^{-1} \mathrm{~s}^{-1}\right)(225)\end{array}$ & No reaction & $1.2 \times 10^{3}$ & $1.7 \times 10^{3}$ \\
$\begin{array}{l}\text { Oxygen addition to carbon-centred } \\
\text { radicals }\left(\mathrm{M}^{-1} \mathrm{~s}^{-1}\right)\end{array}$ & $1.0 \times 10^{9}$ & $3.0 \times 10^{8}$ & $3.0 \times 10^{8}$ \\
$\begin{array}{l}\text { Hydrogen abstraction from UFA } \\
\text { by peroxyl radicals }\left(\mathrm{M}^{-1} \mathrm{~s}^{-1}\right)\end{array}$ & $1.1 \times 10^{-2}$ & $1.9 \times 10^{1}$ & $4.1 \times 10^{1}$ \\
$\begin{array}{l}\text { Hydrogen abstraction from UFA } \\
\text { by alkoxyl radicals }\left(\mathrm{M}^{-1} \mathrm{~s}^{-1}\right)\end{array}$ & $3.8 \times 10^{6}$ & $8.8 \times 10^{6}$ & $1.3 \times 10^{7}$ \\
\hline
\end{tabular}


have illustrated the important role of thermodynamics on peroxide reactions, at increasing temperatures. The effect of temperature on the peroxidation reaction of alkyl radical is described below by equations 36 to 38 . The rate of oxidation increases significantly as temperature rises in the window of 500 to $600 \mathrm{~K}$, since the equilibrium moves to the right. On the other hand, at higher temperature of above $600 \mathrm{~K}$ the oxidation rate falls as the equilibrium shifts to the left, causing the amount of hydroperoxides formed to decrease.

$$
\begin{aligned}
& \mathrm{R}+\mathrm{O}_{2} \rightleftharpoons \mathrm{RO}_{2} \\
& \mathrm{RO}_{2}+\mathrm{RH} \rightarrow \mathrm{ROOH}+\mathrm{R} \\
& \mathrm{ROOH} \rightarrow \mathrm{RO}+\mathrm{OH}
\end{aligned}
$$

\section{Summary}

Linseed oil has found numerous applications in painting, varnishes, wood treatment and linoleum due to its drying properties. However, in the presence of a metal catalyst, the oxidation of linseed oil soaked into lignocellulosic materials, such as cotton rags, may induce their spontaneous heating. As a consequence of the importance of the unsaturated fatty acid (present in linseed oil as triacylglycerols) to nutrition, several studies have been undertaken to investigate the oxidation of the active components in linseed oil; often deploying surrogate compounds, such as ethyl linoleate. These studies led to establishing a generally good understanding of the overall radical chain reactions that operate in the oxidation process. The chemical reactions involve initiation, propagation and termination steps. They comprise oxygen addition to the radicals, formation of hydroperoxides, which are known to be important intermediates, and decomposition of peroxides leading to the formation of volatile organic species and higher molecular weight compounds. However, critical details have eluded comprehension, such as the emergence of the initial radicals, the detailed mechanistic understanding of important chemical species observed in experiments, or the role of most of the transition metals suspected to induce catalytic enhancement of the oxidation reactions.

Several experimental methods have been developed to evaluate the oxidation and self-heating tendency of linseed oil and cotton. Likewise, numerous analytical methods have been applied to identify and quantitate the chemical changes during oxidation, the gaseous and liquid products and the catalytic effect of metal dryers. The chemical structure of the triacylglycerols in the oil determines the reactivity of the species in the radical chain reactions. The significant catalytic pathways proceed either through the decomposition of hydroperoxides or formation of coordination complexes. However, only a limited number of kinetic parameters has been reported for catalytic reactions.

The pathways that operate in the oxidation of linseed oil include those which are known to occur in other applications. For instance, biological systems involve radical chain reactions of lipid peroxidation, and polymer systems comprise crosslinking reactions that rely on the recombination of radicals. Peroxides are formed in low-temperature oxidation of hydrocarbons, and the thermal runaway reactions, involving peroxides, are similar to those that occur in self-heating and autoignition of linseed oil.

The classical models of ignition oversimplify the complexity of the peroxyl chemistry involved in the oxidation reactions. Knowledge of detailed reaction chemistry is required to evaluate the propensity of a material to selfheating from its chemical composition. Although the pathways of the autoxidation and polymerisation have been investigated, detailed mechanisms have not yet been proposed to explain the formation of products identified in experiments. A limited number of publications in literature discusses the formation of carbon dioxide and carbon monoxide during oxidation reactions of linseed oil. Because of its practical importance in the paint industry, previous researchers have mainly focussed on gaining insights into the oxidative drying of oils. Very little effort has gone into unravelling the chemical reactions that govern the selfheating of linseed oil, and considerable research still needs to be conducted to obtain a better understanding of the chemistry of this phenomenon.

This review has demonstrated that the initiation reactions involve singlet oxygen that forms in the presence of light and organic species, such as chlorophyll. The propagation reactions involve triplet (i.e., ground state) oxygen. The present models of self-ignition do not account for this behaviour, and their predictions need to be viewed with great scepticism. For example, the study of Worden, performed with boiled linseed oil, could not even identify subcritical conditions. A significant range of kinetic parameters exists in the reported values, as a consequence of different types of linseed oil being tested and experimental methodologies. This situation is hardly acceptable from the perspective of fire safety as at present no reliable predictions can be made of ignition behaviour of lignocellulosic materials soaked with linseed oil. Further experimental and theoretical progress in the field is urgently needed.

\section{Appendix A. Kinetic parameters from Chen, Jones and adiabatic methods}

A.1. Comparison of Chen and Jones' methods

Both methods assume constant and isotropic material properties, and no water evaporation. The oxygen diffusion in the sample is taken to be fast in comparison to 
oxidation (i.e., Damköhler number is small) and that oxidation itself is not limited by the depletion of the fuel. This allows decoupling of the mass conservation equations (for fuel and oxygen) from the heat conduction equation simplifying the problems to the solution of the latter. The validity of this assumption has not yet been tested for lignocellulosic materials soaked with linseed oil.

Both methods also assume that the overall oxidation reaction is first order with respect to the fuel; i.e., the effect of oxygen concentration is incorporated in the pre-exponential factor $A$. This assumption is much more severe. As demonstrated in this review, the oxidation mechanism constitutes a complex set of radical reactions, which, in the case of boiled oil, are accelerated by a metal catalyst. The initiation reactions involve singlet oxygen and the propagation reactions entail triplet oxygen. From this perspective, the kinetic parameters $(A$ and $E$ ) obtained by either Jones' or Chen's method can only be considered as global in nature; i.e., they represent the effect of the entire chemical mechanism condensed into one global chemical reaction.

As will be demonstrated below, Chen's method introduces no additional assumption, which makes the estimates of $A$ and $E$ to correspond to global but intrinsic material properties. That is, Chen's method yields kinetic constants of fundamental importance. On the other hand, Jones' method comprises an additional assumption that the thermal behaviour of a sample can be described by an average temperature, as measured at the sample's centre. This results in the estimates of $A$ and $E$ to be apparent. Such estimates can be applied to rank various materials (e.g., coals) for their propensity to spontaneous ignition. However, these estimates convey no fundamental meaning.

The derivation of Chen's method starts with the consideration of a differential element near the sample's centre. Imagine that one thermocouple is placed at the centre $\left(T_{\mathrm{C}}\right)$ and one to the side $\left(T_{\mathrm{S}}\right)$. As the time progresses, the temperature profile in the sample will evolve is illustrated below. The locations of the thermocouples are illustrated above in (Scheme 6).

At certain instant, $T_{\mathrm{C}}$ and $T_{\mathrm{S}}$ will cross each other. Now, let us imagine a basket with a differential (i.e., very small) element in its centre as shown in (Scheme 7).

For simplicity, in further considerations, we assume a one dimensional case. For this reason, the volume of the differential element is simply $\Delta x \times 1 \times 1$ (Scheme 8).

At crossing point, $T_{\mathrm{C}}=T_{\mathrm{S}}$, the heat fluxes through $P_{\mathrm{W}}$ and $P_{\mathrm{E}}$ disappear, since

$$
-k_{w} \frac{T_{C}-T_{S}}{\Delta x}(1 \times 1)=0
$$

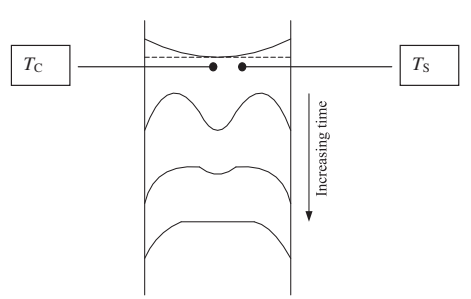

Scheme 6 Graphical interpretation of Chen's method.

and

$$
-k_{E} \frac{T_{S}-T_{C}}{\Delta x}(1 \times 1)=0
$$

where $k_{\mathrm{W}}$ and $k_{\mathrm{E}}$ denote the heat conduction coefficient $\left(\mathrm{W} \mathrm{m} \mathrm{m}^{-1} \mathrm{~K}^{-1}\right)$. Then, the differential energy balance yields

$$
(\Delta x \times 1 \times 1) \rho c \frac{d T_{C}}{d t}=(\Delta x \times 1 \times 1) \rho Q A e^{-\frac{E}{R T C}}
$$

or simply

$$
\frac{d T_{C}}{d t}=\frac{Q A}{c} e^{-\frac{E}{R T_{C}}}
$$

where, $A$ is pre-exponential factor $\left(\mathrm{s}^{-1}\right), Q$ enthalpy of the oxidation reaction $\left(\mathrm{J} \mathrm{kg}^{-1}\right), c$ heat capacity of the bulk sample $\left(\mathrm{J} \mathrm{kg}^{-1} \mathrm{~K}^{-1}\right)$, and $\rho$ bulk density of the sample $\left(\mathrm{kg} \mathrm{m}^{-3}\right)$. Taking the natural logarithm yields the celebrated Chen equation

$$
\operatorname{In}\left(\frac{d T_{C}}{d t}\right)=\operatorname{In}\left(\frac{Q A}{c}\right)-\frac{E}{R T_{C}}
$$

Performing experiments for several $T_{C}$, one plots $\operatorname{In}\left(\frac{d T_{C}}{d t}\right)$ versus $\left(\frac{1}{T_{C}}\right)$ to obtain estimates of intrinsic $E$ and $A$ (or $Q A$ ), in a least square sense.

\section{A.3. Derivation of the heat balance equation underlying Jones' method}

The derivation of Jones' method starts with an integral heat balance around the basket, with the control surface

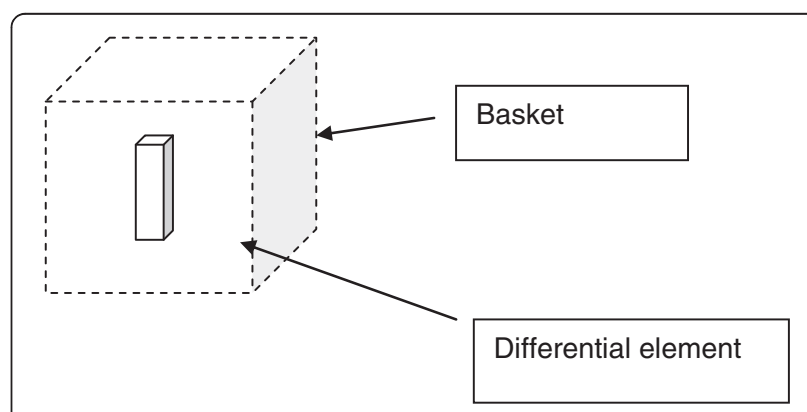

Scheme 7 Differential element in the centre of the basket. 


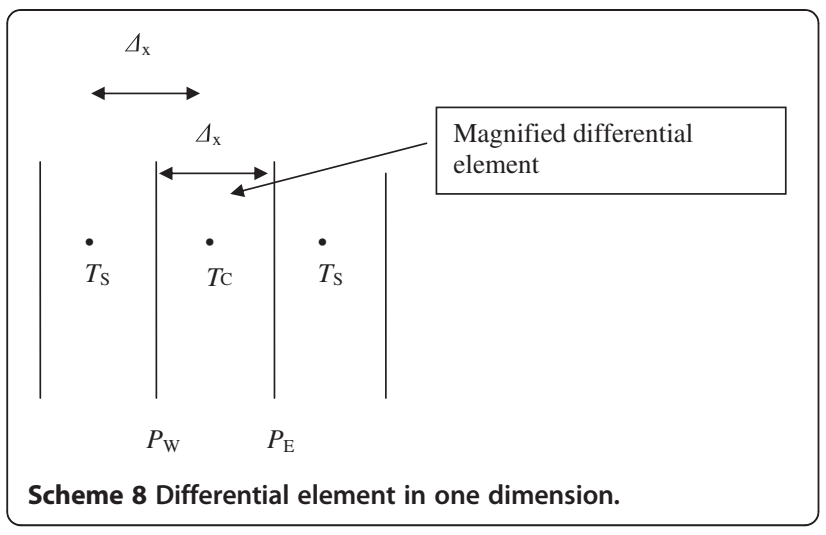

corresponding to the gauze surface. The material in the basket is assumed to be at an average temperature $T_{1}$ aver as measured at the centre of the sample (Scheme 9). The heat transfer across the control surface proceeds by convection. This leads to the following time-dependent ordinary differential equation

$$
a^{3} \rho c \frac{d T_{1, a v e r}}{d t}=6 a^{2} h\left(T_{2}-T_{1 \text { aver }}\right)+a^{3} \rho Q A e^{-\frac{E}{R T_{1 a v e r}}}
$$

where $a$ denotes the dimension of the cube $(\mathrm{m}), T_{1}$ aver average sample temperature (K), as measured by thermocouple 1 at the centre point of the sample, $T_{2}$ - oven temperature $(\mathrm{K})$, as measured by thermocouple 2 near the sample surface, and other symbols have their standard meaning. At the crossing point temperature $\left(T_{2}=T_{1}\right.$ aver $)$, the above equation leads to

$$
\frac{d T_{1, \text { aver }}}{d t}=\frac{Q A}{c} e^{-\frac{E}{R T_{1, \text { aver }}}}
$$

A simple algebraic manipulation then yields the Jones equation

$$
\ln \left(\frac{d T_{1, \text { aver }}}{d t}\right)=\ln \left(\frac{Q A}{C}\right)-\frac{E}{R T_{1, \text { aver }}}
$$

This demonstrates that the kinetic parameters are obtained at an average temperature of the sample. This temperature is taken to correspond to the temperature at the centre of the sample. It is not the true average temperature of the sample. This means that Jones' method yields apparent kinetic parameters of the sample as opposed to the intrinsic (i.e., fundamental) parameters derived by Chen's method. Though, do not forget that, both estimates simplify the detailed radical and catalytic chemistry of the oxidation of linseed oil to one global kinetic step.

The apparent values of $E$ and $A$ are obtained by plotting $\ln \left(\frac{d T_{1, a v e r}}{d t}\right)$ versus $\left(\frac{1}{T_{1, a v e r}}\right)$, from several experiments, analogously to Chen's method.

We conclude this Appendix by observing that, the equation to obtain $A$ and $E$ from an adiabatic reactor

Walls of the basket (sample) denote the control surface. Space delimited by control surface corresponds to the control volume.

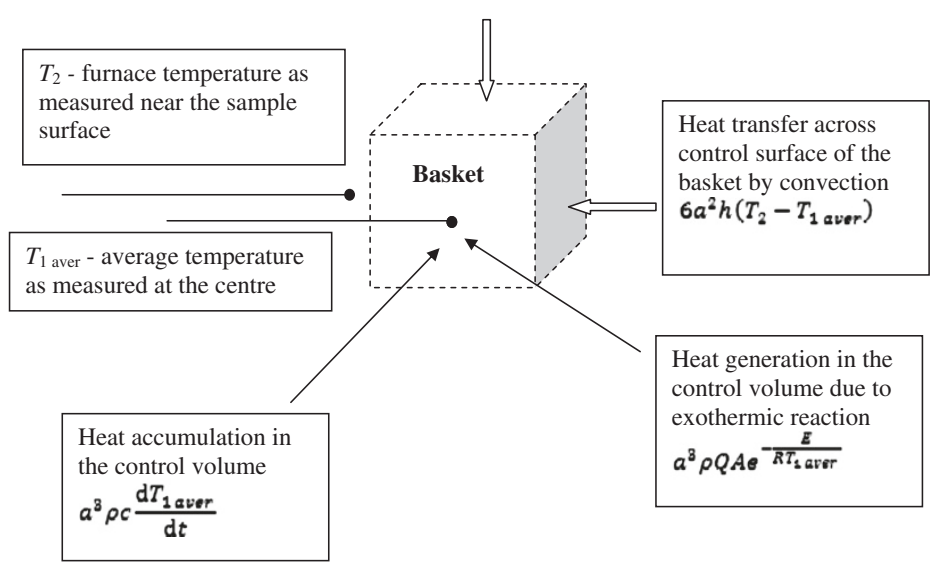

Scheme 9 Heat balance for Jones' method. 
has the same limitations as that of Jones. In the adiabatic reactor, the integral energy balance also yields

$$
\ln \left(\frac{d T_{C, \text { aver }}}{d t}\right)=\ln \left(\frac{Q A}{C}\right)-\frac{E}{R T_{C, \text { aver }}}
$$

where $T_{C \text {,aver }}$ denotes the temperature of the sample, as measured at its centre. However, for an adiabatic reactor, only a single experiment is needed to obtain the apparent values of $A$ and $E$. Complexity of the adiabatic reactor system could be substantial, especially the control system, to ensure no heat-flux conditions at the walls of the sample.

\section{Abbreviations}

Amp: 2-Aminomethylpyridine; APE: Allylic Position Equivalent;

AsA6p: Ascorbic acid 6-palmitate; AV: Anisidine Value; BAPE: Bis-Allylic

Position Equivalent; CAR/PDMS: Carboxen/Polydimethylsiloxane; CFAM: Cyclic Fatty Acid Monomers; Co(II)(acac) 2 : Cobalt(II) acetylacetonate; Co-EH: Cobalt (II)-2-ethylhexanoate; CW/DVB: Carbowax/Divinylbenzene; CyH: Cyclohexane; DHS-TD: Dynamic Headspace-Thermal Desorption; DMPO: 5,5-Dimethyl-1pyrroline N-oxide; DNA: Deoxyribonucleic acid; DNPH: 2,4Dinitrophenylhydrazine; DSC: Differential Scanning Calorimetry; DTA: Differential Thermal Analysis; DVB/CAR/PDMS: Divinylbenzene/ Carboxen/Polydimethylsiloxane; EPR: Electron Paramagnetic Resonance (same as ESR); ESI-MS: Electrospray Ionisation- Mass Spectrometry; ESI-MS/ MS: Electrospray lonisation- Mass Spectrometry/Mass Spectrometry; ESR: Electron Spin Resonance (same as EPR); FAME: Fatty Acid Methyl Esters; Fe-eh: Fe-2-ethylhexanoate; FTIR: Fourier Transform Infrared Spectroscopy; GC-MS: Gas Chromatography-Mass Spectrometry; GC-TOFMS: Gas Chromatography- Time-of-Flight Mass Spectrometry; Hdpm: Dipivaloylmethane; Hmp: 2-hydroxymethylpyridine; HMTETA: 1,1,4,7,10,10-hexamethyl triethylenetetramine; H-NMR: HydrogenNuclear Magnetic Resonance; HPLC: High Performance Liquid Chromatography; $\mathrm{H}_{2}$ tbpppy: 2-[bis(2-hydroxy-3,5-di-tert-butylbenzyl) aminomethyl]pyridine; IR: Infra Red; JSR: Jet-Stirred Reactor; LC-MS: Liquid Chromatography-Mass Spectrometry; LC-MS/MS: Liquid ChromatographyMass Spectrometry/Mass Spectrometry; LOXes: Linoleate:Oxygen Oxidoreductase; MALDI-MS: Matrix-assisted laser desorption/lonisation-mass spectrometry; MALDI-RTOF-MS: Matrix-Assisted Laser Desorption/lonisationReflectron Time of Flight-Mass Spectrometry; MDN: Methyl-N-Duryl Nitrone; MeTACN: Polyamines 1,4,7-trimethyl-1,4,7-triazacyclononane; NFPA: National Fire Protection Association; ODO: Olfactory Detector Outlet; PA: Polyacrylate PDMS-DVB: Polydimethylsiloxane-Divinylbenzene; PUFA: Polyunsaturated Fatty Acid; SEC: Size Exclusion Chromatography; SOP: Secondary Oxidation Products; SPME: Solid Phase Microextraction; SPME-GC-MS: Solid Phase Microextraction-Gas Chromatography-Mass Spectrometry; TD-GC-O/ MS: Thermal Desorption Gas Chromatography combined with Olfactometry and Mass Spectrometry; TGA: Thermogravimetric Analysis; TGA-

DSC: Thermogravimetric Analysis- Differential Scanning Calorimetry; TGADSC-FTIR: Thermogravimetric Analysis- Differential Scanning CalorimetryFourier Transform Infrared Spectroscopy; TGA-DSC-MS: Thermogravimetric Analysis- Differential Scanning Calorimetry- Mass Spectrometry; TGADTA: Thermogravimetric Analysis- Differential Thermal Analysis; TOFMS: Timeof-Flight Mass Spectrometry; TR-FTIR: Time Resolved-Fourier Transform Infrared Spectroscopy; UHP: Ultra High Purity; UV-vis: Ultraviolet-visible; VOC: Volatile Organic Compounds; ZDC: Zinc dialkyldithiocarbamate; ZPVE: Zero Point Vibrational Energies; $\mu \mathrm{GC}$ : Micro Gas Chromatography.

\section{Competing interests}

The authors declare that they have no competing interests.

\section{Authors' contributions}

The first two authors shared equally writing and revising the manuscript. EMK assisted with drafting the manuscript. JCM contributed to the section on kinetics and reaction mechanisms of oil oxidation. All authors read and approved the final manuscript.

\section{Acknowledgements}

This study was supported by a grant from the Australian Research Council. Juita thanks the University of Newcastle for a postgraduate scholarship.

\section{Author details}

${ }^{1}$ Process Safety and Environmental Protection Group, School of Engineering, The University of Newcastle, Callaghan, NSW 2308, Australia. ${ }^{2}$ Also at School of Chemistry, The University of Sydney, Sydney, NSW 2006, Australia.

Received: 10 December 2011 Accepted: 23 May 2012

Published: 19 September 2012

\section{References}

Abraham CJ (1996) A solution to spontaneous combustion in linseed oil formulations. Polym Degrad Stabil 54:157-166

Allen PEM, Patrick CR (1974) Kinetics and Mechanisms of Polymerization Reactions. Ellis Horwood Limited, Chichester

Antunes F, Salvador A, Marinho HS, Alves R, Pinto RE (1996) Lipid peroxidation in mitochondrial inner membranes. I. An integrative kinetic model. Free Radic Biol Med 21:917-943

Ault WC, Cowan JC, Kass JP, Jackson JE (1942) Polymerization of drying oils. Ind Eng Chem 34:1120-1123

Aust SD, Morehouse LA, Thomas CE (1985) Role of metals in oxygen radical reactions. J Free Radic Biol Med 1:3-25

Babrauskas V (2003) Ignition Handbook. Fire Science Publishers

Baccouri B, Temime SB, Campeol E, Cioni PL, Daoud D, Zarrouk M (2007) Application of solid-phase microextraction to the analysis of volatile compounds in virgin olive oils from five new cultivars. Food Chem 102:850-856

Bailey CL, Drago RS (1987) Utilization of O2 for the specific oxidation of organic substrates with cobalt(II) catalysts. Coord Chem Rev 79:321-332

Bakac A (2010) Oxygen activation with transition-metal complexes in aqueous solution. Inorg Chem 49:3584-3593

Battin-Leclerc F (2008) Detailed chemical kinetic models for the low-temperature combustion of hydrocarbons with application to gasoline and diesel fuel surrogates. Prog Energy Combust Sci 34:440-498

Belhaj N, Arab-Tehrany E, Linder M (2010) Oxidative kinetics of salmon oil in bulk and in nanoemulsion stabilized by marine lecithin. Process Biochem 45:187-195

Beltran G, Aguilera MP, Gordon MH (2005) Solid phase microextraction of volatile oxidation compounds in oil-in-water emulsions. Food Chem 92:401-406

Boca R (1981) Molecular orbital study of coordinated dioxygen V. Catalytic oxidation of toluene on cobalt-dioxygen complexes. J Mol Catal 12:351-358

Boca R (1983) Dioxygen activation in transition metal complexes in the light of molecular orbital calculations. Coord Chem Rev 50:1-72

Bors W, Erben-Russ M, Saran M (1987) Fatty acid peroxyl radicals: Their generation and reactivities. Bioelectrochem Bioenerg 18:37-49

Bowes P (1984) Self Heating: Evaluating and Controlling the Hazards. Elsevier Science Publishers B.V, Amsterdam

Bowes PC, Thomas PH (1966) Ignition and extinction phenomena accompanying oxygen-dependent self-heating of porous bodies. Fire Res Stat 10:221-230

Chen XD (1999) On basket heating methods for obtaining exothermic reactivity of solid materials: the extent and impact of the departure of the crossingpoint temperature from the oven temperature. Process Saf Environ Protect 77:187-192

Chen XD, Chong LV (1998) Several important issues related to the crossing-point temperature (CPT) method for measuring self-ignition kinetics of combustible solids. Process Saf Environ Protect 76:90-93

Chen K, Mackie JC, Wojtalewicz D, Kennedy EM, Dlugogorski BZ (2011a) Toxic pollutants emitted from thermal decomposition of phthalimide compounds. J Hazard Mater 187:407-412

Chen K, Wojtalewicz D, Altarawneh M, Mackie JC, Kennedy EM, Dlugogorski BZ (2011b) Formation of polychlorinated dibenzo-p-dioxins and dibenzofurans (PCDD/F) in oxidation of captan pesticide. Proc Combust Inst 33:701-708

Chiniwalla P, Bai Y, Elce E, Shick R, McDougall WC, Allen SAB, Kohl PA (2003) Crosslinking and decomposition reactions of epoxide functionalized polynorbornene. Part I. FTIR and thermogravimetric analysis. J Appl Polym Sci 89:568-577

Choe E, Min DB (2006) Mechanisms and factors for edible oil oxidation. Compr Rev Food Sci Food Saf 5:169-186

Clausen PA, Knudsen HN, Larsen K, Kofoed-Sørensen V, Wolkoff P (2008) Use of thermal desorption gas chromatography-olfactometry/mass spectrometry for 
the comparison of identified and unidentified odor active compounds emitted from building products containing linseed oil. J Chrom A 1210:203-211

Colclough T (1987) Role of additives and transition metals in lubricating oil oxidation. Ind Eng Chem 26:1888-1895

Contini M, Esti M (2006) Effect of the matrix volatile composition in the headspace solid-phase microextraction analysis of extra virgin olive oil. Food Chem 94:143-150

Cox G (1995) Combustion Fundamentals of Fire. Academic, London

Dagaut P, Cathonnet M (2006) The ignition, oxidation, and combustion of kerosene: A review of experimental and kinetic modeling. Prog Energy Combust Sci 32:48-92

Dagaut P, Cathonnet M, Rouan JP, Foulatier R, Quilgars A, Boettner JC, Gaillard F, James $H$ (1986) A jet-stirred reactor for kinetic studies of homogeneous gasphase reactions at pressures up to ten atmospheres (1 MPa). J Phys E: Sci Inst 19:207-209

Dayma G, Sarathy SM, Togbé C, Yeung C, Thomson MJ, Dagaut P (2011) Experimental and kinetic modeling of methyl octanoate oxidation in an opposed-flow diffusion flame and a jet-stirred reactor. Proc Combust Inst 33:1037-1043

De Oliveira Vigier K, Barrault J, Pouilloux Y (2009) Cis-trans isomerization of methyl cis-9-octadecenoate in the presence of cobalt tin catalysts. J Mol Catal A: Chem 306:102-106

Dikalov SI, Mason RP (2001) Spin trapping of polyunsaturated fatty acid-derived peroxyl radicals: reassignment to alkoxyl radical adducts. Free Radic Biol Med 30:187-197

Drysdale D (1985) An Introduction to Fire Dynamics. John Wiley and Sons, Chichester

Erasmus U (accessed 2011) Fat content and fatty acid composition of seed oils. http://curezone.com/foods/fatspercent.asp

Erich SJF, Laven J, Pel L, Huinink HP, Kopinga K (2006a) NMR depth profiling of drying alkyd coatings with different catalysts. Prog Orga Coat 55:105-111

Erich SJF, Laven J, Pel L, Huinink HP, Kopinga K (2006b) Influence of catalyst type on the curing process and network structure of alkyd coatings. Polymer 47:1141-1149

Eriksson M, Fäldt J, Dalhammar G, Borg-Karlson AK (2001) Determination of hydrocarbons in old creosote contaminated soil using headspace solid phase microextraction and GC-MS. Chemosphere 44:1641-1648

Evarts B (2011) Fires caused by spontaneous combustion or chemical reaction. National Fire Protection Association. Fire Analysis and Research Division, Quincy

Feussner I, Kuhn H, Wasternack C (2001) Lipoxygnease-dependent degradation of storage lipids. Trends Plant Sci 6:268-273

Fjällström P, Andersson B, Nilsson C, Andersson K (2002) Drying of linseed oil paints: a laboratory study of aldehyde emissions. Ind Crops Prod 16:173-184

Fukuzumi S, Ohtsu H, Ohkubo K, Itoh S, Imahori H (2002) Formation of superoxide-metal ion complexes and the electron transfer catalysis. Coord Chem Rev 226:71-80

García-Martínez MC, Márquez-Ruiz G, Fontecha J, Gordon MH (2009) Volatile oxidation compounds in a conjugated linoleic acid-rich oil. Food Chem 113:926-931

Gardner HW (1989) Oxygen radical chemistry of polyunsaturated fatty acids. Free Radic Biol Med 7:65-86

Gross D, Robertson AF (1958) Self-ignition temperatures of materials from kineticreaction data. J Res Nat Bur Stand (US) 61:413-417

Guillén MD, Cabo N (2002) Fourier transform infrared spectra data versus peroxide and anisidine values to determine oxidative stability of edible oils. Food Chem 77:503-510

Guillen MD, Goicoechea E (2008) Formation of oxygenated [alpha],[beta]-unsaturated aldehydes and other toxic compounds in sunflower oil oxidation at room temperature in closed receptacles. Food Chem 111:157-164

Güler ÖK, Güner FS, Erciyes AT (2004) Some empirical equations for oxypolymerization of linseed oil. Progr Org Coating 51:365-371

Gunstone F (1996) Fatty Acid and Lipid Chemistry. Blackie Academic and Professional, London

Halliwell B, Gutteridge JMC (2008) Free Radicals in Biology and Medicine. Oxford University Press, New York

Hancock RA, Leeves NJ (1989) Studies in autoxidation. Part I. The volatile byproducts resulting from the autoxidation of unsaturated fatty acid methyl esters. Progr Org Coating 17:321-336

Hanson D, Orlando J, Noziere B, Kosciuch E (2004) Proton transfer mass spectrometry studies of peroxy radicals. Int J Mass Spectrom 239:147-159
Haslbeck F, Grosch W, Firl J (1983) Formation of hydroperoxides with unconjugated diene systems during autoxidation and enzymatic oxygenation of linoleic acid. Biochim Biophys Acta 750:185-193

Havenga WJ, Rohwer ER (1999) Chemical characterization and screening of hydrocarbon pollution in industrial soils by headspace solid-phase microextraction. J Chrom A 848:279-295

Hendriks CF, Heertjes PM, van Beek HCA (1979) Autoxidation of methyl linoleate and methyl linolenate and reactions of the hydroperoxides formed in n-heptane solution. Ind Eng Chem Product Res Dev 18:212-216

Hermans I, Jacobs PA, Peeters J (2006) nderstanding the autoxidation of hydrocarbons at the molecular level and consequences for catalysis. J Mol Catal Chem 251:221-228

Hermans I, Van Deun J, Houthoofd K, Peeters J, Jacobs PA (2007) Silicaimmobilized N-hydroxyphthalimide: An efficient heterogeneous autoxidation catalyst. J Catal 251:204-212

Hilker I, Bothe D, Prüss J, Warnecke HJ (2001) Chemo-enzymatic epoxidation of unsaturated plant oils. Chem Eng Sci 56:427-432

Hill SM, Quintiere JG (2000) Investigating materials from fires using a test method for spontaneous ignition. Fire Mater 24:61-66

Howitt DG, Zhang E, Sanders BR (1995) The spontaneous combustion of linseed oil. In: Proceedings of the 20th International Conference on Fire Safety. Product Safety Corp, Sunnyvale, CA, pp 34-38

loakimoglou E, Boyatzis S, Argitis P, Fostiridou A (1999) Thin film study on the oxidation of linseed oil in the presence of selected copper pigments. Chem Mater 11:2013-2022

Jeleń HH, Obuchowska M, Zawirska-Wojtasiak R, Wąsowicz E (2000) Headspace solid-phase microextraction use for the characterization of volatile compounds in vegetable oils of different sensory quality. Agric Food Chem 48:2360-2367

Jennings GW (1981) Applications of Glass Capillary Gas Chromatography. Marcel Dekker, Inc., New York and Basel

Jiménez A, Beltrán G, Aguilera MP (2004) Application of solid-phase microextraction to the analysis of volatile compounds in virgin olive oils. J Chrom A 1028:321-324

Joffre F, Martin J-C, Genty M, Demaison L, Loreau O, Noel J-P, Sebedio J-L (2001) Kinetic parameters of hepatic oxidation of cyclic fatty acid monomers formed from linoleic and linolenic acids. J Nut Biochem 12:554-558

Juita, Dlugogorski BZ, Kennedy EM, Mackie JC (2010a) The effect of transition metal salts on the peroxide value: spontaneous heating and ignition of lignocellulosic materials impregnated with linseed oil. In: Proceedings of the 8th Asia-Oceania Symposium on Fire Science and Technology., Melbourne, Australia

Juita, Dlugogorski BZ, Kennedy EM, Mackie JC (2010b) Effect of cobalt and cerium on self-heating of linseed oil. In: Proceedings of the 6th International Seminar on Fire and Explosion Hazards. University of Leeds, UK, pp 609-620

Juita N, Dlugogorski BZ, Kennedy EM, Mackie JC (2011a) Roles of peroxides and unsaturation in spontaneous heating of linseed oil. Fire Saf J, in revision

Juita DBZ, Kennedy EM, Mackie JC (2011b) Oxidation reactions and spontaneous ignition of linseed oil. Proc Combust Inst 33:2625-2632

Juita DBZ, Kennedy EM, Mackie JC (2011c) Linseed oil and its tendency to selfheat. Proc Int Symp Fire Saf Sci 10:389-400

Juita DBZ, Kennedy EM, Mackie JC (2011d) Identification and quantitation of organic compounds from oxidation of linseed oil. Ind Eng Chem Res 51:5645-5652

Juita DBZ, Kennedy EM, Mackie JC (2011e) Mechanism of formation of volatile organic compounds from oxidation of linseed oil. Ind Eng Chem Res 51:5653-5661

Kanavouras A, Kiritsakis A, Hernandez RJ (2005) Comparative study on volatile analysis of extra virgin olive oil by dynamic headspace and solid phase micro-extraction. Food Chem 90:69-79

Kenyon RL, Gioyer SW, Georgian CC (1948) Selective extraction of vegetable oils with furfural. Ind Eng Chem 40:1162-1170

Khattab MA, El-Ashael AA, Kandil SH (1999) Effect of contamination of cotton fabric with linseed oil on the activation energies of pyrolysis and oxidation of the fabric. Fire Mater 23:131-137

Klaasen RP, van der Leeuw RPC (2006) Fast drying cobalt-free high solids alkyd paints. Progr Org Coating 55:149-153

Knothe G (2002) Structure indices in FA chemistry. how relevant is the iodine value ? AOCS Press 79:847-854

Kochi JK (1973) Free Radicals. John Wiley \& Sons, New York

Kochi JK, Mains HE (1964) Studies on the mechanism of the reaction of peroxides and alkenes with copper salts. Kochi Mains 30:1862-1872 
Krist S, Stuebiger G, Bail S, Unterweger H (2006) Analysis of volatile compounds and triacylglycerol composition of fatty seed oil gained from flax and false flax. Eur J Lipid Sci Technol 108:48-60

Kubow S (1992) Routes of formation and toxic consequences of lipid oxidation products in foods. Free Radic Biol Med 12:63-81

Kumarathasan R, Rajkumar AB, Hunter NR, Gesser HD (1992) Autoxidation and yellowing of methyl linolenate. Prog Lipid Res 31:109-126

Lazzari M, Chiantore O (1999) Drying and oxidative degradation of linseed oil. Polym Degrad Stabil 65:303-313

Lee J, Kim D-H, Chang P-S, Lee J (2007) Headspace-solid phase microextraction (HS-SPME) analysis of oxidized volatiles from free fatty acids (FFA) and application for measuring hydrogen donating antioxidant activity. Food Chem 105:414-420

Lee J, Min DB (2010) Analysis of volatile compounds from chlorophyll photosensitized linoleic acid by headspace solid-phase microextraction (HS-SPME). Food Sci Biotechnol 19:611-616

Liavonchanka A, Feussner I (2006) Lipoxygenases: Occurence, functions and catalysis. J Plant Physiol 163:348-357

Litwinienko G, Kasprzycka-Guttman T (1999) Study on the autoxidation kinetics of fat components by differential scanning calorimetry. 2 . unsaturated fatty acids and their esters. Ind Eng Chem Res 39:13-17

Liu Z, Kooijman H, Spek AL, Bouwman E (2007) New manganese-based catalyst systems for alkyd paint drying. Progr Org Coating 60:343-349

Mallégol J, Lemaire J, Gardette J-L (2000) Drier influence on the curing of linseed oil. Prog Org Coat 39:107-113

Marshall GL (1986) The analysis of cured drying oils by swollen state 13 C-NMR spectroscopy. Eur Polym J 22:231-241

Martini DS, Braga BA, Samios D (2009) On the curing of linseed oil epoxidized methyl esters with different cyclic dicarboxylic anhydrides. Polymer 50:2919-2925

Meneghetti SMP, de Souza RF, Monteiro AL, de Souza MO (1998) Substitution of lead catalysts by zirconium in the oxidative polymerization of linseed oil. Prog Org Coat 33:219-224

Miccichè F, Oostveen E, van Haveren J, van der Linde R (2005a) The combination of reducing agents/iron as environmentally friendlier alternatives for Cobased driers in the drying of alkyd paints. Progr Org Coating 53:99-105

Miccichè F, van Haveren J, Oostveen E, Ming W, van der Linde R (2006) Oxidation and oligomerization of ethyl linoleate under the influence of the combination of ascorbic acid 6-palmitate/iron-2-ethylhexanoate. Appl Catal Gen 297:174-181

Miccichè F, van Straten MA, Ming W, Oostveen E, van Haveren J, van der Linde R, Reedijk J (2005b) Identification of mixed-valence metal clusters in drier solutions for alkyd-based paints by electrospray ionization mass spectrometry (ESI-MS). Int J Mass Spectrom 246:80-83

Milani B, Stabon E, Zangrando E, Mestroni G, Sommazzi A, Zannoni C (2003) Polymerisation of polar olefins promoted by organometallic cobalt complexes: free radical or coordinative process? Inorg Chim Acta 349:209-216

Mildner-Szkudlarz S, Jeleń HH, Zawirska-Wojtasiak R, Wąsowicz E (2003) Application of headspace-solid phase microextraction and multivariate analysis for plant oils differentiation. Food Chem 83:515-522

Miller DM, Buettner GR, Aust SD (1990) Transition metals as catalysts of "autoxidation" reactions. Free Radic Biol Med 8:95-108

Min DB, Boff JM (2002) Chemistry and reaction of singlet oxygen in foods. Compr Rev Food Sci Food Saf 1:58-72

Minisci F, Recupero F, Pedulli GF, Lucarini M (2003) Transition metal salts catalysis in the aerobic oxidation of organic compounds: Thermochemical and kinetic aspects and new synthetic developments in the presence of N-hydroxy -derivative catalysts. J Mol Catal Chem 204-205:63-90

Moad G, Solomon DH (1995) The Chemistry of Free Radical Polymerization. Elsevier Science Ltd, Oxford

Muik B, Lendl B, Molina-Díaz A, Ayora-Cañada MJ (2005) Direct monitoring of lipid oxidation in edible oils by Fourier transform Raman spectroscopy. Chem Phys Lipids 134:173-182

Muizebelt WJ, Hubert JC, Nielen MWF, Klaasen RP, Zabel KH (2000) Crosslink mechanisms of high-solids alkyd resins in the presence of reactive diluents. Progr Org Coating 40:121-130

Muizebelt WJ, Hubert JC, Venderbosch RAM (1994) Mechanistic study of drying of alkyd resins using ethyl linoleate as a model substance. Progr Org Coating 24:263-279

Muturi P, Wang D, Dirlikov S (1994) Epoxidized vegetable oils as reactive diluents I. Comparison of vernonia, epoxidized soybean and epoxidized linseed oils. Progr Org Coating 25:85-94
Napier DH, Vlatis J, Napier DH, Vlatis J (1981) Safety considerations in the selfheating of two component systems. In: Institute of Chemical Engineers Symposium Series., $p$ 68, 2/F/1-2/F/15

Niczke L, Czechowski F, Gawel I (2007) Oxidized rapeseed oil methyl ester as a bitumen flux: Structural changes in the ester during catalytic oxidation. Prog Org Coat 59:304-311

Nishinaga A, Yamada T, Fujisawa H, Ishizaki K, Ihara H, Matsuura T (1988) Catalysis of cobalt-Schiff base complexes in oxygenation of alkenes: on the mechanism of ketonization. J Mol Catal 48:249-264

Okovytyy S, Gorb L, Leszczynski J (2002) A reinvestigation of the mechanism of epoxidation of alkenes by peroxy acids. A CASSCF and UQCISD study. Tetrahedron Lett 43:4215-4219

Oyman ZO, Ming W, Micciché F, Oostveen E, van Haveren J, van der Linde R (2004) A promising environmentally-friendly manganese-based catalyst for alkyd emulsion coatings. Polymer 45:7431-7436

Oyman ZO, Ming W, van der Linde R (2005a) Oxidation of drying oils containing non-conjugated and conjugated double bonds catalyzed by a cobalt catalyst. Prog Org Coat 54:198-204

Oyman ZO, Ming W, van der Linde R (2007) Catalytic activity of a dinuclear manganese complex (MnMeTACN) on the oxidation of ethyl linoleate. Appl Catal Gen 316:191-196

Oyman ZO, Ming W, van der Linde R, van Gorkum R, Bouwman E (2005b) Effect of [Mn(acac)3] and its combination with 2,2'-bipyridine on the autoxidation and oligomerisation of ethyl linoleate. Polymer 46:1731-1738

Peeters J, Nguyen TL, Vereecken L (2009) HOx radical regeneration in the oxidation of isoprene. Phys Chem Chem Phys 11:5935-5939

Peinado J, Toribio F, Perez-Bendito D (1986) Kinetic fluorimetric determination of organic peroxides and lipohydroperoxides at the nanomole level. Talanta 33:914-916

Pilling MJ (1997) Low-Temperature Combustion and Autoignition. Elsevier, Amsterdam

Ploeger R, Musso S, Chiantore O (2009a) Contact angle measurements to determine the rate of surface oxidation of artists' alkyd paints during accelerated photo-ageing. Progr Org Coating 65:77-83

Ploeger R, Scalarone D, Chiantore O (2009b) Thermal analytical study of the oxidative stability of artists' alkyd paints. Polym Degrad Stab 94:2036-2041

Pocklington WD (1990) Determination of the iodine value of oils and fats. Pure Appl Chem 62:2339-2343

Porter NA, Caldwell SE, Mills KA (1995) Mechanisms of free radical oxidation of unsaturated lipids. Lipids 30:277-290

Rawls HR, Santen PJV (1970) A possible role for singlet oxygen in the initiation of fatty acid autoxidation. J Am Oil Chemist Soc 47:121-125

Ready JM, Jacobsen EN (2002) A practical oligomeric [(salen)Co] catalyst for asymmetric epoxide ring-opening reactions. Angew Chem Int Ed 41:1374-1377

Ribeiro LH, Costa Freitas AM, Gomes da Silva MDR (2008) The use of headspace solid phase microextraction for the characterization of volatile compounds in olive oil matrices. Talanta 77:110-117

Roberfroid M, Calderon PB (1995) Free Radicals and Oxidation Phenomena in Biological Systems. Marcel Dekker, Inc., New York

Rolewski P, Siger A, Nogala-Kałucka M, Polewski K (2009) Chemiluminescent assay of lipid hydroperoxides quantification in emulsions of fatty acids and oils. Food Res Int 42:165-170

Sailer RA, Soucek MD (2000) Investigation of cobalt drier retardation. Eur Polym J 36:803-811

Sarathy SMT, Togbé MJ, Dagaut C, Halter P, Rousselle F, Mounaim C (2009) An experimental and kinetic modelling study of $n$-butanol combustion. Combust Flame 156:852-864

Serfert Y, Drusch S, Schwarz K (2009) Chemical stabilisation of oils rich in longchain polyunsaturated fatty acids during homogenisation, microencapsulation and storage. Food Chem 113:1106-1112

Sharma V, Kundu PP (2006) Addition polymers from natural oils-A review. Progr Polym Sci 31:983-1008

Silva I, Rocha SM, Coimbra MA, Marriott PJ (2010) Headspace solid-phase microextraction combined with comprehensive two-dimensional gas chromatography time-of-flight mass spectrometry for the determination of volatile compounds from marine salt. J Chrom A 1217:5511-5521

Skalský J (1976) Preparation and application of drying agents in paints. Progr Org Coating 4:137-160

Smeets PJ, Woertink JS, Sels BF, Solomon El, Schoonheydt RA (2010) Transitionmetal ions in zeolites: coordination and activation of oxygen. Inorg Chem 49:3573-3583 
Stava V, Erben M, Vesely D, Kalenda P (2007) Properties of metallocene complexes during the oxidative crosslinking of air drying coatings. J Phys Chem Solids 68:799-802

Stavrakou T, Peeters J, Muller J-F (2010) Improved global modelling of HOx recycling in isoprene oxidation:evaluation against the GABRIEL and INTEX-A aircraft campaign measurements. Atmos Chem Phys Discuss 10:16551-16588

Stenberg C, Svensson M, Johansson M (2005) A study of the drying of linseed oils with different fatty acid patterns using RTIR-spectroscopy and chemiluminescence (CL). Ind Crop Prod 21:263-272

Summoogum SL, Mackie JC, Kennedy EM, Delichatsios MA, Dlugogorski BZ (2011) Formation of toxic species and precursors of PCDD/F in thermal decomposition of alpha-cypermethrin. Chemosphere 85:143-150

Suryanarayana C, Rao KC, Kumar D (2008) Preparation and characterization of microcapsules containing linseed oil and its use in self-healing coatings. Prog Org Coat 63:72-78

Swern D (1972) Organic Peroxides. Wiley-Interscience, New York

Tanase S, Bouwman E, Reedijk J (2004) Role of additives in cobalt-mediated oxidative crosslinking of alkyd resins. Appl Catal Gen 259:101-107

Tappel AL, Tappel AA, Fraga CG (1989) Application of simulation modeling to lipid peroxidation processes. Free Radic Biol Med 7:361-368

Thomas S, Ledesma EB, Wornat MJ (2007) The effects of oxygen on the yields of the thermal decomposition products of catechol under pyrolysis and fuelrich oxidation conditions. Fuel 86:2581-2595

Thompson NJ (1928) The spontaneous heating of oils. Oil and Fat Indust 5:317-326

Togbe C, Dayma G, Mze-Ahmed A, Dagaut P (2010a) Experimental and modelling study of the kinetics of oxidation of simple biodiesel-biobutanol surrogates: methyl octanoate-butanol mixtures. Energy Fuel 24:3906-3916

Togbe C, May-Carle J-B, Dayma G, Dagaut P (2010b) Chemical kinetic study of the oxidation of a biodiesel-bioethanol surrogate fuel: methyl octanoateethanol mixtures. J Phys Chem A 114:3896-3908

Tsuruya S, Masuoka T, Masai M (1981) Cobalt ion catalyzed oxidation of benzoin. J Mol Catal 10:21-32

Tuman SJ, Chamberlain D, Scholsky KM, Soucek MD (1996) Differential scanning calorimetry study of linseed oil cured with metal catalysts. Prog Org Coat 28:251-258

Turra N, Acuna AB, Schimmoller B, Mayr-Schmolzer B, Mania P, Hermans I (2011) Aerobic oxidation of cyclohexane catalysed by flame-made nano-structured $\mathrm{Co} / \mathrm{SiO}_{2}$ materials. Top Catal 54:737-745

Turra N, Neuenschwander U, Baiker A, Peeters J, Hermans I (2010) Mechanism of the catalytic deperoxidation of tert-butylhydroperoxide with cobalt(II) acetylacetonate. Chem Eur J 16:13226-13235

van den Berg JDJ, van den Berg KJ, Boon JJ (2002) Identification of non-cross -linked compounds in methanolic extracts of cured and aged linseed oilbased paint films using gas chromatography-mass spectrometry. J Chrom A 950:195-211

van Gorkum R, Berding J, Tooke DM, Spek AL, Reedijk J, Bouwman E (2007) The autoxidation activity of new mixed-ligand manganese and iron complexes with tripodal ligands. J Catal 252:110-118

van Gorkum R, Bouwman E (2005) The oxidative drying of alkyd paint catalysed by metal complexes. Coord Chem Rev 249:1709-1728

Vastine BA, Hall MB (2009) The molecular and electronic structure of carbonhydrogen bond activation and transition metal assisted hydrogen transfer. Coord Chem Rev 253:1202-1218

Wang H, Dlugogorski BZ, Kennedy EM (1999) Experimental study on lowtemperature oxidation of an Australian coal. Energ Fuel 13:1173-1179

Wang $\mathrm{H}$, Dlugogorski BZ, Kennedy EM (2002) Examination of $\mathrm{CO}_{2}, \mathrm{CO}$, and $\mathrm{H}_{2} \mathrm{O}$ formation during low-temperature oxidation of a bituminous coal. Energ Fuel 16:586-592

Wang H, Dlugogorski BZ, Kennedy EM (2006) Tests for Spontaneous Ignition of Solid Materials, Chapter 16. In: Apte V (ed) Flammability Testing of Materials Used in Construction. Woodhead Publishing Limited, Transport and Mining, Cambridge, pp 385-442

Warzeska ST, Zonneveld M, van Gorkum R, Muizebelt WJ, Bouwman E, Reedijk J (2002) The influence of bipyridine on the drying of alkyd paints: a model study. Progr Org Coating 44:243-248

Wiesenborn D, Kangas N, Tostenson K III, Chang CH (2005) Sensory and oxidative quality of screw-pressed flaxseed oil. JAOCS 82:887-892

Wofbeis OS (1987) Fibre-optic sensors in biomedical sciences. Pure Appl Chem 59:663-672
Worden JT (2011) Spontaneous Ignition of Linseed Oil Soaked Cotton using the Oven Basket and Crossing Point Methods. University of Maryland, Maryland

Wornat MJ, Ledesma EB, Marsh ND (2001) Polycyclic aromatic hydrocarbons from the pyrolysis of catechol (ortho-dihydroxybenzene), a model fuel representative of entities in tobacco, coal, and lignin. Fuel 80:1711-1726

Wu J-Z, Bouwman E, Reedijk J (2004) Chelating ligands as powerful additives to manganese driers for solvent-borne and water-borne alkyd paints. Progr Org Coating 49:103-108

Yamada T, Niki E, Yokoi S, Tsuchiya J, Yamamoto Y, Kamiya Y (1984) Oxidation of lipids. XI. Spin trapping and identification of peroxy and alkoxy radicals of methyl linoleate. Chem Phys Lipids 36:189-196

Zhu J, Sevilla MD (1989) Kinetic analysis of free radical reactions in the low temperature autoxidation of triglycerides. Phys Chem 94:1447-1452

\section{doi:10.1186/2193-0414-1-3}

Cite this article as: Juita et al: Low temperature oxidation of linseed oil: a review. Fire Science Reviews 2012 1:3.

\section{Submit your manuscript to a SpringerOpen ${ }^{\circ}$ journal and benefit from:}

- Convenient online submission

Rigorous peer review

- Immediate publication on acceptance

- Open access: articles freely available online

- High visibility within the field

- Retaining the copyright to your article

Submit your next manuscript at $>$ springeropen.com 